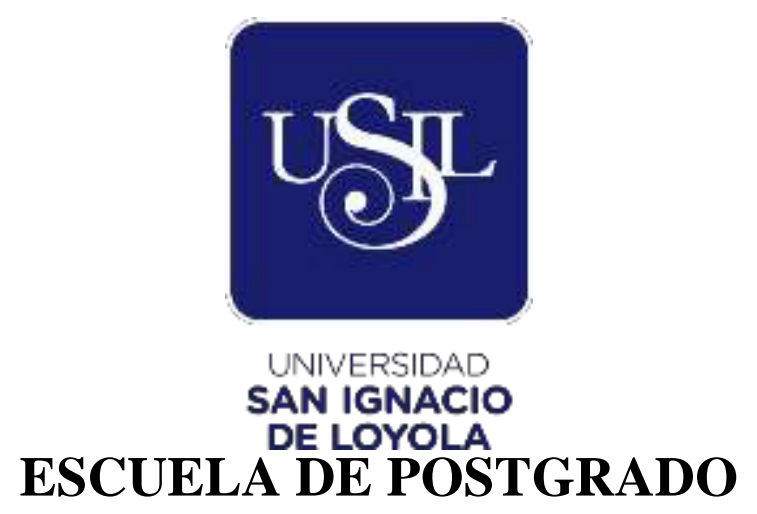

Maestría en Educación con mención en Docencia en Educación Superior

\title{
ESTRATEGIA METODOLÓGICA PARA DESARROLLAR HABILIDADES INVESTIGATIVAS EN LOS ESTUDIANTES DE QUINTO CICLO DE COMUNICACIONES DE UNA UNIVERSIDAD PRIVADA DE LIMA
}

Tesis para optar el grado de Maestro en Educación con

Mención en Docencia en Educación Superior

DELICIA MARÍA YON ACOSTA

Asesor:

Félix Fernando Goñi Cruz

Lima - Perú

2020 


\section{Dedicatoria}

Dedico ese trabajo a mis padres que siempre confiaron en cada decisión que he tomado. A mi Padre por la paciencia y la comprensión y a mi Madre por la fortaleza y la confianza. 


\section{Agradecimiento}

A mis hermanos que colaboraron con mi tranquilidad y motivación a lo largo de todo este proceso, a mis compañeros de clase (sobre todo a Javier, Karla y Merly) que alentaron mi decisión y compartieron sus conocimientos, y sobre todo a mi asesor Fernando Goñi, que con paciencia y sabiduría fue orientándome a concluir esta investigación y a formarme como una docente responsable con rigor científico y pedagógico. 


\section{Indice}

Dedicatoria

Agradecimiento

Indice

Indice de tablas

Indice de figuras

Resumen

Abstract

$\begin{array}{ll}\text { Introducción } & 1\end{array}$

Planteamiento del problema de la investigación 1

Formulación del problema 3

Objetivos de la investigación 3

Categorías y subcategorías apriorísticas $\quad 4$

Justificación $\quad 6$

Metodología de la investigación $\quad 6$

$\begin{array}{ll}\text { Tipo y diseño de investigación } & 7\end{array}$

$\begin{array}{ll}\text { Población, muestra y muestreo } & 7\end{array}$

Métodos teóricos, empíricos y estadísticos $\quad 8$

Técnicas e instrumentos de investigación $\quad 10$

Capítulo I 12

Marco teórico 12

Fundamentación teórica de la investigación 12

Antecedentes de la investigación. 12

$\begin{array}{ll}\text { Antecedentes internacionales. } & 12\end{array}$

$\begin{array}{ll}\text { Teorías y enfoques de las habilidades investigativas } & 14\end{array}$

$\begin{array}{ll}\text { Teoría de la actividad de Leontiev } & 15\end{array}$

$\begin{array}{ll}\text { Desarrollo de las habilidades investigativas desde el enfoque socioformativo } & 16\end{array}$

Aportes de la comunicación audiovisual en el desarrollo de las habilidades investigativas 17

Los pilares del conocimiento como instrumento del proceso investigativo 18 
La investigación audiovisual

$\begin{array}{ll}\text { Fundamentos teóricos de estrategia metodológica audiovisual } & 19\end{array}$

$\begin{array}{ll}\text { Habilidades Investigativas } & 20\end{array}$

$\begin{array}{ll}\text { Habilidades instrumentales y sociales } & 21\end{array}$

$\begin{array}{ll}\text { Estrategia metodológica } & 21\end{array}$

Estrategia metodológica de un trabajo investigativo 22

Capítulo II 23

Diagnóstico o trabajo de campo 23

Análisis e interpretación de los hallazgos por técnicas e instrumentos 23

Análisis e interpretación de las categorías emergentes y las apriorísticas $\quad 28$

Categorías influyentes en el problema 32

Conclusiones aproximativas del diagnóstico 32

Capítulo III 34

Modelación de la propuesta $\quad 34$

Fundamentos científicos de la propuesta $\quad 35$

Fundamento socioeducativo. 35

Fundamento pedagógico. $\quad 35$

$\begin{array}{ll}\text { Fundamento curricular. } & 37\end{array}$

Diseño de la propuesta $\quad 39$

Implementación de la propuesta del modelo de investigación 53

$\begin{array}{ll}\text { Validación de la propuesta } & 73\end{array}$

$\begin{array}{ll}\text { Conclusiones } & 79\end{array}$

Recomendaciones $\quad 81$

Referencias $\quad 82$ 


\section{Indice de tablas}

Tabla 1. Resultados de la validación de instrumentos por juicio de expertos

Tabla 2. Tabla de competencias y capacidades

Tabla 3. Planificación de la etapa 10 preproducción

Tabla 4. Planificación de la etapa 2 o producción

Tabla 5. Planificación de la etapa 3 o postproducción

Tabla 6. Estructura del libro de producción

Tabla 7. Indicadores de la sesión de clase $\quad 74$

$\begin{array}{ll}\text { Tabla 8. Especialistas de la validación } & 77\end{array}$

Tabla 9. Validez interna por juicio de expertos $\quad 79$

Tabla 10. Validez interna por juicio de expertos 80

Tabla 11. Escala de valoración 81

Tabla 12. Valoración interna y externa por criterio de jueces 81 


\section{Indice de figuras}

Figura 1. Categorías apriorísticas y emergentes. Elaboración propia 2019

Figura 2. Narrativa transmedia en un proceso documental.

Elaboración propia 2019

Figura 3. Plataforma audiovisual. Elaboración propia 2019

Figura 4. Estructura documental. Elaboración propia 2019

Figura 5. Propuesta del modelo de investigación. Elaboración propia 2019

Figura 6. Esquema de primera etapa orientada al docente.

Elaboración propia 2019

Figura 7. Libro de producción. Tomado de la Universidad Miguel

Hernámdez- España

Figura 8. Esquema de segunda etapa orientada al docente.

Elaboración propia 2019

Figura 9. Esquema de tercera etapa orientada al docente.

Elaboración propia 2019

Figura 10. Esquema de primera etapa orientada al alumno.

Elaboración propia 2019

Figura 11. Esquema de segunda etapa orientada al alumno.

Elaboración propia 2019

Figura 12. Esquema de tercera etapa orientada al alumno.

Elaboración propia 2019

Figura 13. Esquema de cuarta etapa orientada al alumno.

Elaboración propia 2019

Figura 14. Esquema de quinta etapa orientada al alumno.

Elaboración propia 2019

Figura 15. Validaciones de la Propuesta 


\section{Resumen}

Esta investigación propone el diseño de una estrategia metodológica para desarrollar habilidades investigativas en alumnos del $\mathrm{V}$ ciclo de Comunicaciones en una universidad privada de Lima. Se enmarca dentro del paradigma socio-crítico e interpretativo, basada en una investigación educacional de tipo aplicada, cuya muestra es intencionada de tres docentes y 20 alumnos. Entre las técnicas utilizadas se tiene la entrevista, la encuesta y la observación no participante, y entre los instrumentos están la guía de entrevista, la guía de observación, la prueba pedagógica y el cuestionario; el diagnóstico evidencia que los alumnos tienen pocas habilidades investigativas y no asocian los conocimientos con su entorno, así como el docente no acerca la realidad con los conocimientos impartidos en el aula. La investigación tiene sustento en las teorías de Pollo-Cattaneo (2009), Vygotsky (1978), Tobón(2013), Dumont(2012) Armas y Lorence (2003), Leontiev /1977) y Montes de Oca y Machado Ramírez (2009) , y como propuesta de investigación se presenta un diseño de estrategia metodológica orientada en fases y etapas de investigación que permitirán al alumno el desarrollo de habilidades investigativas mediante un modelo colaborativo, la teoría de la actividad de Leontiev, aprendizaje colaborativo y un enfoque socioformativo en base a una plataforma audiovisual: el documental, que lo acercará a su profesión y a la realidad laboral. En conclusión esta investigación tiene una perspectiva formativa sólida, en la búsqueda de generar la resolución del problema y la cercanía de la realidad a la profesión a través de la propuesta pedagógica.

Palabras clave: Estrategia metodológica, habilidades investigativas, enfoque socioformativo, trabajo colaborativo y comunicación audiovisual. 


\begin{abstract}
This research proposes the design of a methodological strategy to develop investigative skills in students of the $\mathrm{V}$ cycle of communications in a private university of Lima. It is framed within the interpretative critical partner paradigm, based on an applied educational research, the sample is intentional of three teachers and 20 students, among the techniques is the interview, survey and non-participative observation and the instruments were an interview guide, observation guide, pedagogical test and questionnaire; the diagnosis shows that the students have few investigative skills and do not associate the knowledge with their environment, just as the teacher does not approach reality with the knowledge imparted in the classroom. The research is based on the theories of PolloCattaneo (2009), Vygotsky (1978), Tobón (2013), Dumont (2012) Armas and Lorence (2003), Leontiev / 1977) and Montes de Oca and Machado Ramírez (2009) We develop a methodological strategy design oriented in phases and stages of research that will allow the student to develop investigative skills through a collaborative model, Leontiev's activity theory, collaborative learning and a socioformative approach based on an audiovisual platform: the documentary that they will approach him to his profession and the labor reality. In conclusion, this research has a solid formative perspective, in the search to generate the resolution of the problem and the proximity of reality to the profession through the pedagogical proposal.
\end{abstract}

Key words: Methodological strategy, investigative skills, socioformative approach, collaborative work and audiovisual communication. 


\section{Introducción}

El propósito de esta investigación es generar una estrategia metodológica para desarrollar las habilidades investigativas en estudiantes de quinto ciclo de Comunicaciones de una universidad privada de Lima.

El objetivo de la presente investigación es motivar al estudiante a crear dotes de investigador que más adelante lo ayudarán a ser un profesional más capaz y un ser humano holístico. Este modelo surge ante la necesidad de mejorar las competencias del estudiante universitario de comunicaciones en relación a la investigación y como aprovechar su entorno tecnológico y mediático para motivar su acercamiento al campo científico y de desarrollo metodológico de la ciencia y de los procesos de investigación, componentes esenciales para el desarrollo de profesionales integrales tanto en su campo de acción como en la sociedad a la que pertenecen.

Lo fundamental es generar un vínculo con la realidad y su profesión, captando mecanismos que ayudan a su desempeño en el campo de las comunicaciones de manera más interactiva y eficaz.

\section{Planteamiento del problema de la investigación}

Uno de los objetivos del Banco Mundial desde 1963 es concebir como pieza importante de la economía a la universidad por ser uno de los instrumentos primordiales para reducir la pobreza y promover el desarrollo de las naciones, según Salmi (2009), dentro de las características de una universidad de rango mundial se encuentra la excelencia en la investigación, es así que el desarrollo educativo de los países tiene como eje primordial el grado de investigación en educación superior.

En el reporte diagnóstico de la estrategia de competencias de la Organización para la Cooperación y el Desarrollo Económico (OCDE, 2016), se observa que en nuestro país el acceso a las universidades esta mejorando, pero muchos de los estudiantes que egresan de ellas no poseen las habilidades necesarias para la competencia profesional, y una de esas habilidades, que es importante para promover el desarrollo, es la investigación.

Lamentablemente, somos uno de los países en América Latina con una baja inversión para la investigación y el desarrollo, obteniendo en el 2014 el puesto 100 de 144 países (Foro Económico Mundial, 2014), esta posición nos hace entender que nuestro nivel investigativo en educación terciaria no alcanza los rangos que necesitamos para una educación de calidad que promueva el desarrollo. 
Para que nuestro país llegue al objetivo de generar una economía en base al conocimiento necesitaríamos fortalecer la educación superior. Un claro ejemplo de este défícit es que necesitamos de profesionales extranjeros que tengan estas competencias para cubrir muchos puestos de trabajo que podrían ser ocupados por un profesional egresado de una universidad peruana en cualquier carrera y así reducir la tasa de desempleo en jóvenes. Para el Consejo Nacional de ciencia, tecnología e innovación tecnológica (Concytec, 2016), el Perú adolece de profesionales con grado de doctor, que son los expertos cruciales para la investigación y el desarrollo del sector público. Al saber que las habilidades investigativas en los estudiantes de pregrado de las universidades peruanas no tienen la fortaleza necesaria para generar investigadores, el objetivo de esta tesis es buscar el reforzamiento de estas habilidades con una estrategia metodológica mediante una plataforma cercana al estudiante y cambiar el espectro educativo de nuestro país.

La Organización para la Cooperación y el Desarrollo Económico (OCDE, 2016) nos evidencia que México está creando y fortaleciendo oficinas de transferencia de tecnología, a través del Fondo Sectorial de Innovación (Finnova), teniendo como objetivo aumentar las oportunidades de vinculación entre las instituciones que buscan el conocimiento y el sector privado a través de consultorías, concesiones de licencias y empresas de arranque. Se clarifica entonces el objetivo de países con un mayor nivel de educación sobre la importancia de la captación de fondos para la investigación, cosa que no sucede en nuestro país.

Según el Censo Nacional de Investigación y Desarrollo a Centros de Investigación del 2016, Lima tiene un 56.5\% de investigadores a nivel nacional, evidenciando una vez más la falta de importancia de promover e impulsar la inversión en investigación científica, tecnología e innovación en nuestro país, aumentando la brecha en calidad investigativa con respecto a otros países de Latinoamérica que tienen las mismas características. La problemática está presente tanto en las universidades estatales como en las privadas, donde los estudiantes aún no logran desarrollar al máximo sus habilidades investigativas, proyectándose en un manejo superficial de los métodos científicos eficientes y el uso de un proceso eficaz para llegar a la captación, registro y evidencia de la información que lleve a procesos de índole investigativa.

Frente a la problemática descrita en párrafos anteriores, se plantea una propuesta para desarrollar las habilidades investigativas en estudiantes de quinto ciclo de comunicaciones, que permitirá que los futuros profesionales desarrollen procesos metodológicos que lleven a los estudiantes terciarios a potenciar sus habilidades 
investigativas con procedimientos cercanos y de lenguaje masivo para orientar e informar a la población estudiantil y a la ciudadanía en general.

\section{Formulación del problema}

¿Cómo contribuir al desarrollo de las habilidades investigativas en estudiantes de quinto ciclo de Comunicaciones en una Universidad Privada de Lima?

De este problema se desprenden los siguientes problemas específicos.

\section{Preguntas específicas.}

¿Cuál es el estado actual del desarrollo de las habilidades investigativas en estudiantes universitarios de quinto ciclo de Comunicaciones en una Universidad Privada de Lima?

¿Cuáles son los fundamentos teóricos y metodológicos que sustentan la estrategia metodológica para desarrollar las habilidades investigativas en estudiantes universitarios de quinto ciclo de Comunicaciones en una Universidad Privada de Lima?

¿Qué criterios teóricos, didácticos y prácticos se debe de tener en cuenta en la modelación de la propuesta de la estrategia metodológica para desarrollar las habilidades investigativas en estudiantes universitarios de quinto ciclo de Comunicaciones en una Universidad Privada de Lima?

¿Cómo validar la propuesta de una estrategia metodológica para desarrollar las habilidades investigativas en estudiantes universitarios de quinto ciclo de Comunicaciones en una Universidad Privada de Lima?

\section{Objetivos de la investigación}

\section{Objetivo General.}

Proponer una estrategia metodológica para contribuir al desarrollo de habilidades investigativas en los estudiantes de quinto ciclo de Comunicaciones en una Universidad Privada de Lima.

\section{Objetivos específicos.}

Diagnosticar el estado actual del desarrollo de las habilidades investigativas en los estudiantes de Comunicaciones en una Universidad Privada de Lima.

Sistematizar los fundamentos teóricos y metodológisos que sustenten la estrategia metodológica para desarrollar las habilidades investigativas en los estudiantes de Comunicaciones de quinto ciclo en una Universidad Privada de Lima. 
Determinar los criterios teóricos, didáctios y prácticos a tomar en cuenta en la modelación de la estrategia metodológica para desarrollar las habilidades investigativas en los estudiantes de quinto ciclo de Comunicaciones en una Universidad Privada de Lima.

Validar por juicio de expertos la estrategia metodológica para desarrollar las habilidades investigativas en los estudiantes de quinto ciclo de Comunicaciones en una Universidad Privada de Lima.

\section{Categorías y subcategorías apriorísticas}

\section{Habilidades investigativas.}

La primera categoría que se investigó fueron las habilidades investigativas que según Montes de Oca y Machado Ramírez en el 2009, recalcan que son habilidades comunes en cualquier carrera universitaria y están explícitamente dentro de los planes de estudio y del currículo, en conclusion son básicas para formar futuros profesionales.

De esta categoría se desprenden las subcategorias: observación, clasificación, hipótesis, experimentación y comprobación que según Puche en el 2015 son procesos propias de las habilidades investigativas que buscan acercar al alumno al mundo de manera eficiente y exitosa y resolver problemas construyendo significando, contrastándolo y creando nexos para poder comprobar un hecho o idea.

Observación.

Para Puche (2001), la subcategoría de observación es un medio que el alumno posee para resolver el mundo de manera eficiente y exitosa, realizando procesos y convirtiéndose asi en productor.

Clasificación.

El autor de referencia de las subcategorías de las habilidaes investigativas, Puche (2001) refiere que la Identificación de semejanzas y diferencias de los objetos para poder agruparlos identificando sus criterios nos ayudará al proceso investigativo y al objetivo de crear la habilida de investigar.

Hipótesis.

Una de las etapas más importantes al desarrollar una habilida investigativa es la Hipótesis que busca identificar respuestas a los problemas previamente planteados(Puche, 2001).

Experimentación.

Cuando se genera la hipótesis se busca inmediatamente el proceso que la 
compruebe y para ello aparece la experimentación que recursos seguros que se aplican para verificar o comprobar una idea o hecho (Puche, 2001).

Comprobación.

Para cerrar el ciclo de un a investigación se necesita que lo anteriormente reflexionado y ejecutado llegue a un sistema de verificación, y es asi que se busca solucionar problemas comprendiendo el mundo que nos rodea (Puche 2005)

\section{Estrategia metodológica.}

Según Ocando (2009) son procedimientos utilizados por el docente en forma rígida o flexible y reflexiva para promover el logro de aprendizaje en sus alumnos, empleando para tal fin todos los métodos, técnicas, medios y recursos necesarios. El docente utiliza las estrategias de una manera consciente e intencional, orientadas al éxito del alumno en la realización de actividades para alcanzar el aprendizaje.

Las subcategories son: Planificación didáctica, métodos y técnicas de enseñanza aprendizaje y los recursos educativos.

\section{Planificación didáctica.}

Según Ocando (2009), la planificación didáctica consiste en un ejercicio de formulación y establecimiento de objetivos de carácter prioritario, cuya característica principal es el establecimiento de los cursos de acción para alcanzar dichos objetivos. A demás que es una herramienta de diagnóstico, análisis, reflexión y toma de decisiones, en torno a los procesos de enseñanza aprendizaje.

Métodos y técnicas de enseñanza aprendizaje.

Para Ocando (2009), es el conjunto lógico de los procedimientos didácticos que tienden a dirigir el aprendizaje, incluyendo en él desde la presentación y elaboración de la materia hasta la verificación y competente rectificación del aprendizaje.

Además, se refiere al planeamiento general de la acción de acuerdo con un criterio determinado y teniendo en vista determinadas metas.

\section{Recursos educativos}

Recursos educativos: constituyen todos los instrumentos de apoyo, herramientas y ayudas didácticas (guías, libros,materiales impresos y no impresos, esquemas,videos, diapositivas, imágenes, herramientas interactivas digitales, etc.) que se construye o seselecciona con el fin de tener mayor acercamiento a los estudiantes, al conocimiento y a la construcción de los conceptos para facilitar de esta manera el aprendizaje. 


\section{Justificación}

\section{Teórica.}

Las habilidades investigativas son pilares de conocimiento y generan nuevos constructos, creando una educación de mayor nivel tanto académica como social, es necesario que el estudiante de educación terciaria tenga interiorizado los siguientes conceptos, que define Reyes en el 2012, objeto de estudio, conceptos de estudio, sujeto de estudio y el contexto de estudio para poder establecer un esquema que lo llevará a la culminación de su proceso investigativo con éxito.

Según Castillo (2008), es necesario apoyarse en las TIC para generar y optimizar el aprendizaje y la investigación, porque son medios que motivan el conocimiento, el estudiante universitario en la actualidad genera un rápido reconocimiento de la tecnología y de las plataformas de contenido audiovisual, entonces, si queremos acercar al alumno a la investigación debemos utilizar vías atractivas y de fácil manejo para ellos, aumentando de esta manera sus potencialidades.

En conclusión, se eligió la estrategia metodológica como medio de evidencia de la investigación para ayudar al estudiante terciario a desarrollar la gestión y el desempeño de las habilidades investigativas para generar contenido que enriquezca a la comunidad y al conocimiento universitario.

\section{Metodológica.}

La estrategia metodológica permite una interacción entre los investigadores y la población estudiantil, generando debates y visualización de futuros temas de investigación. Los diferentes procesos metodológicos que se abordan en dicha propuesta sirven a los docentes, estudiantes y a otros investigadores a sistematizar los procesos de investigación con base en plataformas cercanas a ellos generando contenidos de forma profesional y con base científica.

\section{Práctica.}

Este estudio permite realizar una revisión de la metodología de enseñanza universitaria para el desarrollo de habilidades investigativas orientada a alumnos del quinto ciclo de Comunicaciones y permitir que el modelo transforme la práctica pedagógica del docente y mejore el aprendizaje del alumno en el campo de las habilidades investigativas, 
creando un espacio atractivo de investigación para el estudiante terciario, motivando su acercamiento a la investigación.

Su innovación incrementa la motivación para desarrollar las habilidades investigativas en jóvenes universitarios que tendrán un mayor dominio del lenguaje (oral, escrito y audiovisual), mejores habilidades cognitivas como interpretación, síntesis, deducción, y además podrán socializar su conocimiento, teniendo mayor comprensión de la problemática y de su entorno laboral, y sobre todo se incrementa la investigación para fomentar un mayor desarrollo en el campo educativo y laboral del país.

Este proyecto, beneficia al estudiante unversitario de quinto ciclo de la Facultad de Comunicaciones, que genera mayores habilidades para desempeñarse eficientemente en su entorno laboral y en la sociedad, y dotará a la institución de un grupo humano capaz de generar y replantear conocimientos que ayuden a su prestigio y valoración en el mundo académico, así como también aporta al país, incrementando el nivel de desarrollo y abriendo un nuevo mercado a la investigación local, sin necesidad de importar profesionales que manejen el tema de investigación. En conclusión, los estudiantes de quinto ciclo de Comunicaciones en una Universidad Privada de Lima, gracias a una estrategia metodológica, desarrollarán sus habilidades investigativas.

\section{Metodología de la investigación}

La investigación tiene un enfoque cualitativo y se enmarca dentro del paradigma sociocrítico e interpretativo que según Mosteiro y Porto (2017), busca la autoreflexión dentro de los procesos de conocimiento, estructurando relaciones sociales y propiciando reflexión y crítica, al respecto Ruiz en el 2011 afirma que las ciencias sociales últimamente se centran en un paradigma naturalista- interpretativo donde la subjetividad se vuelve fuente de conocimiento y nos muestra a un sujeto y objeto afectados por el mismo fenómeno y contexto.

Entonces el paradigma naturalista- interpretativo colabora con el proceso de investigación al tener mayor cercanía con el investigador y el contexto socio-cultural, pudiendo obterner información y problemáticas con mayor autenticidad. Esta investigación no solo se analiza a nivel metodológico o procedimental, sino que busca identificar las implicaciones éticas, sociales y políticas entendiendo así la investigación como un acto y discurso social cuyo objetivo es una investigación educativa con acertiva información.

\section{La investigación cualitativa en el contexto educativo.}

Existe gran cantidad de programas y metodologías desarrolladas en América Latina que 
tienen como objetivo incrementar los niveles de calidad educativa, cuyo aspecto fundamental es la investigación en educación y sobre educación. Según Moteiro y Porto (2017), la investigacion educativa a seguido su desarrollo con el debate sobre la naturaleza de la ciencia dando paso a una nueva teoría orientándose a una investigación más aplicada.

En esta investigación se busca componentes que sensibilicen los conceptos y vayan con las técnicas de observación que ayuden a encontrar categorías más humanistas y cercanas a nuestra relidad educativa. Lo cualtitativo nos ayuda a comprender mejor los fenómenos sociales y educativos.

\section{Tipo y diseño de investigación}

El estudio responde a una investigación de tipo aplicada que según Vargas (2009), consiste en elaborar conocimiento, así como también soluciones en contextos y realidades complejas, además, su objetivo se orienta al desarrollo de habilidades investigativas con la elaboración de un modelo con un propósito proyectivo y práctico y así podemos realizar una investigación científica implementada en un contexto real y cotidiano del estudiante.

La investigación aplicada tiene una base de investigación científica, evidenciando un marco teórico de la problemática expuesta, y luego con nuetra práctica en campo consolidamos el saber, aplicamos nuestros conocimientos y enriquecemos nuestro acervo cultural, gracias a un modelo que nos permitirá resolver el problema base.

Para Murillo (2008), la investigación aplicada es la “investigación práctica o empírica", que busca la aplicación o utilización de los saberes previos con los nuevos conocimientos que adquiere el individuo, gracias a la práctica investigativa y a un procedimiento organizado, sistemático y con rigor científico se comprende el entorno, por eso la investigación que se pretende desarrollar tiene un enfoque cualitativo de tipo aplicada que se orienta al desarrollo de habilidades investigativas con la elaboración de un modelo con propósito proyectivo y práctico.

En cuanto al diseño, el estudio obedece a un formato no experimental, de corte transversal descriptivo, que según Hernandez, Fernandez y Baptista (2014), lo no experimental considera el fenómeno y sus componentes y define las variables de la relación entre las herramientas metodológicas brindadas por el docente y el desempeño de los alumnos para crear este acercamiento a la invetsigación.

\section{Población, muestra y muestreo}




\section{Población de estudio.}

Según Hernández, Fernández y Baptista (2010) "una población es el conjunto de todos los casos que concuerdan con una serie de especificaciones" (p. 174). La población participante, objeto de estudio, estuvo constituída por estudiantes y docentes de quinto ciclo de la Carrera de Comunicaciones en las diferentes sedes de la institución educativa de una universidad Privada de Lima Este. De un universo de 5,600 estudiantes de pregrado y casi 3000 docentes en todas las sedes universitarias, el aproximado de estudiantes de 5 to ciclo de la carrera son alrededor de 300 alumnos y 80 profesores.

\section{Muestra y muestreo.}

De acuerdo a Valderrama (2013) "muestreo es el proceso de selección de una parte representativa de la población, la cual permite estimar los parámetros de la poblacion" (p. 188).

En este trabajo se aplicó el muestreo no probabilístico donde existe clara influencia del investigador, pues este selecciona la muestra atendiendo a razones de comodidad y según su criterio. Se trabajó con una muestra de 20 alumnos del quinto ciclo de la Facultad de Comunicaciones de una universidad privada de Lima Este y se selecciónó tres docentes de dicho curso.

\section{Unidad de análisis.}

En este trabajo se utilizó la siguiente unidad de análisis: Alumnos del quinto ciclo de Comunicaciones, distribuidos en tres salones y docentes del área de comunicaciones que imparten ese curso.

\section{Métodos teóricos, empíricos y estadísticos}

En el conocimiento científico existen dos grandes diferencias entre el método teórico y empírico, lo teórico nos ayuda en base a fundamentos, procesos de análisis, observación, síntesis y conclusiones y a determinar fenómenos para poder entender las leyes que los rigen, es por eso que esta investigación utiliza los métodos científicos de análisis y síntesis, inducción y deducción, vinculación de lo abstracto a lo concreto y una modelación del diseño de la propuesta que resolvera la interrogante del escaso desarrollo de las habilidades investigativas en estudiantes de comunicaciones. Como dice Puche (2001) la observación es un medio que el alumno posee para resolver el mundo de manera eficiente y exitosa convirtiéndose en productor del conocimiento, por eso creamos un modelo donde el alumno universitario a partir de su realidad visualice nuevos recursos para transformar una problemática y generar una solución realista.

Según Cerezal y Fiallo (2016), el método histórico-lógico se basa en aquello que 
caracteriza al objeto en su desarrollo histórico y evolución a través de la investigación. Este método se empleó para enfocar la esencia del estudio, que es el objeto del problema y no solamente se buscó enumerar los hechos obserbados en las clases, sino describirlos y encontrar la conexión entre y la metodología del docente para determinar la solución del problema de la falta de desarrollo de las habilidades investigativas.

Al utilizar el método análisis-síntesis relacionamos el todo y sus partes, como lo menciona Cerezal y Fiallo (2016), el siguiente método se utilizó para buscar que el docente investigador genere un proceso creativo y científico que ayude a comprender los factores que determinan la causa de que las habilidades investigativas de los estudiantes universitarios son tan bajas o poco desarrolladas. Toda esta conjunción de factores ayudó a determinar y a comprender las relaciones que acentuan o discriminan estas habilidades.

Para Ruiz (1999), el método de inducción y deducción nos explica que a la ciencia le gusta contrastar su verdad con la realidad y tenemos como investigadores que ir de lo particular a lo general. Utilizamos este método para que a partir de casos particulares el alumno comprobara cúales son los factores determinantes de la hipótesis de manera empírica, guiado por la metodología del docente para luego inducir una nueva forma de llevar la enseñanza-aprendizaje.

Para De La Garza (2017), la abstracción parte de la conciencia de lo concreto, de lo real, buscando como está constituido el objeto de estudio y como se capta el fenómeno desde lo esencial, es así que este método nos ayudo a la abtraccion de los diversos niveles de comunicación de la investigación, encontrando los fundamentos necesarios para que la investigación no quede en un nivel superficial, solo basta concretar aquellos fundamentos para llegar realistamente a una solución que encamine correctamente al alumno en el proceso investigativo.

Para Pérez (1996), a partir de lo abstracto se contruye un modelo para explicar la realidad. Es así que este método nos ayudó a establecer el marco teórico y el trabajo de campo, buscando una propuesta que logre sistematizar toda esa información en el diseño del modelo para desarrollar las habilidades investigativas.

Según Cerezal y Fiallo (2016), el desarrollo de métodos empíricos permite recopilar datos que nos ayudan a poder entender el fénomeno de investigación, cuando algo se repite constantemente crea en nosotros un precedente que se vuelve creencia positiva y a partir de ahí se explica lo real y lo concreto. Es por eso que se utilizó la observación no participativa, no estructurada y real, cuyo instrumento principal fue la guía de observación de la clase de Narrativas audiovisuales del quinto ciclo de la Facultad de Comunicaciones de una Universidad privada de Lima Este, así como 
también encuestas y entrevistas a los alumnos y docentes para ver en la práctica el desempeño de dichas habilidades. El objetivo era analizar el entorno de clase y la realidad educativa del curso, experimentando en un entorno pedagógico para luego determinar los factores del problema y como salir de él.

En relación con los métodos matemáticos y estadísticos, los primeros colaboraron en nuestra investigación con el proceso de datos en aquellas aplicaciones de instrumentos de diagnóstico como la prueba pedagógica, y los segundos para procesar la información descriptiva y el análisis de estos como en la guía de obserbación. 


\section{Técnicas e instrumentos de investigación}

Técnicas.

Según Valderrama (2013) aquellos que llamamos técnicas son procedimientos o recursos que el investigador toma para enfrentarse a los hechos y acercar esa nueva realidad a sus conocimientos, en esta etapa es necesaria la ayuda de instumentos para acceder, guardar y sistematizar esa información, es por ello que se utilizaron las siguientes técnicas.

\section{Entrevista.}

Según Lanuez, Martínez y Pérez (2008) la entrevista "es el intercambio verbal entre dos personas, el (los) entrevistado(s) y el (los) entrevistador(es), que se desarrolla con el objeto de obtener determinados datos que interesan al (a los) entrevistador (es), y que coadyuvan a dar solución de un problema en la investigación que se desarrolla" (p.89). Dichas entrevistas se realizaron a tres docentes que imparten el curso de Narrativas audiovisuales del quinto ciclo de la facultad de Comunicaciones de una Universidad Privada de Lima para conocer como es su metodología, y que tipos de conceptos son básicos dentro de su curso y es por ello que se realizó una entrevista de tipo semiestructurada.

\section{Encuesta.}

En términos de Llanos y Fernandez (2005) la encuesta "es un conjunto de estímulos sistemáticos aplicados a determinadas unidades de análisis, sobre la base de un conjunto de respuestas predeterminadas" (p. 76). Dicha información ayudó a poder recoger información sobre la muestra y enfocarnos al actual estado de las habilidades investigativas.

\section{Instrumentos.}

Según Llanos y Fernandez (2005) los instrumentos son un recurso que sirve al investigador para extraer información, es por ello que una guía de entrevista semiestructurada y una prueba pedagógica colaboraron con ayudar a obtener información del contexto real de la clase enfocado en la categoría principal: las habilidades investigativas. Cabe mencionar que las preguntas tanto como la prueba pedagógica y la guía de entrevista semi-estructurada están basadas en la relación del estudiante y del maestro con las habilidades investigativas y la estrategia metodológica.

\section{Prueba Pedagógica.}

Fiallo y Cerezal (2002) nos demuestran que las pruebas pedagógicas se utilizan con frecuencia en la investigación pedagógica con el objetivo de diagnosticar como se 
encuentra el cococimiento, los hábitos y las habilidades de los sujetos.

Es por ello, que dicha prueba ayudó al investigador a conocer la realidad de las habilidades investigativas y como se desarrolla la metodología dentro del curso de Narrativas audiovisuales.

\section{Cuestionario.}

Según Rodriguez y Pérez (2017), los cuestionarios ayudaron a definir el nivel de desarrollo del área de investigar para saber el indice de la habilidad investigativa dentro de los estudiantes de pregrado, sobre todo en conceptos y metodologías de trabajo docente.

\section{Validación de los instrumentos.}

Los instrumentos de recolección fueron entregados a dos expertos, dos temáticos y un metodólogo, emitiendo a su juicio la validez de estos y posterior aplicación. Cada experto recibió la ficha de validación, los instrumentos y la matriz de categorías. (Ver anexo 2). Los expertos validaron de manera independiente la pertinencia, relevancia y construcción gramatical de los ítems de cada instrumento (ver anexo 3); obteniéndose los resultados mostrados en la tabla 1.

\section{Tabla 1.}

Resultados de la validación de instrumentos por juicio expertos

\begin{tabular}{|c|c|c|c|}
\hline & & Instrumentos & \\
\hline Expertos & Especialidad & $\begin{array}{l}\text { Guía de entrevista } \\
\text { semi estructurada a } \\
\text { docentes }\end{array}$ & $\begin{array}{l}\text { Prueba } \\
\text { pedagógica a } \\
\text { estudiantes }\end{array}$ \\
\hline Dr. José Muñoz Salazar & Metodólogo & Aplicable & Aplicable \\
\hline $\begin{array}{l}\text { Master Levy Mancilla Mc } \\
\text { Kinlay }\end{array}$ & Temático & Aplicable & Aplicable \\
\hline Master Roger Solis Campos & Temático & Aplicable & Aplicable \\
\hline
\end{tabular}

Fuente: Elaboracion propia (2019)

De acuerdo a la tabla se observa que los instrumentos de recolección de datos son aplicables y óptimos, habiendo algunas observaciones que fueron tomadas en cuenta para la aplicación en campo. 


\section{Capítulo I}

\section{Marco teórico}

\section{Fundamentación teórica de la investigación}

\section{Antecedentes de la investigación.}

\section{Antecedentes internacionales.}

Blanco (2017), desarrolló un estudio con la finalidad de proponer un modelo teórico metodológico para el desarrollo de las habilidades investigativas en el procedimiento docente de la carrera de Medicina, el tipo de estudio fue científico y cuyo diseño de integración sistémica de los componentes organizacionales y personalizados busco resultados en la ejecución como el proceso de tareas investigativas, la población de estudio estuvo constituída por 44 estudiantes de tercero a quinto año de la Carrera de medicina y como resultado de esta investigación se evidenció la necesidad de desarrollar habilidades investigativas en los estudiantes de Medicina por la escasez de estas dentro de sus competencias, comprobándose la efectividad del modelo teórico en la práctica estudiantil, constatando avances en los estudiantes a un nivel adecuado.

En el 2015, Tuárez realizó una tesis sobre la formación de las habilidades investigativas en los estudiantes de tercer semestre de la carrera de ciencias psicológicas de la Universidad de Guayaquil, tenía como objetivo identificar cuales son los criterios para formar esas habilidades y su importancia en la formación de los estudiantes, se tomó a 240 estudiantes del tercer semestres en los años 2015 y 2016, la investigación a realizar es de tipo descriptiva, cuyo diseño se baso en formulación del problema científico, objetivos e hipótesis de investigación, selección de población, muestra y tipo de muestreo, se determinó que los estudiantes tienen un nivel básico en relación con las habilidades investigativas y que el índice metodológico del curso no cumple con las espectativas de las competencias, ni de los alumnos, y se tiene que fortalecer desde la mallas la metodología y el nivel de excigencia de las habilidades investigativas.

La plataforma de investigación científica de la Universidad Complutense de Madrid genera productos audiovisuales de la Facultad de Ciencia de la Información de dicha Universidad. Parte de su estrategia metodológica es la generación de documentales, cortos y otras series de productos audiovisuales que han llevado a realizar una serie documental en TVE, su objetivo es crear lazos de comunicación entre 
la comunidad científica y el ciudadano mediante la divulgación de la ciencia, la cultura y la cooperación.

Cardoza, Carmona, Ramos y Ribón (2015), buscaron como objetivo diseñar una propuesta de lectura y escritura mediante estrategias metodológicas para mejorar las habilidades comunicativas en estudiantes de primer grado de la Institución educativa Luis Carlos López, realizando una investigación de tipo descriptiva partiendo del diseño de una prueba diagnóstica en una población de 19 estudiantes, estableciéndose que existián muchas dificultades en la lectura y cmo una estrategia lúdica pedagógica pudo mejorar las actividades y habilidades con ayuda de los procesos cognitivos y realización de actividades.

\section{Antecedentes nacionales.}

En 2017, Blumen y Rivero buscaron promover el desarrollo de habilidades investigativas creando un curso propedeútico relacionado con métodos e investigación virtual. Basados en un enfoque participativo y autónomo, fomentaron el trabajo colaborativo apoyado en las competencias de investigación y cuyo diseño fue no experimental, implementándosé como curso en la plataforma digital de forma masiva y de acceso abierto.

En el mismo año, Espinoza realizó una tesis para promover las habilidades investigativas y el liderazgo creativo en Estudiantes de Ciencias matemáticas e informática en la Universidad nacional del Centro del Perú, su objetivo era establecer la relación entre las habilidades referidas y el liderzgo, se realizó en base a una investigación descriptiva con diseño correlacional, teniendo como muestra a 89 estudiantes de una población de 116 alumnos, para recabar la información necesaria a nivel de campo, se aplicó cuestionarios midiendo la variable competencia investigativa, concluyéndose que existe una relación altamente positiva entre el liderazgo creativo y las habilidades investigativas.

En el año 2009, Lanchipa realizó una tesis para optar el título de Magister en Educación con mención en Docencia en el nivel Superior sobre el método investigativo y desarrollo de habilidades para investigar en estudiantes de la Escuela de Medicina Humana de la Universidad Nacional "Jorge Basadre Grohman" de Tacna. La investigación fue de tipo tecnológica con un diseño pre-experimental y de método investigativo, seleccionándose una muestra de 40 estudiantes de la mencionada Universidad, realizándose pruebas de evaluación, encuestas a docentes, procesamientos estadísticos de los datos, realizándose la operacionalización de la 
variable dependiente. En conclusión, se evidenció la influencia significativa del método investigativo en la mejora del desarrollo de las habilidades cognitivas para realizar las investigaciones.

En 2015, Guillén busca explicar las habilidades investigativas dentro del área de Ciencia y ambiente en estudiantes de 5 años poniendo énfasis en la observación, la formulación de la hipótesis, la experimentación y la verbalización, integrando datos cuantitativos y cualitativos para obtener el grado de magister en Ciencias de la Educación de la Universidad Cayetano Heredia, realizando un enfoque mixto a nivel descriptivo, aplicando un diseño de triangulación donde los instrumentos a utilizar fueron las guias de observación tanto para docentes como para alumnos de una muestra de 60 alumnos de 5 años. La conclusión evidenció que $52 \%$ de la muestra logro desarrollar las habilidades investigativas buscadas en la investigación: observación, formulación de hipótesis, experimentación y verbalización.

En 2015, Quispe realiza una tesis buscando el desarrollo de las habilidades investigativas en estudiantes de Ciencias, tecnología y ambiente de segundo de secundaria en la Universidad Nacional de Educación Enrique Guzmán y Valle, utilizando sesiones de aprendizaje con webquest, cuyo objetivo era medir que tanto esta plataforma ayuda al desarrollo de habilidades investigativas, el tipo de investigación fue experimental utilizando métodos de medición, de inducción, comparativo y estadístico, realizando un diseño pre-experimental, con instrumentos como el pretest, el postest, el webtest y las fichas de trabajo. En esta investigación la población fue del mismo número que la muestra y consta de 133 alumnos del segundo grado de secuandaria de dicha institución del curso de Ciencias, tecnología y ambiente. Es así que se concluyó que el uso del webquest permite el desarrollo e incremento de las habilidades investigativas en los alumnos.

\section{Teorías y enfoques de las habilidades investigativas}

Para Montes de Oca y Machado (2009) las habilidades investigativas se desarrollan en un profesional cuando este domina globalmente ciertas acciones y procesos que están ligados a las fases del conocimiento para la resolución de problemas que existen en su cotidianidad educativa e investigativa. No solamente el estudiante de educación terciaria tiene que estar capacitado para la resolución de problemas académicos, sino tambien tiene que aperturarse a que todo el conocimiento recibido ayude a generar soluciones en su entorno laboral y en su vida cotidiana. No solo queremos desarrollar buenos profesionales, sino buenos ciudadanos. 
Necesitamos de habilidades investigativas para crear o determinar un nuevo conocimiento, según Hernández (2016) estas habilidades son de tipo instrumentales y de tipo social que llevarán a un desarrollo integral del investigador de pregrado y la realización de proyectos multidisciplinarios que ayuden a la formación de futuros investigadores. Por eso, nos basamos en el trabajo de Reyes (2012) donde el investigador debe de interiorizar el objeto de estudio, los conceptos de estudio, el sujeto de estudio y el contexto de estudio para poder establecer un esquema que divida su trabajo en introducción, revisión de la literatura,método de investigación, análisis de los resultados, conclusiones y por último fuentes de información que ayudarán que la estratégia metodológica tenga una base sólida de la recopilación de la información para gererar la investigación.

\section{Teoría de la actividad de Leontiev}

La teoría de Leontiev busca una relación dialéctica entre sujeto y objeto de estudio, visualizamos la transformación del sujeto al tener relación con el objeto y como se regula la acción entre ambos. Dentro de esta relación se identifican componentes como: la ejecución y la orientación que llevarán a cabo un logro u objetivo a partir de la realización de la tarea condicionada al logro de la actividad de estudio, mediada por instrumentos de memorización y comprensión que ayudarán a desarrollar las habilidades investigativas.

Dentro del proceso de construcción de habilidades investigativas necesitamos vincular dos actividades, la actividad humana y la actividad intelectual. La primera tiene que ver con la relación práctica con los objetos y como llegamos a interiorizar y elevarl lo investigado a un plano representativo. Aquí lo más importante es el poceso de subjetivizar al objeto. Como herramienta funfamental categorizamos a partir de las características del objeto llegando a lo abstracto, produciendo actos intelectuales, actos de comunicación y acciones de estudio.

En segunda instancia nos encontramos con la actividad intelectual, donde los métodos forman parte indispensable de los procesos, aquí la percepción va de la mano con la actividad investigativa, vemos las estructuras complejas que ya entran en el campo de lo abstracto, del pensamiento conceptual, comenzamos a seleccionar material, fundamentalizar las acciones intelectuales, la comprensión del texto y la memorización. 


\section{Desarrollo de las habilidades investigativas desde el enfoque socioformativo}

A partir de un contexto claro y vislumbrando su proyecto ético de vida, el alumno puede tener una formación integral según este enfoque liderado por Tobón, con la base de un trabajo colaborativo que busca emprendimiento y una co-creación apoyándose en las tecnologías de la información y la comunicación. Es aí que el estudiante terciari a partri de una transversalidad de la investigación pone en evidencia el proceso de logro de metas que apoyen su desarrollo indicidual, social y contextual transcendiendo los procesos mentales del construccionismo y del socioconstructivismo.

Dentro de los temas a escogen en un proceso investigativo, el alumno tiene que sentirse identificado con la problemática, es así que ls soluciones generadas se volverán significativas para ellos y su comunidad y su talento como investigadores se formará a un nivel complejo y aplicando la metacognición. Partre de las caracteísticas de un estudiante universatario es la capacidad de interpretar, identificar, argumentar y resolver problemas, que son bases indispensables en un proceso investigativo, el saber hacer, el saber ser, el saber convivir y el conocer son normas claras en un enfoque socioformativo que brinda al alumno una línea clara en una investigación aplicada.

Según Tobón las competencias de este enfoque se caracterizan por ser integrales, no se fragmenta el saber, la evaluación debe ser de la misma forma(integral), deben de estar acompañados de procesos colaborativos, apoyñandose en las nuevas TICS, dando una solución concreta al problema en cuestión que no solo piense en el individuo sino en la comunidad, creando entonces un conocimiento co-creador apoyándose en diferentes áreas que articulen entre sí, de la mano de valores constituidos y por supuesto que sean investigaciones de calidad integrando procesos internos y externos.

Algo que debe estar claro es la veracidad de la información y su pertinencia en relación con el sujeto y objeto de estudio, así como su desarroolo y la inclusión dentro de los procesos y la proyección final para cumplir con los retos del contexto y el mercado laboral de nuestros futuros profesionales transcendiendo el aprendizaje buscando la formación integral del individuo. Es indispensable el manejo de la resolución de problemas en profesionales de la comunicación mediante la colaboración de sus saberes, tanto académicos como no académicos, en contextos, educaionales, organizacionales y sociales.

A partir de la sociofromación se pueden generar soluciones a los problemas de investigación como proyectos formativos, análisis de los casos de 
problemática contextual, estrategias didácticas, trabajo colaborativo, y ayudando al alumno a poder manejar procesos cognitivos más complejos, a reoganizar a crear estrategias flexibles, y comprender las partes a parti de un todo, y no quedarse en el estancamiento y buscar el dinamismo necesario para las competencias necesarias de la Carrera de Comunicaciones.

La flexibilidad ayuda a la creatividad y el poder afrontar estratégicamente el cambio de las nuevas tecnólogias de la información, además la metodología empleada en este enfoque es muy semejante a los procesos investigativos como: buscar una problemática a resolver y trazar los objetivos, analizar los saberes previos e investigar, trabajar colaborativamente, gestionar y co-crear conocimiento, contextualizar y diagnosticar, resolver el problema y socializar el proceso.

\section{Aportes de la comunicación audiovisual en el desarrollo de las habilidades investigativas}

Las nociones de tiempo y espacio han cambiado y la tendencia informativa donde la imagen es el principal influenciador y matriz de la información cada vez van en aumento, esta acogida de las nuevas generaciones al formato audiovisual ha hecho que no solo se vuelva una representación de la realidad sino también una reconstrucción de la misma. $Y$ gracias a esto se ha evidenciado que se pueden utilizar como herramientas del desarrollo investigativo desde un carácter documental e informativo, donde lo sensorial es pieza clave para el desarrollo de la información.

Las posibilidades narrativas del video amplian las posibilidades de nuevos discursos y del espectro del currículo. Todo esto a partir de una nueva reconstrucción de la realidad a partir de evidencias audiovisuales desde la dimensión técnica y la dimensión científica, que va de la mano sobre todo con los estudiantes terciarios de comunicación audiovisual. Salimos de la conceptualización de lo masivo, siempre ligado a los medios, para centrarnos en lo particular.

En la actualidad los recursos para la toma de información son mas accesibles a los alumnos y aunque parezca un comentario sin importancia, también son de menor tamaño y peso, ayudando a que el regristro sea de menor dificultad. Una buena realización audiovisual ayudará a que podamos tener una mayor perspectiva crítica y selectiva apoyándonos en la relación sujeto- objeto, para conocer y reconocer mejor el entorno y los fenómenos sociales. 


\section{Los pilares del conocimiento como instrumento del proceso investigativo}

Según Delors (1994) la amplitud del conocimiento educativo permite que el individuo descubra e incremente sus posibilidades creativas, llevándolo a trascender más alla de la educación como instrumento del conocimiento. Delors además nos dice que existen 4 pilares del conocimiento y estos son: Aprender a conocer (comprensión, descubrimiento y conocimiento del entorno) que genera una relación entre lo concreto y lo abstracto, aquí buscamos ser "el amigo de la ciencia" como dice Delors (1994), teniendo así dos tipos de conocimiento: el inductivo y el deductivo.Aprender a hacer(utilización de los conocimientos para mi mi futuro desenvolvimiento), aprender a convivir(crear objetivos y proyectos comunes fortaleciendo el autoconocimiento y el conocimiento del otro) y aprender a ser (la conducta individualista no motiva, se debe desarrollar desde uno mismo para colaborar con el resto) .

El investigador se ocupará de disgregar cada uno de los elementos registrados en los 4 pilares que además son elementos comunes del proceso investigativo, primero tenemos que conocer y descubir el tema a investigar relacionando dos conocimientos: la inducción y la deducción, luego captamos los nuevos conocimientos para gestionar su utilización en el siguiente periodo donde se gestionan las hipótesis, como tercer punto, se formarán los objetivos comunes y un sistema de colaboración y por último el aprender a ser que está vinculado estrechamente a la buena convivencia con el entorno ayudará a los estudiantes a convertirse en agentes de cambio y gestionadores de nuevo conocimiento que colaborará no solamente a la investigación sino a la comunidad .

\section{La investigación audiovisual}

Según Dumont, Istance y Benavides (2012) no podemos negar que las nuevas platafomas tecnológicas y la economía basada en el conocimiento motivan que los sistemas educativos a nivel mundial pongan interés en la tecnología asociada al conocimiento para generar éxitos en sus procesos, es por ello que nuestra estrategia se basa en una plataforma digital que es un medio cercano y empático para el alumno de pregrado claramente identificado en sus quehaceres cotidianos para lograr desarrollar las habilidades investigativas en nuestro grupo de estudio.

También debemos resaltar que estos procesos deben ir acompañados de un docente investigador respaldando la afirmación de Sánches (1987), que dice que el proceso de enseñanza dirigido a una investigación tiene que ir acompañado de la emisión de saberes teóricos y prácticos, además de la transmisión de estrategias, habilidades y destrezas.El alumno estará motivado por una plataforma cotidiana para él 
y un continuo monitoreo y transmisión de conocimientos por parte del docente, además como dice Baer \& Schnettler (2009) las nuevas tecnologías audiovisuales ayudan a documentar de formas poco tradicional los procesos de investigación, ampliando y mejorando el espectro de estudio, generando que la investigación no se quede en una fase de reconocimiento simplemente.

A lo largo del tiempo desde que aparecieron los fomatos audiovisuales se han generado intercambios entre las ciencia y tecnología, como el caso de Mead y Bateson (1986) son los primeros en realizar esta conjunción para concretar una investigación metodológica sobre la cultura en Bali, es así que podemos determinar que la metodología usada como formato documentalista para la captación y registro de la problemática es uno de los mejores ejemplos del apoyo de la plataforma digital para la investigación en una fase cualitativa.

\section{Fundamentos teóricos de estrategia metodológica audiovisual}

En la metodología de trabajo audiovisual se debe de tener en consideración, según García (2008), informarse sobre el tema a tratar, buscando en bibliografía, videografía, confrontando así las teorías a tratar para de acuerdo a eso encontrar la estructura audiovisual idonea para la investigación, buscar personajes y lugares para la grabación, aprendizaje cooperativo, aprendizaje tecnológico, evaluación formativa y enfoque basado en la investigación.

Se combinarán diversos procesos metodológicos comenzando con el modelo colaborativo de Formación de investigadores propuesto por Rodríguez, Benites y García Martínez que consiste en la colaboración de dos aspectos: la asignación de temas de investigación y la dinámica de grupo orientada al ser (al llegar a ser investigador). A estos procesos se agregarán algunos conceptos de la estrategia de aprendizaje ABSTI 3 que es un modelo que constuye etapas donde el docente monitorea y establece objetivos: planificación, proceso y sistematización.

Aquí un docente investigador es el que se encargará del grupo de investigadores y se eligirá un tema en concenso a diferencia de la propuesta original de Rodríguez y compañía donde el docente es el que elije el tema a investigar, además se direccionará al alumno a crear investigación de especialidad que es un trabajo de investigación documental o exploratorio de un tema. 


\section{Habilidades Investigativas}

El carácter investigativo de la educación superior no se puede basar simplemente en los cursos que se dicten en cada especialidad, es por eso que para aprovechar las potencialidades de la generación de habilidades investigativas tenemos que saber la orientación y conceptualización de estas para llegar a desarrollarlas en estudiantes terciarios. Según Montes de Oca y Machado (2009) estas habilidades deben de comprenderse como habilidades profesionales que son comunes en cualquier carrera universitaria y estan explicitamente dentro de los planes de estudio y del currículo y a la vez ayudan a los futuros profesionales a resolver problemas de contenido específico de su disciplina.

Para enseñar a investigar necesitamos transmitir la teoría y la práctica para generar destrezas en los alumnos que están relacionadas a la mentalidad científica, entrenando la modulación de concocimientos y su producción. Para Montes de Oca y Machado (2009) las habilidades investigativas se desarrollan en un profesional cuando este domina globalmente ciertas acciones y procesos que están ligados a las fases del conocimiento para la resolución de problemas que existen en su cotidianidad educativa e investigativa. No solamente el estudiante de educación terciaria tiene que estar capacitado para la resolución de problemas académicos, sino tambien tiene que aperturarse a que todo el conocimiento recibido ayude a generar soluciones en su entorno laboral y en su vida cotidiana. No solo queremos desarrollar buenos profesionales, sino buenos ciudadanos.

Necesitamos de habilidades investigativas para crear o determinar un nuevo conocimiento, según Hernández (2016) estas habilidades son de tipo instrumentales (dominio del lenguaje, manejo de las operaciones cognitivas, saber cuestionar y observar) y de tipo social (trabajo en equipo, socialización de la construcción del conocimiento, comprensión, dialogo y aportación a foros)

Estas habilidades llevan a un desarrollo integral del investigador de pregrado y a la realización de proyectos multidisciplinarios que ayuden a la formación de futuros investigadores. Por eso esta investigación seguirá lo planteado por Reyes (2012) donde el investigador debe de interiorizar el objeto de estudio, los conceptos de estudio, el sujeto de estudio y el contexto de estudio para poder establecer un esquema de Ruta Meta que divida el proceso en introducción, revisión de la literatura,método de investigación, análisis de los resultados, conclusiones y por último fuentes de información que ayudarán a que la estratégia didáctica lleve al alumno a una base sólida de recopilación de la información para gererar investigación. 


\section{Habilidades instrumentales y sociales}

Hernández (2016), propone dos tipos de habilidades investigativas: las habilidades instrumentales y las habilidades sociales. Las primeras tienen que ver con el dominio del lenguaje, como el estudiante maneja las operaciones cognitivas, el saber observar y el saber cuestionar. Dominar el lenguaje implica la lectura, las emisiones de mensajes en texto y su interpretación, el manejo de operacions cognitivas se caracteriza en la inferencia, la iducción, la deducción, la síntesis y la interpretación, el estudiante también tiene que saber observar y cuestionar, que básicamente nos muestra como examina con atención y se pregunta respecto a lo observado.

Las habilidades sociales que se consideran dentro del proceso de habilidades investigativas son: el trabajo en equipo, como se socializa la construcción del conocimiento, la comprensión y el diálogo, junto con la aportación en foros académicos o espealizados, para el autor es indispensable este proceso de socialización para el proceder científico, las habilidades de participación, colaboración, expresión, escucha y dialógo son imprescindibles en el estudiante para colaborar con el forjamiento del nuevo concocimiento. Esta modalidad de aprendizaje lleva a un diálogo que estimula los procesos grupales y la socialización de los saberes previos y la cosntrucción del nuevo conocimiento para laborar proyectos de investigación que son más eficacez en línea.

\section{Estrategia metodológica}

El presente trabajo tiene como una de las categorías la Estrategia metodológica enfocada en el entorno audiovisual que ha abierto un abanico de posibilidades para lograr investigación desde entornos domésticos hasta sistematizaciones más elaboradas, pero necesitamos enfocarnos en el concepto fundamental de la metodología, que para autores como Tobón (2016), es el camino o ruta que se traza para sistematizar la enseñanza en relación con el objeto a estudiar y como llegamos a los objetivos del estudio. Entonces, aquellos procedimientos establecidos que nos ayudan a alcanzar los objetivos dentro de un proceso racional de pensamiento y análisis, donde necesito ciertas habilidades específicas son los que me llevan a una estrategia metodológica investigativa.

Es así que podemos tener un concepto más holístico de la metodología que según Gordillo (2007), es la evidencia del proceso sistemático donde adquirimos modos o formas de conocimiento, mientras que el método es más restringido y controlado. Barriga (2010) enfatiza que este proceso debe estar orientado por un docente investigador para que se pueda estimular el desarrollo de las habilidades de un alumno investigador que este en conexión con su entorno. Una estrategia metodológica ayudará en el desarrollo de las habilidades investigativas porque dinamizará el proceso de la 
dialéctica, el pensamiento crítico, el aprendizaje crítico, la valorización, la categorización, la metacognición y habilidades que fomenten la investigación.

La estrategia metodológica según Barriga y Hernández (2002), el procedimiento que me ayuda a la reflexión de un tema y tienen como objetivo el logro de un aprendizaje y deben de estar de la mano con un proceso motivacional y de trabajo colaborativo. Estos mismos autores afirman en el 2010 que estos diversos procedimientos concientizan y se convierten en un aprendizaje sostenido en el tiempo y más consciente hasta llegar al autoaprendizaje y la autoevaluación desarrollando habilidades específicas e independencia cognoscitiva del estudiante terciario.

Según Velásquez (2014), es importante destacar que el docente encargado de este acompañamiento tiene que problematizar, dialogar, reflexionar y valorar el contenido de la metodología, donde los estudiantes son parte esencial de las transformaciones desde sus saberes, todo orientado a una disciplina específica que siga un método activo.

Tobón (2013), recalca la idea de que tenemos que entrenar a los alumnos en la realización de la actividad de aprendizaje donde solucionan el problema, lo comprenden y utilizan guías y herramientas para su propio aprendizaje y evaluación autónoma, todo este paquete de ideas ayudan a gestionar el pensamiento crítico y la reflexión, es así que en la siguiente investigación se tendrá en consideración las siguientes aspectos delimitados por De Armas y Lorence (2003): objetivo general , fundamentación (sistematización de conceptos), etapas, procedimiento de cada etapa, representación gráfica y por último la evaluación (objetivos), todas estas fases deben de acompañarse de instrumentos que colaboren con los objetivos específicos y generales.

\section{Estrategia metodológica de un trabajo investigativo}

Según Armas y Lorence (2003) y Rodríguez (2002) pusieron como indicadores de una estrategia metodológica los siguientes puntos: diagnóstico, etapas (utilización de información) y evaluación, que ayudarán a obtener una estrategia como resultado científico de los procesos determinados por ciertas directrices para mejores resultados del proceso enseñaza aprendizaje. El diagnóstico se puede realizar de los resultados de evaluación de profesores, desarrollo individual, entrevistas, pruebas de conocimiento y observación participante, en nuestra segunda fase destaca el enfoque , las características, la selección del sistema y de los medios adecuados; y por último en la fase de evaluación lo corroboramos con el criterio de especialistas y sondeos de aprendizaje, todos estos elemeentos nos ayudarán a tener en claro nuestros indicadores y herramientas de evaluación 


\section{Capítulo II}

\section{Diagnóstico o trabajo de campo}

En el siguiente capítulo se describen los hallazgos encontrado al aplicar las diferentes técnicas e instrumentos de recolección de datos: cuestionario a alumnos, encuestas a docentes, prueba pedagógica y observación de clase. El cuestionario a estudiantes se aplicó con el objetivo de conocer la perspectiva que tienen de la clase de Narrativas audiovisuales del $\mathrm{V}$ ciclo de la Facultad de Comunicaciones de una universidad privdada de Lima Este, para ver como se desarrollan las habilidades investigas en clase y el manejo de la estrategia metodológica por parte del docente. Igualmente se aplicó una prueba pedagógica para conocer el nivel académico que tienen dichos estudiantes referenete a la temática de habilidades investigativas. Para recolectar la perspectiva de los docentes se les realizó entrevistas con la finalidad de constatar los conocimientos teóricos y metodológicos que poseen para desarrollar las habilidades investigativas dentro del curso en los estudiantes y finalmente se realizó la observación de clase, con el objetivo de constatar que los conocimientos brindados en la entrevista se realicen en el curso de Narrativas audiovisuales.

\section{Análisis e interpretación de los hallazgos por técnicas e instrumentos}

Según González (2013), ciertos procesos de forma directa y poco elaborada tienen que ver con referentes filosóficos para defender la investigación cualitativa, evidenciado en una relación epistemológica sobre la teoría y la metodología basados en modelo de evidencias subjetivas y es donde surgen otras subjetividades y consecuencias epistemológicas, es por eso que nos basamos en herramientas que evidencien codificaciones cualitativas para buscar los análisis del presente trabajo

Con toda la información recolectada y de forma profunda y analítica observamos los datos que pueden llevar a las nuevas categorías desde el punto de partida de la creatividad del investigador como nos comenta Gibbs (2012) para poder desarrollar el proceso, así como también certificar nuestras categorías existentes.

No solamente realizamos procedimientos en base a herramientas sino una propuesta que esta ligada a la subjetividad que orienta al estudio para conocer más la investigación ligado a los procesos humanos de naturaleza cultural que esta relacionada a las ciencias sociales, y en este caso a la comunicación como lo dice en el 2013 González Reyes.

Por eso en base a una metodología dentro del proceso de indagación se creo un espacio crucial en el proceso investigativo con las herramientas necesarias para interpretar los datos con respecto al objeto de estudio y el contexto presentado en la problemática como lo explica Mayz en 2009, describiendo las situaciones y acciones 
para describir las situaciones en base a nuestros sujetos de estudio. Ordenamos la información recopilada de la siguiente manera:

\section{Encuesta realizada a estudiantes.}

La investigación que realizamos es de tipo aplicada educacional y orintada a la resolución de problemas con situaciones prácticas en base a una metodología que según Gordillo (2007) es la evidencia del proceso sistemático donde adquirimos modos o formas de conocimiento, mientras que el método es más restringido y controlado. Barriga (2010) enfatiza que este proceso debe estar orientado por un docente investigador para que se pueda estimular el desarrollo de las habilidades de un alumno investigador que este en conexión con su entorno. Una estrategia metodológica ayudará en el desarrollo de las habilidades investigativas porque dinamizará el proceso de la dialéctica, el pensamiento crítico, el aprendizaje crítico, la valorización, la categorización, la metacognición y habilidades que fomenten la investigación.

(Anexo 2)

Entonces sabiendo que nuestra meta es desarrollar habilidades investigativas nos apoyamos en las encuestas de 14 preguntas a un grupo de 20 estudiantes del quinto ciclo de Comunicaciones de la UPN, cuyo objetivo era el cococimiento de la identificación con el curso y como sentían la metodología desarrollada en el mismo. En dichas encuestas encontramos los siguientes resultados:

En la pregunta número 1 ¿Consideras que la investigación científica es importante para tu desarrollo profesional y personal?, observamos que un $90 \%$ de los entrevistados refiere la investigación científica como muy importante para el desarrollo profesional y personal, mientras un $10 \%$ creen que simplemente es importante. Esto queda en claro que el estudiante ve como base fundamental de su carrera audiovisual la investigación científica, como lo resalta Salmi (2009) diciendo que una de las características de una universidad de rango mundial es la excelencia en la investigación.

Observamos en la tercera pregunta: ¿El profesor realiza actividades en clases que te permiten desarrollar tus habilidades como la observación, la clasificación, la formulación de hipótesis, la experimentación y la comprobación?, el resultado pone en manifiesto que según los alumnos el profesor nunca realiza actividades que permiten desarrollar sus habilidades de observación, clasificación, hipótesis, experimentación y comprobación, el porcentaje que piensan el siguiente anunciado es un 55\%, mientras un $40 \%$ cree que esta interacción se realiza pocas veces y un reducido $5 \%$ manifiesta que es casi siempre que el profesor permite desarrollar estas habilidades en clase si 
combinamos diversos procesos metodológicos comenzando con el modelo colaborativo de Formación de investigadores propuesto por Rodríguez, Benites y García Martínez, de asignación de temas de investigación y la dinámica de grupo orientada al ser (al llegar a ser investigador). A estos procesos se agregarán algunos conceptos de la estrategia de aprendizaje ABSTI en 3 etapas donde el docente monitorea y establece objetivos: planificación, proceso y sistematización, podriamos ver cambios en como el alumno ve al docente y su compromise con el curso.

En la pregunta 11 ¿Consideras que la forma de evaluación del profesor contribuye para que logres las habilidades investigativas?, las respuestas a dicha pregunta evidencian que un $50 \%$ de la totalidad de los alumnos cree que pocas veces el profesor contribuye con los logros de las habilidades investigativas, mientras que un 50 $\%$ cree que son nulas estas contribuciones. Esto nos acerca aún mas a la falt de genaración de dichas habilidades, ya que si el docente no genera esa base el alumno no podrá desempeñar el resto de sus objetivos académicos con respecto a la generación de habilidades. Según el Censo Nacional de Investigación y Desarrollo a Centros de Investigación del 2016, Lima tiene un 56.5\% de investigadores a nivel nacional, evidenciando una vez más la falta de importancia de promover e impulsar la inversión en investigación científica, tecnología e innovación en nuestro país, aumentando la brecha en calidad investigativa con respecto a otros países de Latinoamérica que tienen las mismas características, y esto parte desde el docente.

En la pregunta 14 ¿El docente emplea instrumentos científicos que te permiten explorar la realidad?,observamos que un $50 \%$ cree que el docente pocas veces emplea instrumentos científicos que te permiten explorar la realidad, mientras que un $25 \%$ creee que se emplea instrumentos casi siempre y otro $25 \%$ nunca emplea estos instrumentos. Parte del desarrollo de estas habilidades es darles a los alumnos las herramientas para trabajarlas, entonces aquí vemos otra vez la problemática de la falta de investigación del alumno por una falta de acompañamiento del docente. Según Castillo (2008) hay que apoyarnos en las TIC para generar y optimizar el aprendizaje y la investigación, porque son medios que motivan el conocimiento. El estudiante universitario en la actualidad genera un rápido reconocimiento de la tecnología y de las plataformas de contenido audiovisual, si queremos acercar al alumno a la investigación debemos utilizar vías atractivas y de fácil manejo para ellos, aumentando de esta manera sus potencialidades. 
Ante la evidencia presentada por los estudiantes pudimos constatar que el alumno no se siente identificado con la metodología ni la didáctica desarrollada en clase para concretar el objetivo de desarrollar habilidades investigativas. Los alumnos si creen importante generar estas habilidades dentro de su Carrera, pero no hay identificación con la investigación ni con los componentes de esta.

La metodología desarrollada por el professor debe ser menos expositiva y crear desde el aula el método científico que se necesita para la ralización del documental que es fuente de la investigación. Las habilidades como la observación, la clasificación, la formulación de hipótesis, la experimentación y la comprobación deben de ser relacionadas con el proceso documentalista.

El docente tiene que acercar al estudiante de una manera más dinámica y didáctica a el proceso investigativo desde los procesos científicos básicos. Este curso es básicamente la realización desde 0 de un documental por eso los procesos deben de estar bien claros y cercanos a alos alumnos, si desde un comienzo existe una brecha de falta de identificación, cercanía, motivación y generación del nuevo conocimiento de la habilidad investigativa, el alumno no podrá desarrollarlas correctamente y esto se evidencia aún más por la falta de metodología del docente y la escasa vinculación del alumno con este proceso científico.

\section{Entrevista a los docentes.}

La recopilación de informacón que se evidenció en la entrevista a docentes, es que de 13 preguntas a 3 docentes del curso de Narrativas audiovisuales del V ciclo de la Facultad de comunicaciones de una Universidad Privada de Lima Este, tenían la orientación a conoccer su práctica didáctica y metodologógica y cúal era la importancia de las habilidades investigativas dentro del proceso de investigación documentalista. (ver Anexo 2).

Con respecto a la pregunta número 1 ¿Cuál es la importancia que le da usted a la investigación científica en el curso de Narrativas audiovisuales?, Los entrevistados respondieron que es de mucha relevancia porque los alumnos generen alrededor de este tipo de investigación un product audiovisual con veracidad, al momento de documentar hechos. Recurrir a la investigación teórica o de campo fortalece el discurso, es así que se evidencia el alto grado de correlación con la realidad y se evita generar noticias $u$ opiniones alejadas de la verdad.

En la pregunta número 3: ¿Qué potencialidades considera usted que posee la investigación en la carrera de Comunicaciones para contribuir al desarrollo de las 
habilidades investigativas?, según los docentes entrevistados, gracias a este proceso el alumno pueda generar sus propias conclusiones a partir del acercamiento entre la teoría

y la práctica, estan orientadas a a que el comunicador no debe fallar pues con sus discursos va configurando la realidad de las audiencias. Si se configura con información que no es cierta o que es errónea, las personas tomarían decisiones que les afectaría en su cotidiano y a su vez produciríamos material que no contribuye al proceso educativo de enseñanza aprendizaje.Últimamente el contenido multiplataformas ha hecho revolucionar la carrera, dándole realce a la forma de interacción que tiene el público a los contenidos audiovisuales y la manera en cómo los usuarios ahora generan sus propios contenidos en base a un producto ya realizado.

En la pregunta número 5: ¿Qué metodología utiliza en su clase para contribuir al desarrollo de las habilidades investigativas de sus estudiantes?, la metodología de los docentes se basa en la realización de un documental de 30 minutos, así se acompaña al estudiante en el desarrollo de un libro de producción primero para determinar la problemática, los objetivos, la sinopsis y el público objetivo del producto final, para realizar esta primera etapa se necesita que el grupo investigue en internet, libros y su entorno la realidad de la problemática y los contenidos teóricos, una vez que sabemos la base teórica de del documental, se sigue con la parte de confrontar la realidad del personaje con pre entevistas que ayudaran a esquematizar una escaleta que será la base de la historia, luego se enlaza la realidad con los contenidos que se pueden generar en base trasmedia, se planifica la realización, entrevistas y contenidos audiovisuales que sostendrán la historia y por úlimo, la postproducción donde se ordena la información para realizar un contenido audiovisualmente atractivo que cumpla los objetivos primarios de investigación y desarrollo de las habilidades investigativas dento de una estrategia metodológica basada en un formato documental.

\section{Prueba pedagógica.}

Los hallazgos encontrados en la prueba pedagógica desarrollada a 20 alumnos de $\mathrm{V}$ ciclo del curso de Narrrativas Audiovisuales de la Carrera de Comunicaciones de la una universidad de Lima Este nos han ayudo a medir los conocimientos sobre habilidades investigativas y el proceso documental en los estudiantes.

Se realizó una prueba de 14 preguntas que contenían items como el desarrollo professional, relacionado con las habilidades investigativas, como es que el professor realiza las actividades en clases, que métodos realiza el docente, y las evaluaciones brindadas en el curso. 
En resumen despúes de esta prueba evidenciamos que existe un nivel medio en cuanto a las habilidades investigativas de los alumnos y un muy reducido $24 \%$ de alumnos que tienen un nivel alto del desarrollo de habilidades investigativas, es clarísmo que los estudiantes aún no logran desarrollar sus habilidades investigativas, proyectándose en un manejo superficial de los métodos científicos eficientes y el uso de un proceso eficaz para llegar a la captación, registro y evidencia de la información que lleve a procesos de índole investigativa.(Ver Anexo 2)

\section{Observación de clase.}

Los hallazgos encontrados en las observaciones de clases evidenciaron que el docente lleva una buena relación con los alumnos y brinda los conceptos necesarios para poder generar investigación a partir de la clase.

Los alumnos comienzan a reducir las intervenciones cuando no se identifican con la película o documental expuesto como ejemplo. Parece ser que los alumnos no tienen un background cinemetográfico, que es importante para tener la habilidad de la composición y la narrativa audiovisual.

Por la falta de conocimiento sobre el tema documental los estudiantes no establecen un diálogo muy fluído, el docente tendría que estimular y encontrar junto con el estudiante el objetivo de la investigación. Los estudiantes expresan libremente sus opiniones con respeto al docente.

La metodología del docente no parece cumplir con los requerimientos de los alumnos y por ende se aleja de los objetivos del curso. El docente conoce su tema, pero la forma como llega al alumno a veces parece ser confusa y poco práctica.

El docente debería poner en práctica las etapas del proceso documental y no dejarlo sólo en la teoría, dejar que el alumno vaya motivando su rol investigativo, orientados hacia la comprensión y que apliquen acciones conceptuales, procedimentales y actitudinales que contribuyan a dicha investigación y el logro de los objetivos de aprendizaje.

El docente necesita ubicar al alumno en un proceso de análisis síntesis, comparación, diagnóstico y planteamiento de la problemática para el logro científico. E trabajo colaborativo no se dió en esta sesión, pero se suele dar a menudo a lo largo del curso (Ver Anexo 2).

Análisis e interpretación de las categorías emergentes y las apriorísticas 
A continuación, presentaremos las categorías emergentes que surgieron al realizar el trabajo de campo gracias a a este proceso de codificación y categorización hemos descubierto 6 categorías emergentes de las cuales tres son aprirístticas y tres son nuevas.

El siguiente proceso ayuda a redactar las conclusiones aproximativas para cada nueva categoría emergente agrupando los códigos por semejanzas considerando temas importantes dentro de nuestra investigación.

Finalmente se realizó la interpretación y discusión de los resultados, aplicando la triangulación teórica, y lo presentamos en la siguiente figura:

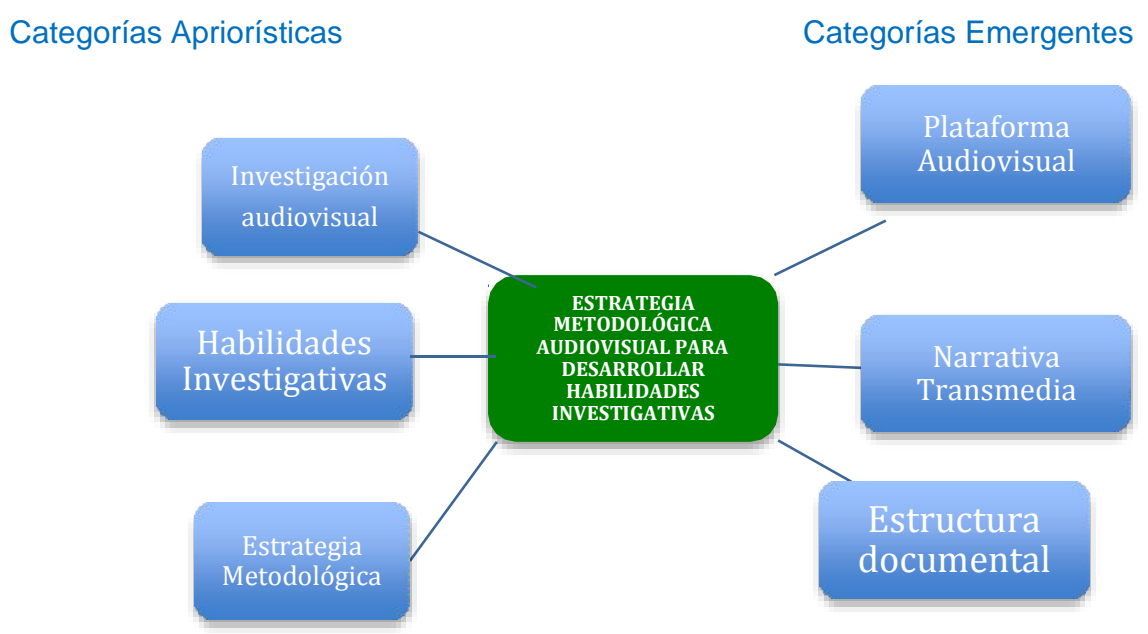

Figura 1. Categorías emergentes y apriorísticas

Fuente: Elaboracion propia (2019)

A continuación, se describen los hallazgos encontrados sobre las categorías genéricas o explicativas que coinciden con las apriorísticas:

\section{Narrativa transmedia en un proceso documental.}

Según los entrevistados para generar un documental se necesita de la narrativa audiovisual pero basada en la investigación y en base a las TIC para poder generar un buen discurso, creando una escaleta, un guion técnico, realizando así documentales.

Según Luzzien en 2015, Internet y la Web 2.0 reconfiguraron los límites entre productores y consumidores estableciendo como estándar el término "prosumidores". Dichos procesos acompañados por un ecosistema de herramientas, redes y plataformas digitales en constante cambio y evolución han realizado cambios radicales en la forma como producimos y como llegamos a los públicos objetivos.

Los alumnos se acercarán a su realidad grabando fragmentos de la vida 
cotidiana y luego generarán un código narrativo que sera comprendido cuando se proyecte en pantalla. Los proyectos que tienen en mente y se desarrolllan por un proceso evolutivo colaborarán que gracias a la diversidad de plataformas y formatos se pueda compartir esa información en diversos campos visuales, se vincula entonces el medio digital con el proceso narrativo y puede encontrarse desfragmentada a través de diferentes medios interactivos.

Cuando un alumno tiene tanta cercanía con los medios digitales y el docente sabe interactuar con dichos medios y acerca esta plataforma o modo de crear a las actividades del curso, el alumno tendrá una mayor motivación para generar procesos investigativos.

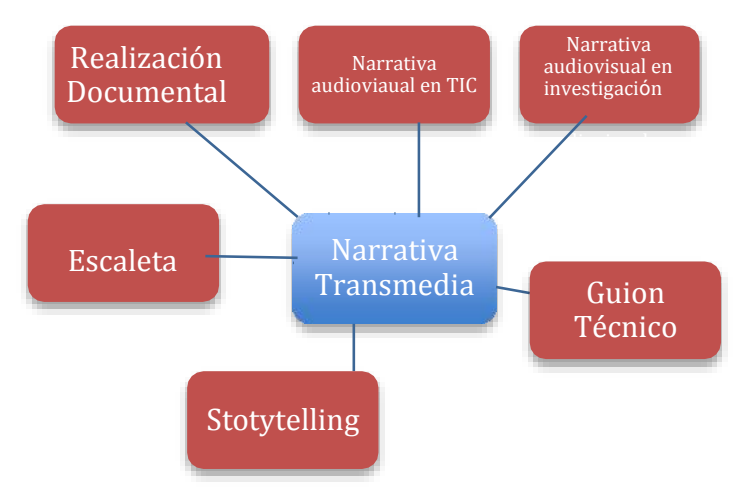

Figura 2. Narrativa Transmedia en un proceso documental.

Fuente: Elaboracion propia (2019)

\section{Plataforma Audiovisual.}

Según Dumont, Istance y Benavides (2012) no podemos negar que las nuevas platafomas tecnológicas y la economía basada en el conocimiento motivan que los sistemas educativos a nivel mundial pongan interés en la tecnología asociada al conocimiento para generar éxitos en sus procesos, es por ello que al analizar el trabajo de campo, nuestra estrategia se basa en una plataforma auiovisual que es un medio cercano y empático para el alumno de pregrado claramente identificado en sus quehaceres cotidianos para lograr desarrollar las habilidades investigativas en nuestro grupo de estudio.

El alumno estará motivado por una plataforma cotidiana para él y el un continuo monitoreo y transmisión de conocimientos por parte del docente, las nuevas tecnologías audiovisuales ayudan a documentar de formas poco tradicional los procesos de investigación, ampliando y mejorando el espectro de estudio, ayudando a que la 
investigación no se quede en una fase de reconocimiento simplemente.

La investigación videográfica entonces puede llevarnos desde el estudio de la antropología hasta la etnografía como lo evidencia Goffman (1983) que explica que este recurso tiene un vínculo muy fuerte con la investigación, sobre todo porque parte de ella tiene que ver con la grabación de encuentros, acontecimientos, actuaciones sociales para poder determinar las estructuras básicas del "orden de las interacciones".

La plataforma audiovisual entonces es considerada como parte de un ambiente innovador de aprendizaje y puede desempeñarse con éxito utilizando los siguientes componentes: Aprendizaje cooperativo, aprendizaje, aprendizaje tecnológico, evaluación formativa y enfoque basado en la investigación.

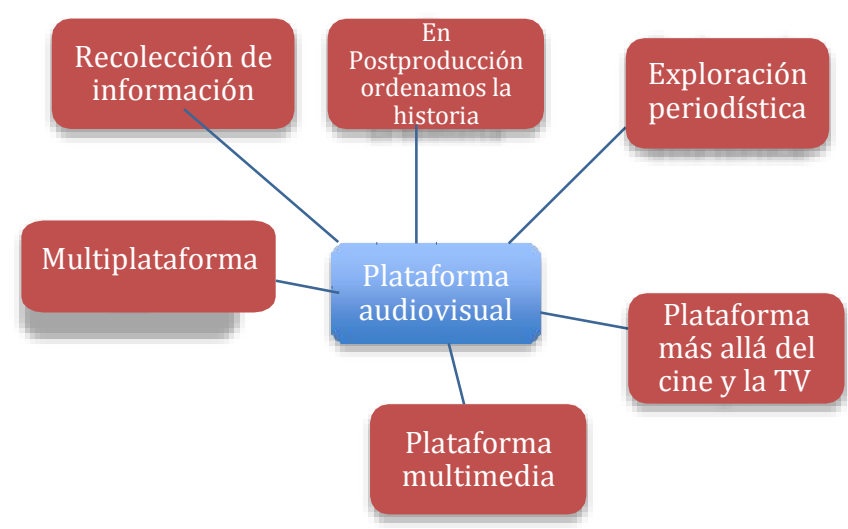

Figura 3. Plataforma audiovisual

Fuente: Elaboracion propia (2019)

\section{Estructura documental.}

La expresión narrativa documental brinda un ámbito perfecto para la experimentación y mezcla de formatos y géneros. A partir de los resultados extraídos del análisis, las formas de expresión narrativas documentales interactiva y transmedia parecen ofrecer nuevas vías de experimentación con los medios, soportes y narrativas en el contexto comunicativo actual.

Todo ello sugiere la existencia de un terreno fértil para elaborar una clasificación de lo real, con el objetivo de evaluar sus soportes, formatos, discursos, medios, plataformas y géneros y diseñar nuevos discursos narrativos de interactividad y multimodalidad. mediático - con sus ricas intersecciones entre ficción y no ficción- para posicionarse en una línea preferente de actuación respecto los nuevos medios de comunicación, con apoyo de una evaluación sumativa, fomentando que el alumno a 
través de exposiciones de los avances de su trabajo evidencie las fortalezas y debilidades de su proceso (investigativo) documental.

Es bueno considerar la temática de la investigación como parte de la evaluación, si es que esta es innovadora o requiere de un poceso más elaborado de investigación, ya que mientras más investigación se realicé mayor puntaje se colocará. También se tiene en cuenta el trabajo colaborativo y la autoevauación ya que estos procesos son grupales.

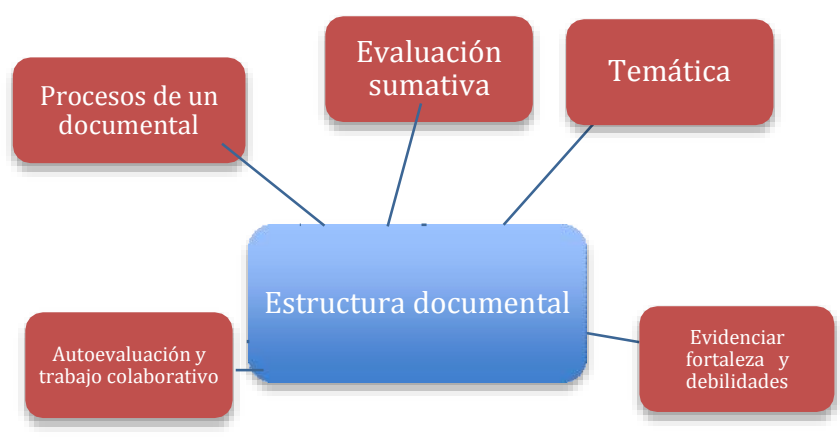

Figura 4. Estructura documental

Fuente: Elaboracion propia (2019)

\section{Categorías influyentes en el problema}

En el trabajo de campo se identificaron las siguientes categorías, investigación audiovisual, plataforma audiovisual, habilidades investigativas, narrativa transmedia, estrategia metodológica y estructura documental, que son aquellas que generarron mayor influencia con I problemática colaborando con la realización del modelado para solucionar lo que está ocurriendo en la actualidad con el desarrollo de las habilidades investigaciones en alumnos de $\mathrm{V}$ ciclo de la Facultad de Comunicaciones.

Podemos observer que el estado actual de dicho problea es el siguiente: tenemos estudiantes con dificultades en el manejo de las habilidades investigativas, estudiantes que no realcionan la realidad con la iinvestigación, y que no cuentan con metodología para elaborar investigaciones, docentes que realizan evaluaciones que no estan a la par con el desarrollo de estas habilidades investigativas y es así que no se adecua una metodología a la realidad del alumno y es por ello que los estudiantes no cran productors cjatractivos ni con rigor científico.

\section{Conclusiones aproximativas del diagnóstico}

En el diagnóstico se ha obsrvado que los alumnos no presentan un buen desarrollo de 
habilidades investigativas por la falta de conocimiento y acercamiento al proceso documentalista y de investigación. Conocen algunos referentes, pero son demasiado básicos para una indagación más profunda y veraz.

El alumno siente falta de cercanía con respecto al curso con relación a su contexto y vivencia mediática, es por eso que necesita buscar referentes como las redes sociales y los formatos trasmedia que cautiven su interés y lo acerquen a la realidad profesional. Eso se visualiza no solo en el desarrollo de la didáctica del curso sino en el sistema de evaluación que no cumple con sus expectativas.

Su falta de experiencia y dominio en el proceso investigativo hace que no generen productos audiovisualmente atractivos y con rigor científico, si bien se podría dar el caso que lo primero si se de, la veracidad y calidad de información al generar un producto audiovisual no cumple con las expectativas ni objetivos científicamente necesarios para que dichos productos sean creíbles en su totalidad. 


\section{Capítulo III}

\section{Modelación de la propuesta}

\section{Propósito de la investigación}

El modelo de estrategia metodológica para el desarrollo de habilidades investigativas surge ante la necesidad de mejorar las capacidades del estudiante universitario de comunicaciones en relación a la investigación y como aprovechar su entorno tecnológico y mediático para motivar su acercamiento al campo científico y de desarrollo metodológico de la ciencia, así como también, a los procesos de investigación, componentes esenciales para el desarrollo de profesionales holísticos e integrales tanto en su campo de acción como en la sociedad a la que pertenecen, generando un vínculo con la realidad y su profesión, captando mecanismos que ayudarán a su desempeño en el campo de las comunicaciones de manera más interactiva y eficaz.

Las habilidades investigativas son importantes para crear la formación científica del estudiante universitario que va de la mano con las funciones de una casa de estudio superior, que es fomentar, generar y difundir la investigación en sus estudiantes, cuyos logros son aprender a utilizar las técnicas informativas y orientarse adecuadamente de una metodología de investigación científica.

Al generar estas habilidades el estudiante podrá ejecutar y planificar con éxito procesos integrales que corresponden a la carera de Comunicaciones y además adquirirá un sistema de conocimientos relacionados a la formación científica que incrementará su enseñanza - aprendizaje a un nivel que transcienda más allá de las aulas universitarias, formando ciudadanos vinculados al desarrollo social, laboral, de innovación y científico.

El propósito de este modelo es acompañar metodológicamente al alumno en base de plataformas audiovisuales y lenguaje de medios que él ya conoce, para desarrollar las habilidades de un investigador, trabajo que se logrará al realizar un documental audiovisual de 30 minutos de duración en el curso de narrativas audiovisuales de la carrera de Comunicaciones motivando al estudiante a crear dotes de investigador que más adelante lo ayudarán a ser un profesional más capaz y un ser humano holístico. 


\section{Fundamentos científicos de la propuesta}

\section{Fundamento socioeducativo.}

Las universidades privadas de Lima Este son instituciones que tienen como objetivo brindar educación de calidad y accesible para poder contribuir al desarrollo sostenible del país y apoyar a transformar positivamente las vidas de sus estudiantes y de la sociedad. Es por eso que dichas instituciones para colaborar con el aumento de los estándares educativos a nivel nacional, se preocupan por generar sedes en los lugares de mayor población de Lima: San Juan de Lurigancho, Los Olivos, Breña, Comas, además de sedes en dos departamentos importantes del país: Trujillo (sede principal) y Cajamarca.

En primer lugar los estudiantes de estas universidades son hijos de padres emprendedores, quienes tienen expectativas elevadas a nivel profesional, pero que no tienen la solvencia económica para poder pagar una Universidad privada de un rango más alto como la U. Pacífico, la U. de Lima o la U. Católica.

Por eso hemos decidido realizar el trabajo de modelamiento en edichas universidades, ya que los alumnos tienen la motivación suficiente para generar emprendimientos que incrementarán sus estándares de calidad de vida y educación y es nuestro deseo con esta propuesta romper con el mal manejo de las habilidades investigativas y con los paradigmas de una educación tradicional alejada del cambio permanente de la sociedad y que este orientada a la investigación como lo menciona Salmi (2009).

Nuestro foco recaerá en estudiantes de $\mathrm{V}$ ciclo de la facultad de comunicaciones de la sedes de Lima Este que llevan el curso de Narrativas Audiovisuales y que necesitan dentro de su proceso de enseñanza- aprendizaje contar con habilidades investigas para el desarrollo de un documental, formato fundamental aplicado en la Carrera.

\section{Fundamento pedagógico.}

\section{El documental base para la investigación.}

La búsqueda del desarrollo de las habilidades investigativas se genera gracias el apoyo del formato documental, que ha cumplido históricamente un rol fundamental en la cultura, y hoy adquiere nuevos formatos por causa de los cambios tecnológicos. Frente a este contexto, el desafío es ser capaces de hallar códigos narrativos originales para los medios de está generación. Se busca que el alumno de 20 años se identifiqué con el curso, orientándolo a la tecnología y al manejo de información continua del que ya está acostumbrado en su cotidianidad. 
Los comunicadores de hoy necesitan tener ciertas competencias que estén orientadas a la investigación para poder desarrollar contenido audiovisual innovador, transmediático y que nos muestren historias cautivantes, es por eso que este este modelo busca que el estudiante este en contacto con su entorno y los procesos para identificar y generar un marco de investigación en base a experiencias reales, estructurando procesos y evidenciando un nuevo conocimiento desde el inicio hasta el logro final.

\section{Enfoque socioformativo.}

Esta estrategia metodológica esta basada en un enfoque socioformativo cuyo propósito es generar una transformación en el estudiante a partir de la convivencia que tenga con el objeto de estudio del documental teniendo como objetivo la sostenibilidad ambiental e incrementando el pensamiento complejo como lo describe Tobón (2013, p. 23), el contexto sociocultural donde se involucra el alumno busca como producto final la realización y estructuración de un proceso documental que propone una relación que involucre competencias profesionales y componentes del nuevo conocimiento, así como también su entorno.

Cada comunidad tiene sus necesidades y estas deben de ir de la mano con el accionar del estudiante terciario que pertenece a ella, es por eso que con relación a la parte social esta necesidad de cambio e integración y creando un proyecto de vida clarificado para los estudiantes en relación con las metas, el problema, el producto. Los instrumentos y la mejora que se da gracias a la implementación de esa idea, que comienza desde la elección del tema a investigar hasta como el grupo evoluciona para lograr el objetivo final, que es el desarrollo de un documental de 30 minutos de duración con base en un formato storytelling en plataforma transmedia. La relación sujeto- objeto cambia cuando el grupo de estudiantes interactúan con esta nueva realidad mediada por sus propios conocimientos y experiencias diversas. En la primera fase se une la investigación con la búsqueda de información temática, entonces aquí podemos entender como lo dijo Moreno Angarita en 1997 "que el grupo ofrece un caldo de cultivo en el que se posibilita la relación entre el aprendiz y el investigador experimentado", y aquí tenemos que enfatizar que el investigador experimentado es el docente, que se encuentra permanentemente acompañando la investigación de los estudiantes y guiando su desempeño investigativo.

\section{Modelo de Formación de Investigadores y modelo ABSTI.}

Según Montes de Oca (2009) la creación de modelos basados en la solución de tareas 
investigativas (modelo ABSTI) colaboran con que el alumno alcance la consciencia para dominar las tareas que el docente determinará a lo largo del curso, todo esto teniendo como objetivo el desarrollo de las habilidades investigativas. Los procesos según este modelo estarán orientados a la planificación, organización y la ejecución. En dichos procesos tenemos que acompañar al alumno en el control y evaluación, tanto como proceso y como producto. Se necesita que exista entre ellos la retroalimentación con los pares para poder avanzar en su desarrollo, nada es definitivo hasta la presentación del documental.

El docente debe de sistematizar los objetivos del proceso, se debe de especificar el tipo de actividad a desarrollar por cada paso y concretizar en una evaluación dicho objetivo. Por ser un proceso multidimensional tenemos que modelar este proceso, para orientarlo a una mejor ejecución de las habilidades, es por eso que se seguirá un enfoque colaborativo que incrementará el trabajo en grupo, evidente en un proceso documental, porque necesitamos del apoyo de todo el equipo para llegar al logro final y la formación de investigadores como lo registra Pollo (2009) en su modelo colaborativo de formación de investigadores.

\section{Aprendizaje colaborativo.}

La base para un trabajo documental es el trabajo en grupo y la colaboración del equipo, es por eso que nos hemos orientado al Aprendizaje Colaborativo de Tobón que propone el establecimiento de metas claras, premiar los logros puntuales, compartir recursos, asignación de funciones individuales que se verán clarificados en los cargos de producción, utilizar la imaginación y a actuar frente a la problemática exterior.

\section{Aprendizaje basado en proyectos.}

Ante la necesidad de que el estudiante forme competencias que logren ayudar en su desempeño profesional, los docentes deben de implementar en su didáctica el desarrollo de tareas que ayuden al alumno a tener un rol más activo dentro del proceso de investigación, una de esas estrategias es la de realizar un aprendizaje en base a proyectos o ABP, según Díaz Barriga (2015) el estudiante planifica, escucha, negocia, evalua y genera ideas para la ejecución de un objetivo o proyecto final. En el caso de esta investigación el proyecto final es un documental y la ejecución de un libro de producción

\section{Fundamento curricular.}

Según la ley universitaria, publicada en El Peruano en el 2014, en el Artículo tres, cuatro, cinco, seis y siete, parte de los principios y características básicas de las 
universidades públicas y privadas es la educación basada en la investigación, y es deber y derecho de ellas producirlas e inculcarlas dentro de su campus, motivando seriamente al estudiante a que produzca habilidades investigativas. Además, este documento tiene un capítulo completo que nos recalca la importancia de la investigación universitaria. En el peruano en el artículo 48 dice: "La investigación constituye una función esencial y obligatoria de la universidad (...) en especial énfasis a la realidad nacional. Los docentes, estudiantes y graduados participan en la actividad investigadora en su propia institución o en redes de investigación nacional o internacional” (EI Peruano, 2014). Es por eso que nuestro objetivo es desarrollar estas habilidades, competencias que el estudiante de educación terciaria debe poseer para ser un profesional holístico tanto en la institución a la que pertenece a lo largo de su período de estudio, como en el campo laboral.

El perfil de la carrera de Comunicación audiovisual es el siguiente: Formamos profesionales con una visión integral de las comunicaciones con énfasis en gestionar, diseñar y realizar contenidos audiovisuales transmedia (construidos para diversas plataformas y medios de comunicación) de gran calidad para marcas y medios informativos o de entretenimiento. En el perfil del egresado se manifiesta que el alumno será un estratega de la comunicación con habilidad para liderar y trabajar en equipo, para asumir retos y adaptarte al cambio, a su vez comprenderá, respetará y promoverá el valor de la diversidad cultural, así como también generará innovación, desarrollo y gestión en la dirección y ejecución de proyectos audiovisuales para multiplataformas y diversos medios, cabe mencionar que también a esto va vinculado los proyectos de ficción, documentales, televisivos, radiales ya sea soportes tradicionales o digitales.

En relación con la malla curricular el curso de narrativas audiovisuales se encuentra en el $\mathrm{V}$ ciclo de la Carrera de Comunicaciones y proporcionará al estudiante la habilidad de generar productos audiovisuales en base a una narrativa con un proceso metodológico y científico que regirá la formación de otros productos audiovisuales a lo largo de su Carrera universitaria.

El presente curso al ser de naturaleza teórico- práctico brindará al estudiante la orientación para la realización y concepción de proyectos audiovisuales en formato documental. Al finalizar el curso, el alumno tendrá las siguientes competencias, redactadas en el syllabus de la institución superior. (Ver en anexos). También se puede observar según el siguiente cuadro algunas de las competencias y capacidades que busca generar el curso en las diferentes sesiones de clase. 
Tabla 2

Tabla de competencias y capacidades

\begin{tabular}{|c|c|c|c|c|}
\hline Competencia & Capacidad & $\begin{array}{l}\text { Sesiones } \\
\text { de } \\
\text { aprendizaje }\end{array}$ & Contenido & Indicadores \\
\hline $\begin{array}{l}\text { Elabora } \\
\text { temáticas } \\
\text { base }\end{array}$ & $\begin{array}{l}\text { Investiga } \\
\text { sobre } \\
\text { el tema } \\
\text { elegido }\end{array}$ & $\begin{array}{l}\text { Sesión N } \\
01\end{array}$ & $\begin{array}{l}\text { La } \\
\text { Preproducción } \\
\text { Audiovisual }\end{array}$ & $\begin{array}{l}\text { Construye los principios básicos } \\
\text { del libro de producción en base a } \\
\text { un tema elegido para el desarrollo } \\
\text { del documental. }\end{array}$ \\
\hline $\begin{array}{l}\text { Recopila } \\
\text { Infromación }\end{array}$ & $\begin{array}{l}\text { Investiga } \\
\text { sobre } \\
\text { el tema } \\
\text { elegido }\end{array}$ & $\begin{array}{l}\text { Sesión Nº } \\
02\end{array}$ & $\begin{array}{l}\text { Tipos De } \\
\text { Documental }\end{array}$ & $\begin{array}{l}\text { Investiga la temática a utilizar en el } \\
\text { documental. Identifica que } \\
\text { documental realizará, } \\
\text { diferenciándolo de los otros tipos. }\end{array}$ \\
\hline $\begin{array}{l}\text { Desarrolla } \\
\text { formatos } \\
\text { innovadores }\end{array}$ & $\begin{array}{l}\text { Reorganiza la } \\
\text { información y } \\
\text { la proyecta en } \\
\text { formatos } \\
\text { específicos }\end{array}$ & $\begin{array}{l}\text { Sesión Nº } \\
03\end{array}$ & $\begin{array}{l}\text { Formatos: Plan } \\
\text { De Rodaje, } \\
\text { Storyboard, }\end{array}$ & $\begin{array}{l}\text { Construye a partir de lo aprendido } \\
\text { sus propios formatos de acuerdo } \\
\text { al tema escogido en su } \\
\text { documental }\end{array}$ \\
\hline $\begin{array}{l}\text { Organiza su } \\
\text { esquema de } \\
\text { producción }\end{array}$ & $\begin{array}{l}\text { Identifica } \\
\text { Los cargos } \\
\text { de producción }\end{array}$ & $\begin{array}{l}\text { Sesión Nº } \\
04\end{array}$ & $\begin{array}{l}\text { Flujo De } \\
\text { Trabajo }\end{array}$ & $\begin{array}{l}\text { Organiza de acuerdo a lo } \\
\text { investigado el trabajo en las } \\
\text { diferentes áreas de producción }\end{array}$ \\
\hline $\begin{array}{l}\text { Consyruye } \\
\text { narrativa } \\
\text { audiovisual }\end{array}$ & $\begin{array}{l}\text { Reorganizar } \\
\text { iinformación } \\
\text { de producción }\end{array}$ & $\begin{array}{l}\text { Sesión N } \\
05\end{array}$ & $\begin{array}{l}\text { Storytelling en } \\
\text { Fomatos } \\
\text { Digitales }\end{array}$ & $\begin{array}{l}\text { Identifica la línea narrativa que } \\
\text { seguirá su documental, incluyendo } \\
\text { las características del storytelling }\end{array}$ \\
\hline $\begin{array}{l}\text { Planifica } \\
\text { el trabajo de } \\
\text { producción }\end{array}$ & $\begin{array}{l}\text { Genera } \\
\text { formatos } \\
\text { De trabajo }\end{array}$ & $\begin{array}{l}\text { Sesión Nº } \\
06\end{array}$ & $\begin{array}{l}\text { Desglose, } \\
\text { Plan De } \\
\text { Trabajo }\end{array}$ & $\begin{array}{l}\text { Construir un plan de trabajo y un } \\
\text { desglose de producción adecuado } \\
\text { al tema y al tiempo del documental }\end{array}$ \\
\hline
\end{tabular}

Fuente: Elaboracion propia (2019)

\section{Diseño de la propuesta}

La propuesta tiene el siguiente modelo iconográfico que representa dos proceso s importantes dentro del curso de narrativas audiovisuales, las etapas que que van orientadas al docente y las fases orientadas al alumno, ambas mediadas por un docente facilitador en el marco de una evaluación sumativa y formativa 


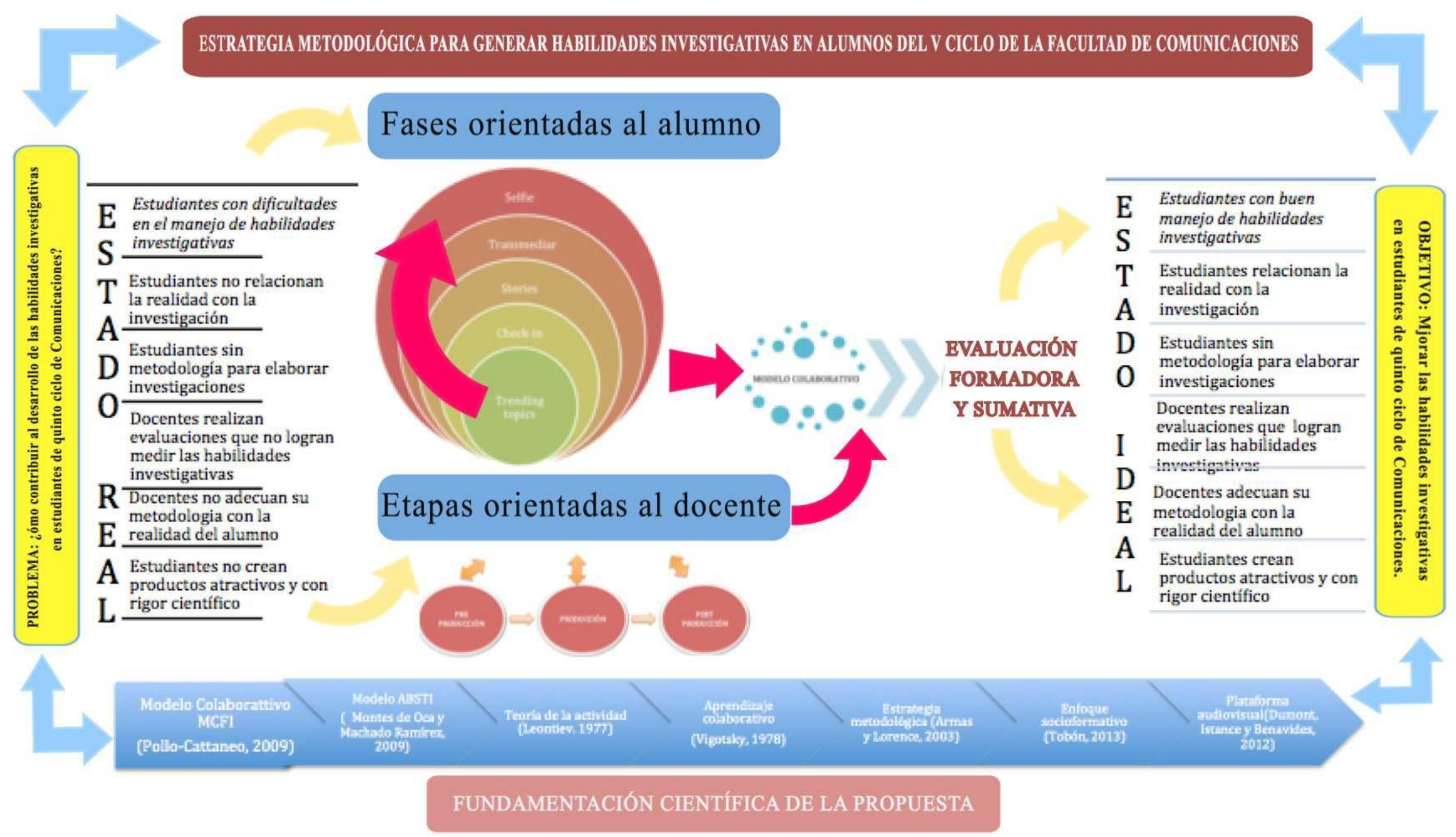

Figura 5. Propuesta del modelo de investigación

Fuente: Elaboración propia (2019) 


\section{Descripción del modelo.}

Es una propuesta que nace de la reflexión respecto al estado actual de las habilidades investigativas y el manejo de la inbvestigación por parte de los estudiantes tercearios. Se aplicará dicho modelo a los estudiantes de quinto ciclo de la Facultad e Comunicaciones de una universidad de Lima Este en el curso de Narrativas audiovisuales . Nuestro objetivo final es el desarrollo de un documental siguiendo la metodología descrita en este modelo para interiorizar y desarrollar con mayor eficacia y eficiencia las habilidades hacia la investigación.

La propuesta esta diseñada en dos áreas, etapas para el docente y fases para el alumno. Cada una de estas etapas o fases estan orientadas a las 16 sesiones del curso de narrativas audiovisuales, en el caso del docente las etapas son tres realiadas a los largo del taller y en el cso de los alumnos las fases son cinco y se encuentran en cada sesión de clase. Las etapas del docente son: preproducción, producción y postproducción, cuyos objetivos son: estructurar y gestionar los recursos del documental antes de su realización, monitorear la realización del producto audiovisual y por último orienta a editar dicho producto para su adecuada sistematización y conclusión.La fases para el alumno son: tending topics, Check-in, Stories, transmediar y selfie (evaluación formadora y sumativa), que tienen como metas la orientación y asimilación de la habilidad, el dominio de esta, sistematización del proceso y por último la evaluación desde una perspectiva formadora y sumativa.

Los productos que sostendrán nuestro modelo básicamente son dos: un documental de 30 minutos de duración y un libro de producción de dicho documental donde se evidenciará los procesos de forma sistematizada, el documental es el producto final y el libro de producción es la evidencia de la investigación realizada para la culminación de ese proyecto.

\section{Objetivos}

\section{Objetivo general de la propuesta.}

Desarrollar habilidades investigativas en los estudiantes de quinto ciclo de la Facultad de comunicaciones gracias a una estrategia metodológica planteada en el taller de narrativas audiovisuales.

\section{Objetivo específicos.}

Aplicar un propuesta metodológica con los estudiantes donde se evidencie las etapas de una investigación vinculadas a un proceso documental. 
Gererar en los estudiantes la habilidad de relacionar la realidad con la invetsigación.

Motivar a partir de la investigación a generar no solo contenidos atractivos y novedosos sino que tengan rigor científico.

Realizar evaluaciones que logren medir el desempeño de las habilidades investigativas.

Generar que el docente en su labor pedagógica valore los procesos investigativos dentro del desarrollo profesional del estudiante universitario, convirtiéndose en docente investigador.

\section{Implementación de la propuesta del modelo de investigación}

La implementación de dicha propuesta se efectuará dentro del curso de Narrativas audiovisuales dictado en el quinto ciclo de Comunicaciones y constará de tres etapas claras orientadas al docente: La planificación o preproducción, el proceso o realización y la sistematización o postproducción, así como cada sesión de clase presentará cinco fases orientadas al alumno: Trending topics (Orientación del nuevo contenido), Checkin(asimilación de la habilidad), Stories(dominio de la habilidad), Transmediar (sistematización de la habilidad) y Selfie (evaluación formadora y sumativa) . 


\section{Planificación de la propuesta de investigación}

\section{Tabla 3}

\section{Planificación de la etapa 1 o preproducción}

\begin{tabular}{|c|c|c|c|c|c|}
\hline ETAPA & Objetivo & FASE & Estrategia & Meta & Producto \\
\hline & $\begin{array}{l}\text { Estructurar y } \\
\text { gestionar los }\end{array}$ & $\begin{array}{l}\text { Trending } \\
\text { Topics }\end{array}$ & $\begin{array}{l}\text { Orientación del nuevo } \\
\text { contenido } \\
\text { (Instrucciones y tema) }\end{array}$ & Selección del tema & $\begin{array}{l}\text { Elección del tema } \\
\text { documental }\end{array}$ \\
\hline & $\begin{array}{l}\text { recursos de } \\
\text { un producto } \\
\text { audiovisual }\end{array}$ & Check-in & $\begin{array}{l}\text { Asimilación de la } \\
\text { habilidad (nuevos } \\
\text { conocimientos ) }\end{array}$ & $\begin{array}{l}\text { Utilización de la } \\
\text { habilidad }\end{array}$ & $\begin{array}{l}\text { Esquema de } \\
\text { producción }\end{array}$ \\
\hline & $\begin{array}{l}\text { antes de su } \\
\text { realización }\end{array}$ & Stories & Dominio de la habilidad & $\begin{array}{l}\text { Ejecución de la } \\
\text { habilidad }\end{array}$ & $\begin{array}{l}\text { Escaleta } \\
\text { Resumenes }\end{array}$ \\
\hline & & Transmedia & $\begin{array}{l}\text { Sistematizar la } \\
\text { habilidad }\end{array}$ & $\begin{array}{l}\text { Relacionar nuevo } \\
\text { conocimiento con } \\
\text { saberes previos }\end{array}$ & $\begin{array}{l}\text { Post del momento } \\
\text { Hashtag(\#) }\end{array}$ \\
\hline & & Selfie & Evaluación & $\begin{array}{l}\text { Autoreflexión } \\
\text { Avances }\end{array}$ & Autoevaluación \\
\hline
\end{tabular}

Fuente: Elaboracion propia (2019) 
Tabla 4

Planificación de la etapa 2 o producción

\begin{tabular}{|c|c|c|c|c|c|}
\hline ETAPA & Objetivo & FASE & Estrategia & Meta & Producto \\
\hline & $\begin{array}{l}\text { Realizar un } \\
\text { producto } \\
\text { audiovisual }\end{array}$ & $\begin{array}{l}\text { Trending } \\
\text { Topics }\end{array}$ & $\begin{array}{l}\text { Orientación del nuevo } \\
\text { contenido } \\
\text { (Instrucciones y tema) }\end{array}$ & $\begin{array}{l}\text { Posicionamiento } \\
\text { del tema }\end{array}$ & $\begin{array}{l}\text { Clips de } \\
\text { grabación }\end{array}$ \\
\hline & $\begin{array}{l}\text { en base a } \\
\text { una } \\
\text { escaleta }\end{array}$ & Check-in & $\begin{array}{l}\text { Asimilación de la habilidad } \\
\text { (nuevos conocimientos ) }\end{array}$ & $\begin{array}{l}\text { Utilización de la } \\
\text { nueva habilidad }\end{array}$ & $\begin{array}{l}\text { Grabación } \\
\text { Document }\end{array}$ \\
\hline & $\begin{array}{l}\text { utilizando } \\
\text { una }\end{array}$ & Stories & Dominio de la habilidad & $\begin{array}{l}\text { Ejecución de la } \\
\text { habilidad }\end{array}$ & Grabación \\
\hline & $\begin{array}{l}\text { estrategia } \\
\text { storytelling }\end{array}$ & Transmedia & Sistematizar la habilidad & $\begin{array}{l}\text { Relacionar nuevo } \\
\text { conocimiento con } \\
\text { saberes previos }\end{array}$ & $\begin{array}{l}\text { Post } \\
\text { Hashtag(\#) }\end{array}$ \\
\hline & $\begin{array}{l}\text { con } \\
\text { estrategia } \\
\text { transmedia }\end{array}$ & Selfie & Evaluación & Autoreflexión & $\begin{array}{l}\text { Autoevaluación } \\
\text { Avances }\end{array}$ \\
\hline
\end{tabular}

Fuente: Elaboracion propia (2019) 


\section{Tabla 5}

Planificación de la etapa 3 o postproducción

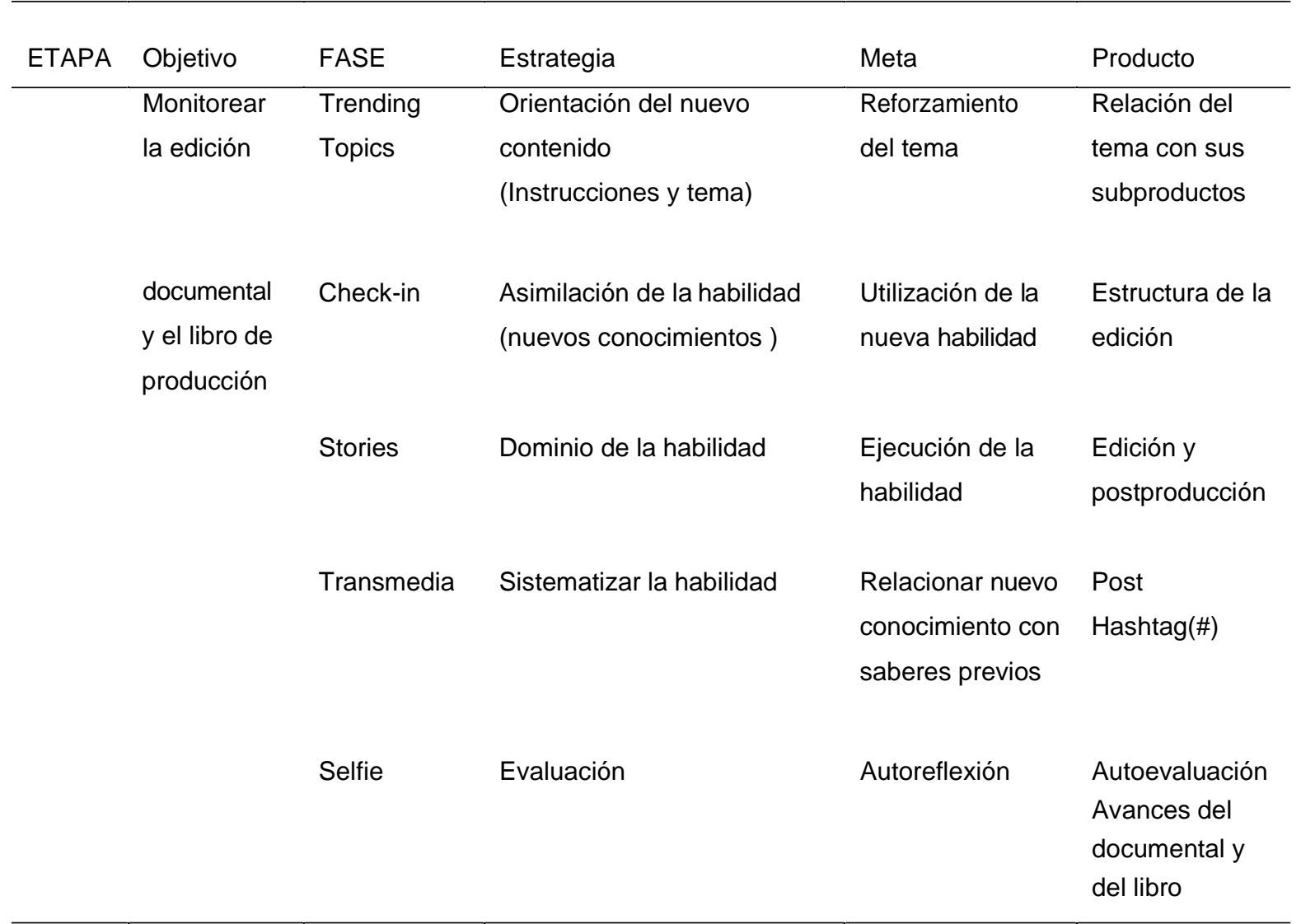

Fuente: Elaboracion propia (2019) 


\section{Etapas para el desarrollo del curso de narrativas audiovisuales (metodología para el docente)}

Etapa 1: planificación o preproducción.

En esta etapa el docente guiará toda la previa de la realización del documental: libro de producción (desglose de producción, plan de trabajo y plan de rodaje), tipos de documental, formatos, flujo de trabajo storytelling. A esta etapa también se le llama preproducción y lo que se realiza el docente básicamente es orientar al alumno a la investigación ante cada proceso para que la información que los estudiantes vayan a compartir sea veraz. Aquí se describe el proyecto audiovisual y las temáticas de las sesiones.

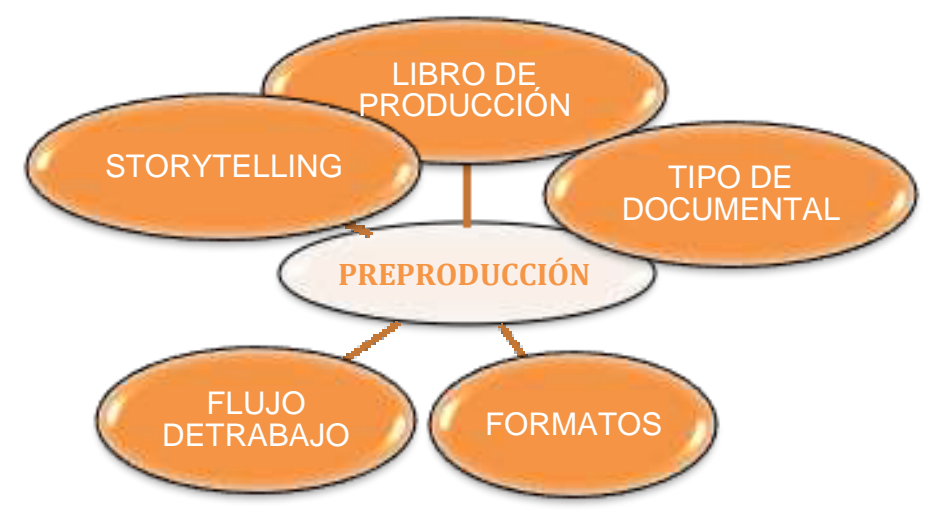

Figura 6. Esquema de primera etapa de la propuesta orientada al docente Fuente: Elaboracion propia (2019)

Esta etapa consta de cinco sesiones de aprendizaje: uno (la preproducción audiovisual), dos (tipos de documental), tres (formatos) ,cuatro(flujos de trabajo) y seis(Desglose y Plan de trabajo, ambos referentes al libro de producción). El docente acompañará al estudiante con diversas tareas para poder construir el libro o carpeta de producción, que comprende todos los factores a tener en cuenta para la realización del documental, producto final del curso de Narrativa audiovisual

Los pasos cinco, seis y siete del libro de producción (ver figura de estructura del libro de producción) se realizan en la etapa tres o llamada postproducción audiovisual. En esta primera etapa el docente ayuda a desarrollar las habilidades investigativas en los estudiantes para que ellos comiencen a tener una relación más cercana con el objeto de estudio, ve el problema, identifica su campo de estudio y a partir de la observación, la clasificación y la hipótesis va delimitando el terreno a investigar. Primero tiene que generar la identificación de nuevos conocimientos, luego desarrollar en el alumno la interpretación de lo observado e identificar los elementos de interés, más adelante 
agrupar conceptos, ideas, situaciones, y al realizar este proceso de indagación comienza a generar en el estudiante la construcción de su propio significado a partir de lo vivido, comenzando a generar el nexo entre lo observado y su realidad. Para este momento es pieza clave el libro de producción cuyo esquema colocamos a continuación.

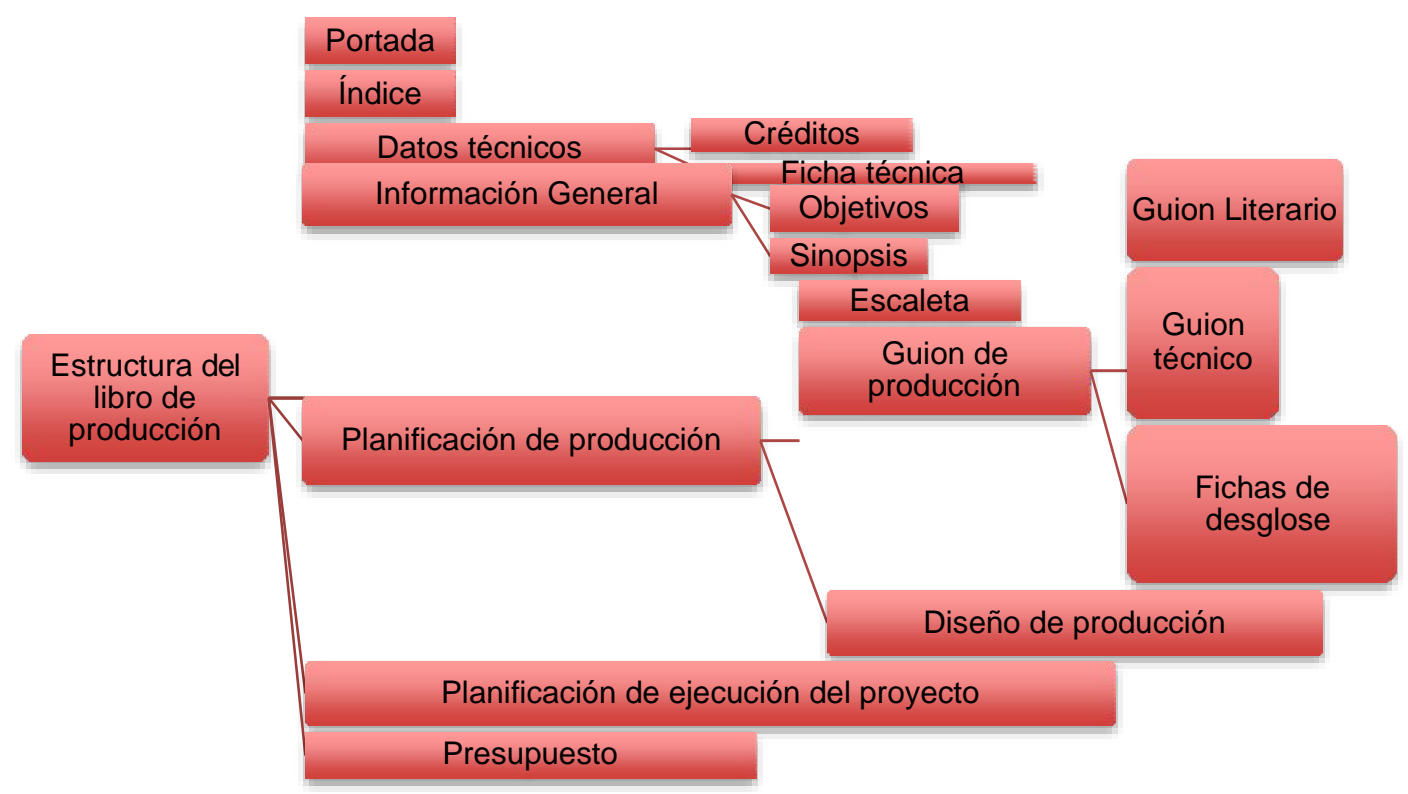

Figura 7. Libro de producción (esquema trabajo)

Fuente: Tomado de la Universidad Miguel Hernández (España, 2017)

\section{Tabla 6}

\section{Estructura del libro de producción}

PORTADA

Titulo:" (nombre del documental)"

Logo y nombre de la productora

DESCRIPCIÓN DE LA PRODUCCIÓN

Título

Duración del documental

Nombre de la productora (dirección/link de presencia en redes sociales)

Equipo de realización (el nombre de los integrantes del equipo, primero nombrando al productor, director, guionista, etc. Nombres completos y datos de contacto como e-mails y números telefónicos)

Público objetivo (audiencia)

Tema

Objetivo principal

Objetivo(s) secundario(s)

PRESENTACIÓN DEL DOCUMENTAL

Introducción

DESARROLLO DE LA PROPUESTA 
Motivación (justificación)

Investigación bibliográfica (textos, diarios, revistas)

Investigación audiovisual (material de archivo, reportajes, entrevistas previas)

Sinopsis (entre 10 a 12 líneas)

Perfil de personajes (todos los personajes)

Principal(es)

Secundario(s)

Modo (según las propuestas de Bill Nichols)

Guion imaginario (relato, cuento)

\section{DISEÑO DE PRODUCCIÓN}

Cronograma de producción (semanas, meses)

Locaciones (fotos y descripción)

Escaleta (estructura del documental en bloques)

Plan de rodaje

Reportes de script

Presupuesto (costos totales y/o auspicios)

Estrategia de divulgación (plan de distribución)

\section{CONCLUSIONES Y RECOMENDACIONES}

Los realizadores dan su parecer respecto a lo que ha significado este proyecto; ya sea, en abordaje, desarrollo de contenidos, aspectos técnicos, etc. ¿Qué concluyen como equipo y qué recomendarían a su espectador?

\section{ANEXOS}

Documentación de derechos de imagen cedidos

Documentación de derechos musicales cedidos

Afiche del proyecto documental

Fuente: Tomado de la Universidad Privada del Norte ( 2019)

En esta etapa el docente tiene que tener en claro su sentido de responsabilidad en cuanto a la generación de investigación por parte del alumno, ayuda a planificar las bases de su investigación a partir de teoría y casuística elaboradas en cada sesión, confronta al alumno con la realidad y las fuentes de información para generar un producto veraz y bien estructurado. Las actividades psíquicas y prácticas dadas por el docente tienen que ser complejas y generar conflicto cognitivo en el alumno. Es claro determinar el objetivo y la fundamentación de cada sesión por parte del docente, así como también, aplicar un diagnostico o prueba para ver en que estado se encuentra el alumno al iniciar el curso.

Etapa 2 : proceso o producción.

En esta etapa el docente relaciona al alumno con su compromiso con el campo de estudio, pide al alumno que salga a grabar y a ejecutar lo planeado en la primera etapa, aquí las ideas se materializan y la escaleta o estructura del documental va tomando 
forma. Comenzamos a comparar la teoría con la práctica y estamos a puertas del proceso de sistematizar información audiovisual.

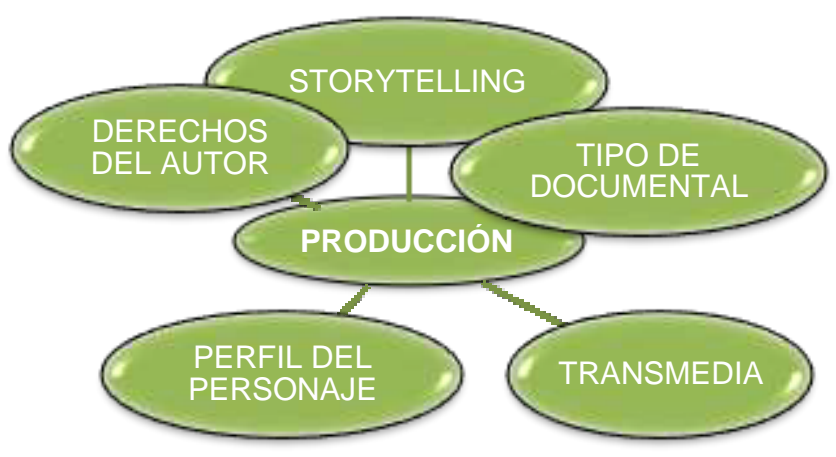

Figura 8. Esquema de segunda etapa de la propuesta orientada al docente Fuente: Elaboracion propia (2019)

Esta etapa consta de cinco sesiones de aprendizaje: sesión dos (tipos de documental, que está incluido en la primera etapa también), sesión seis (storytelling en formatos digitales), sesión 10 (derechos de autor), sesión 11(perfil del personaje) y sesión 14 (transmedia). Aquí el docente enviará al alumno a salir a campo y grabar el documental con la base de la primera etapa, siguiendo una escaleta. Junto con el docente los alumnos comprueban la hipótesis ante un tema específico, procesan la información, transfieren lo aprendido a la vida real, reconocen los aciertos y errores de su aprendizaje investigativo, ordenan lo grabado y le dan sentido a la historia.

El docente brindará al estudiante las herramientas prácticas necesarias para el trabajo de campo, ya que las grabaciones no contarán con la presencia del profesor. Para tales eventos se proporcionará a los alumnos material didáctico que colaborará con el proceso de investigación de dicho documental. Se elaborará material como: hojas de desglose, plan de producción, plan de rodaje que eran previamente evaluados por el docente antes de la realización. Aquí el alumno será guiado ante la comprobación y experimentación al acercarse totalmente a su objeto de estudio.

Etapa 3: sistematización o postproducción.

El docente investigador guiará al estudiante en la etapa de edición del documental, captando los momentos que van a contribuir con contar de la manera más interesante, amena y verdadera la historia. Aquí se comienza a elaborar el producto final que evidenciará toda la investigación en video y en el libro de producción. 


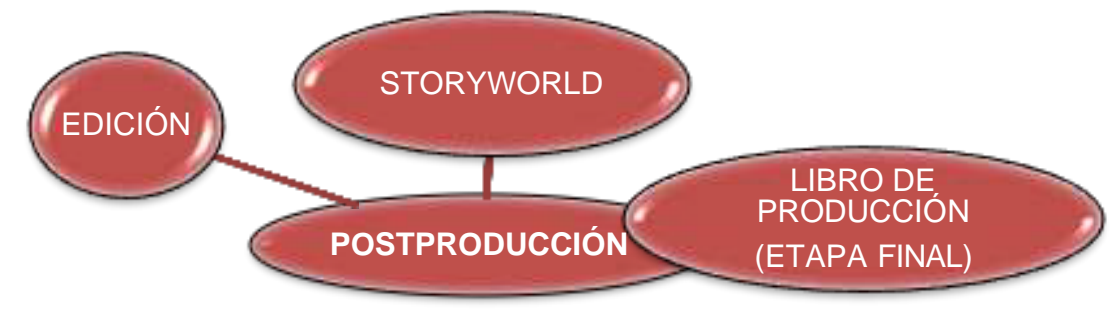

Figura 9. Esquema de tercera etapa de la propuesta orientada al docente Fuente: Elaboracion propia (2019)

Esta etapa consta de siete sesiones de aprendizaje que ayudarán a consolidar el proceso de investigación: sesión siete(libro de producción, etapa final), sesión ocho (storyworld), sesión nueve (avance del libro de producción ), sesión 12(avance documental), sesión 13(visionado), sesión 15 (revisión final) y sesión 16(presentación final).Aquí el docente relaciona la experimentación con la hipótesis, conceptualiza la realidad de acuerdo a lo vivido por el alumno y lo orienta a materializar su producto audiovisual y libro de producción, donde muestra las evidencias de su proceso investigativo.

Al sistematizar la habilidad, el grupo de tareas finales se convierten en desarrollo de objetivos que nos darán como resultado el desarrollo de la habilidad investigativa., en resumen, la acción orientada por el docente desarrolla la habilidad, y este mecanismo ayuda a cuanto más complejas y frecuentes sean las áreas el alumno dominará aún más la habilidad.

Fases de cada sesión de aprendizaje base para generar las habilidades investigativas (metodología orientada al alumno)

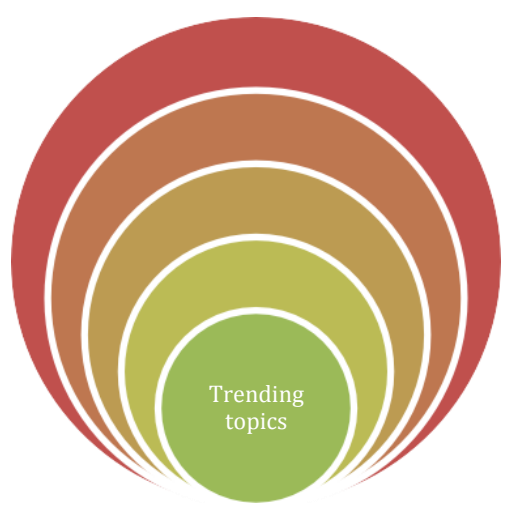

Figura 10. Esquema de primera fase de la propuesta orientada al alumno Fuente: Elaboracion propia (2019) 


\section{Trending topics.}

Los trending topics, son aquellos temas de gran interés en redes sociales, ayudan a encontrar información por temas, al elegirlo este debe de estar implementado con una etiqueta o tag que hará que el alumno al compartir contenido en redes u otros formatos pueda magnificar la expansión de su target o público objetivo. Todas las sesiones se abrirán con un Trending topic que ayude al estudiante a conectarse con el desarrollo de la clase. Este momento básicamente es la orientación del nuevo contenido a partir de la identificación de un tema que regirá el desarrollo de la sesión de clase, creando un conflicto cognitivo entre lo que sabe y debe saber del proceso documentalista, enfrentamos al alumno con aquello que no sabe o desarrolla con dificultad convenciéndolo que es necesario el aprendizaje investigativo.

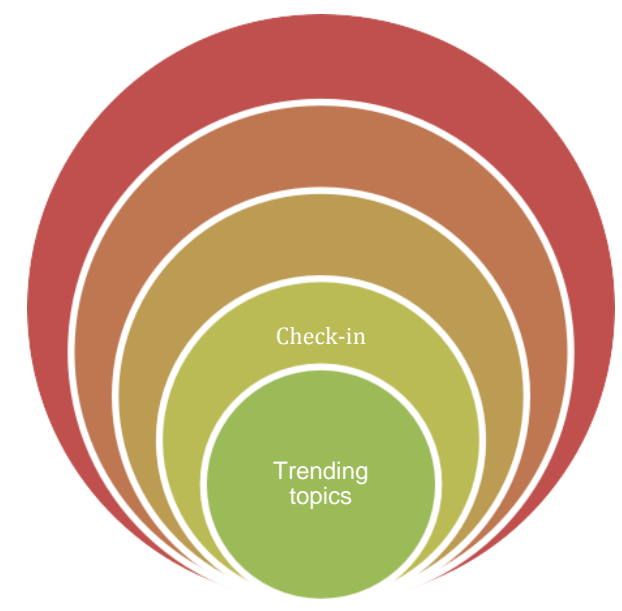

Figura 11. Esquema de la segunda fase de la propuesta orientada al alumno Fuente: Elaboracion propia (2019)

\section{Check-in.}

Luego de saber el tema importante que regirá la sesión entraremos al segundo momento, que llamaremos: Check-in, como lo dice su nombre, es nuestro inicio de registro, etapa donde el docente realizará tareas para ingresar al estudiante al tema de la clase con mayor rigor académico. Esto ayudará a que se enriquezca la relación entre el sujeto y objeto de estudio. Esta etapa recae en la didáctica de clase buscando familiarizar al alumno en su proceso investigativo, generando tareas o situaciones nuevas en las que es necesario aplicar la habilidad investigativa, cada nueva tarea sacará a la luz nuevos sistemas de conocimientos que ayudarán el proceso de investigación, es importante indicar al alumno hacia donde vamos todo el tiempo para gestionar con éxito la metodología investigativa.

Por ejemplo en la sesión 1 luego de encontrar el tema documental a desarrollar por cada grupo, el docente pondrá en la pizarra 5 cuadros con las características de los 
cargos de producción a emplearse en el documental, cada estudiante se acercará a leer las actividades como dinámica de museo y se colocará debajo del cargo que le parezca más idóneo y cómodo para él. Es así que ya ingresamos al tema de la clase que es: "cargos de producción", esto nos ayudará a saber que alumnos se sienten más cómodos con tal o cual trabajo de campo para la investigación del documental.

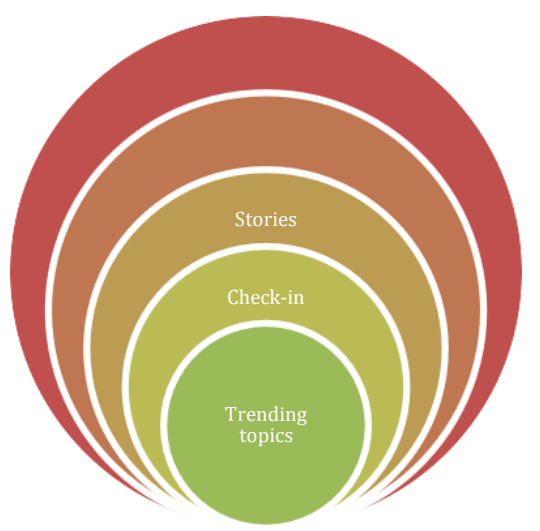

Figura 12. Esquema de la tercera fase de la propuesta orientada al alumno Fuente: Elaboracion propia (2019)

\section{Stories.}

Es hora de contar historias, y demostrar el dominio de la habilidad, en este caso, usaremos la capacidad de contar historias de los alumnos para relacionar la frecuencia de las tareas y su periodicidad para ver como ejecuta las acciones en base a un sistema de conocimientos. Realizará labores independientes que impliquen investigación a partir del conocimiento adquirido y como y porque ejecutar dicho conocimiento.

Siguiendo el ejemplo de la sesión 1, se juntarán por grupos de acuerdo a las habilidades escogidas y buscarán en relación a los links compartidos por el docente la información correspondiente al cargo escogido y realizarán una exposición en PPT, además de ello tendrán que buscar un dato adicional y poner como ejemplo a un representante de ese cargo con su respectiva descripción, entonces comenzamos el proceso de contar historias. 


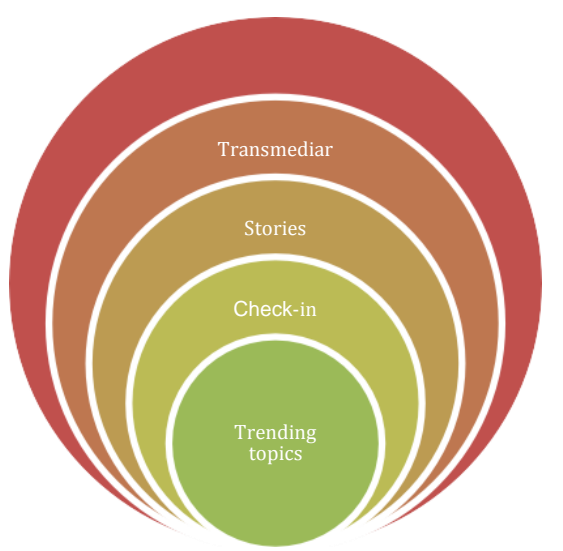

Figura 13. Esquema de la cuarta fase de la propuesta orientada al alumno Fuente: Elaboracion propia (2019)

\section{Transmediar.}

Se creará un fan page del curso y este tendrá contenido proporcionado por los alumnos. En este momento el alumno ya debe ser capaz de relacionar el nuevo conocimiento con los que ya posee, es decir asimilarlo, resumiendo, lo que ha comprendido en la sesión de clase debe evidenciarse en una publicación o foto en la red social, con un propósito claro. Lo que genera un proceso transmedia es que el alumno a partir del recurso de investigación lo unifique con las TIC, entonces estamos acercando al objeto de estudio a la realidad del sujeto, la variedad de formatos y plataformas ayudan al alumno a crear formatos de convergencia que modifican sus paradigmas y lo enfrentan con la realidad.

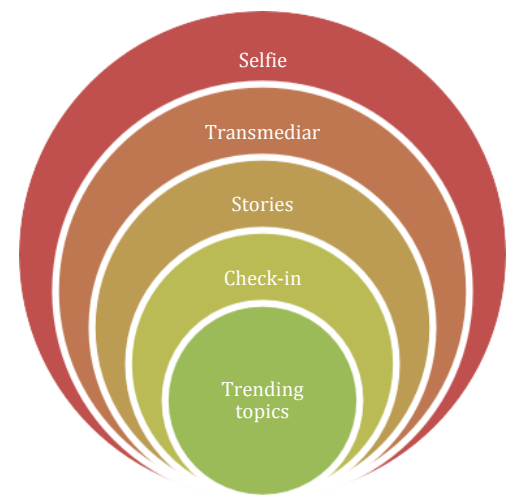

Figura 14. Esquema de la quinta fase de la propuesta orientada al alumno Fuente: Elaboracion propia (2019)

\section{Selfie.}

En la etapa Selfie, es momento de la autoevaluación, y la comprobación de los logros de los objetivos de la sesión a partir de una situación brindada en clase que manifieste la utilización de la habilidad investigativa. 
Por ejemplo, en la primera sesión el docente colocará una diapositiva donde preguntará a los estudiantes sobre su desempeño en clase de manera individual y cual de sus compañeros merece una calificación sobresaliente. Esta evaluación se realizará de manera personal enviándola al correo institucional del docente.

\section{Organización y aplicación de las actividades y estrategias activas}

Actividad a desarrollarse en la sesión uno: La preproducción

\section{ESCOGE TU CARGO}

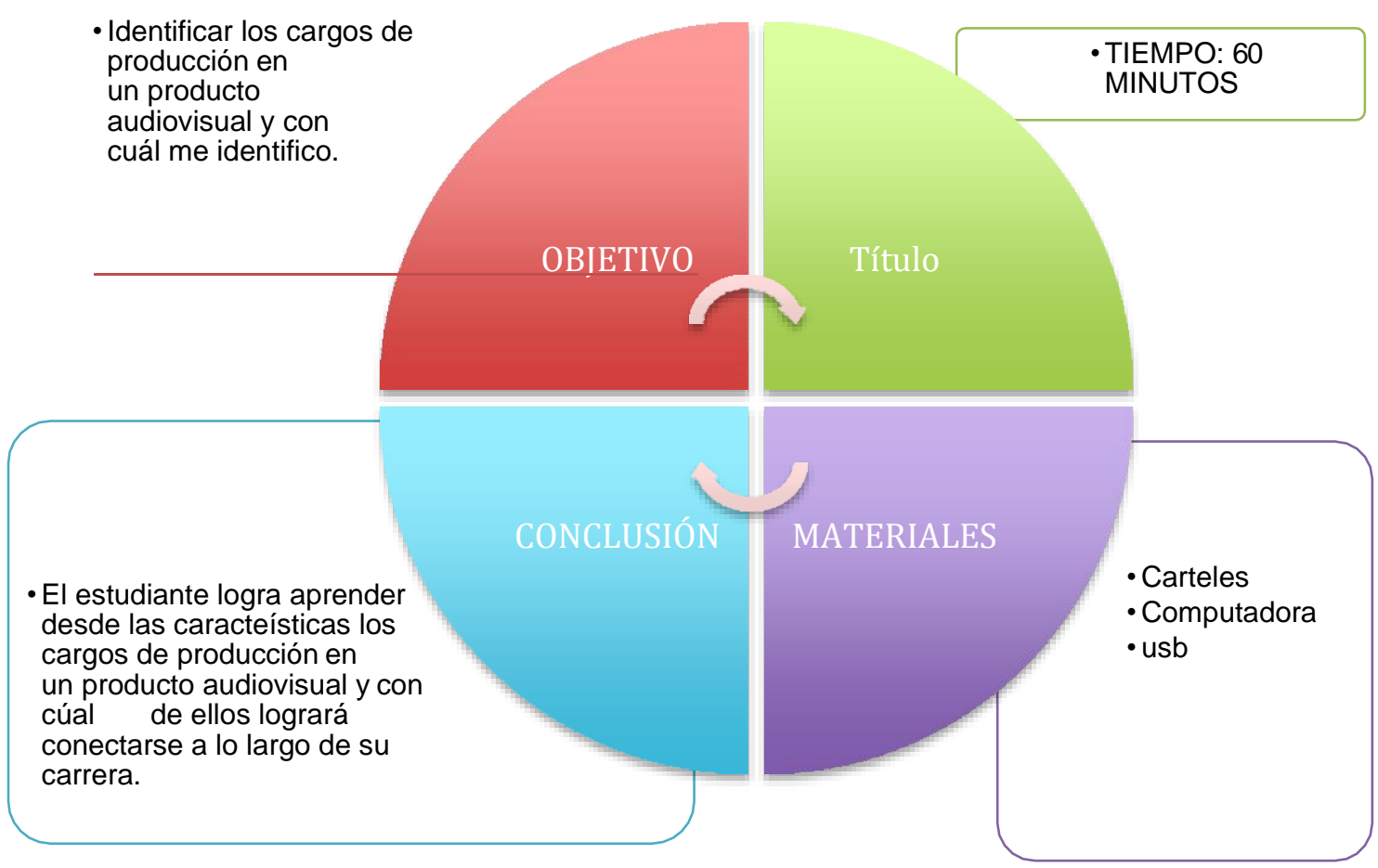

\section{Desarrollo de la actividad:}

-El docente coloca 5 carteles de las características de los cargos de producción, pero sin poner a que cargo pertencen (Dirección, Dirección de fotografía, producción, dirección de arte y dirección de sonido) 
-Los alumnos se colocarán debajo del cartel cuyas características son cercanas a él o simplemente le gustan.

-El docente revelará los nombres de los cargos y formará grupos de acuerdo a lo elegido. Así por ejemplo todos los que eligieron dirección formaran un grupo, no importa el número de integrantes.

- Los grupos leeeran el material proporcionado por el docente en el aula virtual y realizarán un ppt resumiento lo más importante.

- Elegirán además a un representante de ese cargo en internet, lo investigarán y adicionarán esa infromación en el ppt a presentar.

-Se les da un tiempo de 60 minutos.

- Se sortea el orden de los grupos.

-Cuando se acabe el tiempo cada grupo saldrá a exponerde acuerdo al sorteo al azar.

Actividad a desarrollarse en la sesión dos: Tipos de documental

\section{REAL O FICCIÓN}

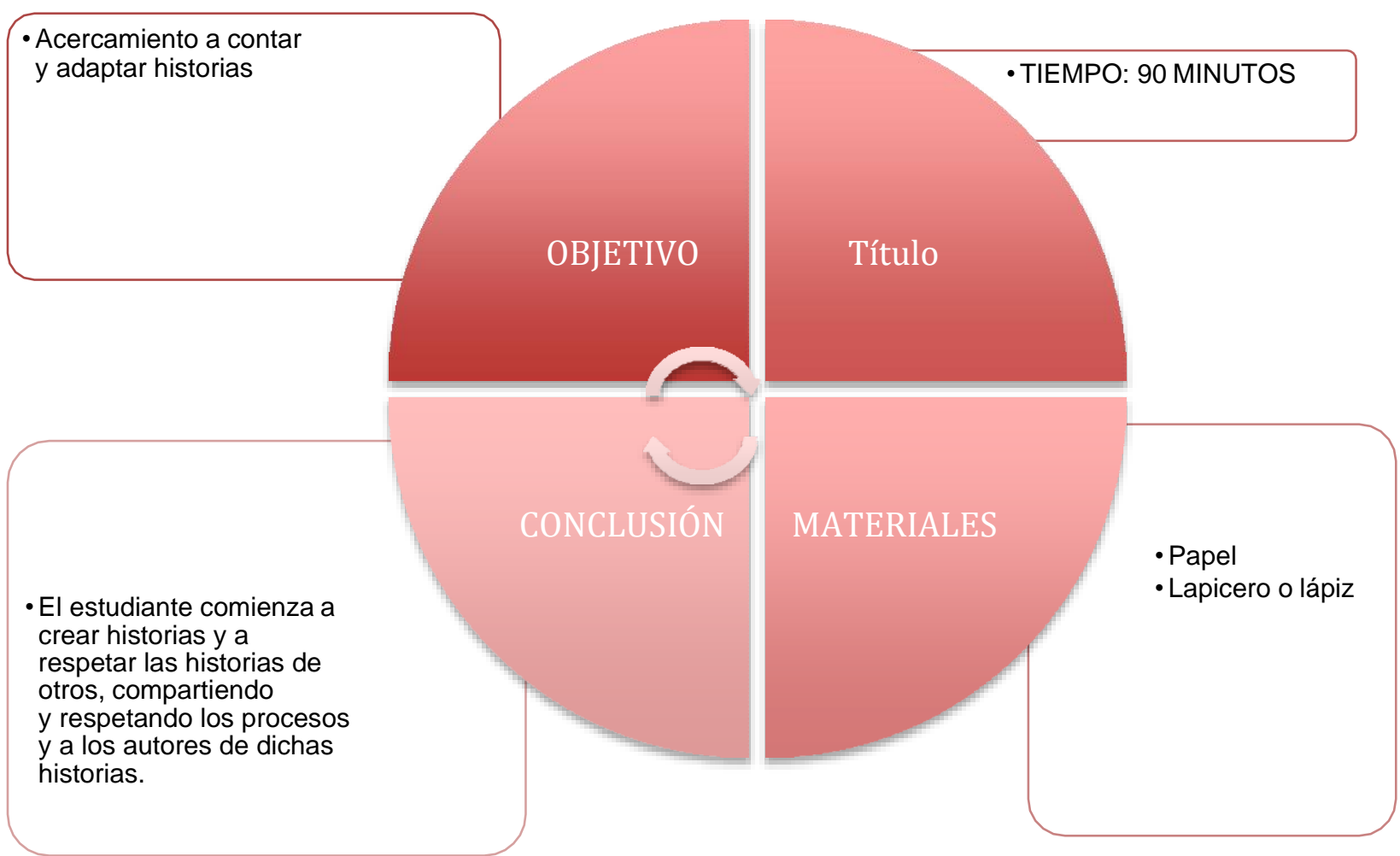




\section{Desarrollo de la actividad:}

-Cada alumno creará las sinopsis de un documental que quiera hacer (creación propia)

- Se les da 20 minutos para la redacción

-El docente recogerá las hojas

-El docente entregará las hojas, pero esta vez no a sus autores sino intercambiará las historias.

- Los alumnos tendrán que crear a partir de la historia que les toco una ficción

-Se les da un tiempo de 30 minutos.

- El docente por lista pedirá a los alumnos que cuenten sus nuevas historias

-Al final se realizará una votación para determinar que historia repotencio la sipopsis original.

\section{Actividad a desarrollarse en la sesión tres: Formatos}

\section{GUIONES}

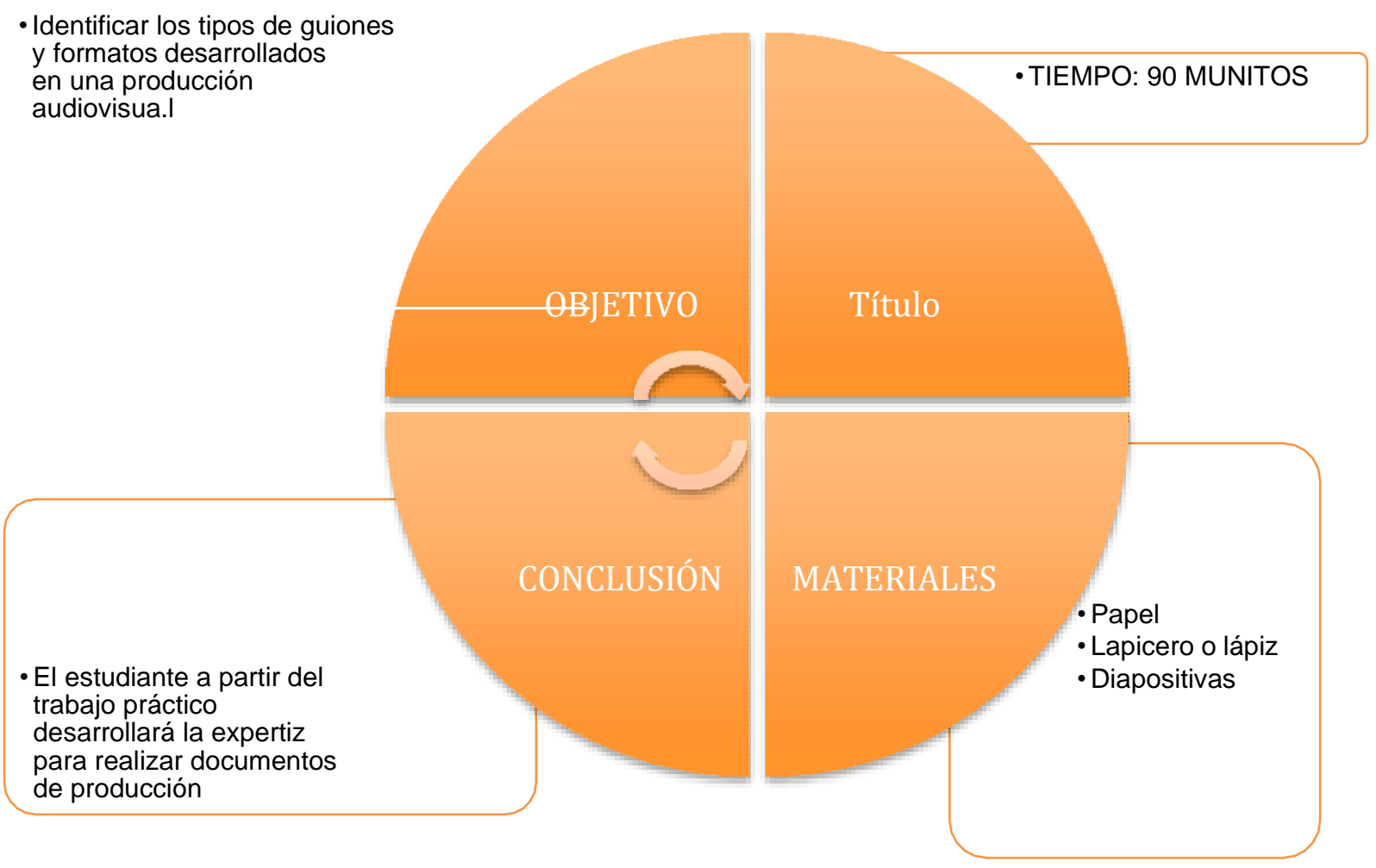




\section{Desarrollo de la actividad:}

-El docente colocará unas diapositivas de temas para generar historias.

-Los alumnos individualmente crearán un guion literario y técnico en 40 minutos.

-Luego se formarán grupos (grupos definidos por el documental) y se eligirá uno de los guiones

- Los alumnos tendrán que realizar un plan de rodaje y desglose de producción de dicho guion, se les da un tiempo de 30 minutos.

- Una vez terminado el tiempo un miembro del grupo saldrá al frente de la clase a representar a su grupo

-Se generará un debate y preguntas sobre el proceso.

Actividad a desarrollarse en la sesión cuatro: Flujo de trabajo

\section{INICIO DE MI LIBRO DE PRODUCCIÓN}

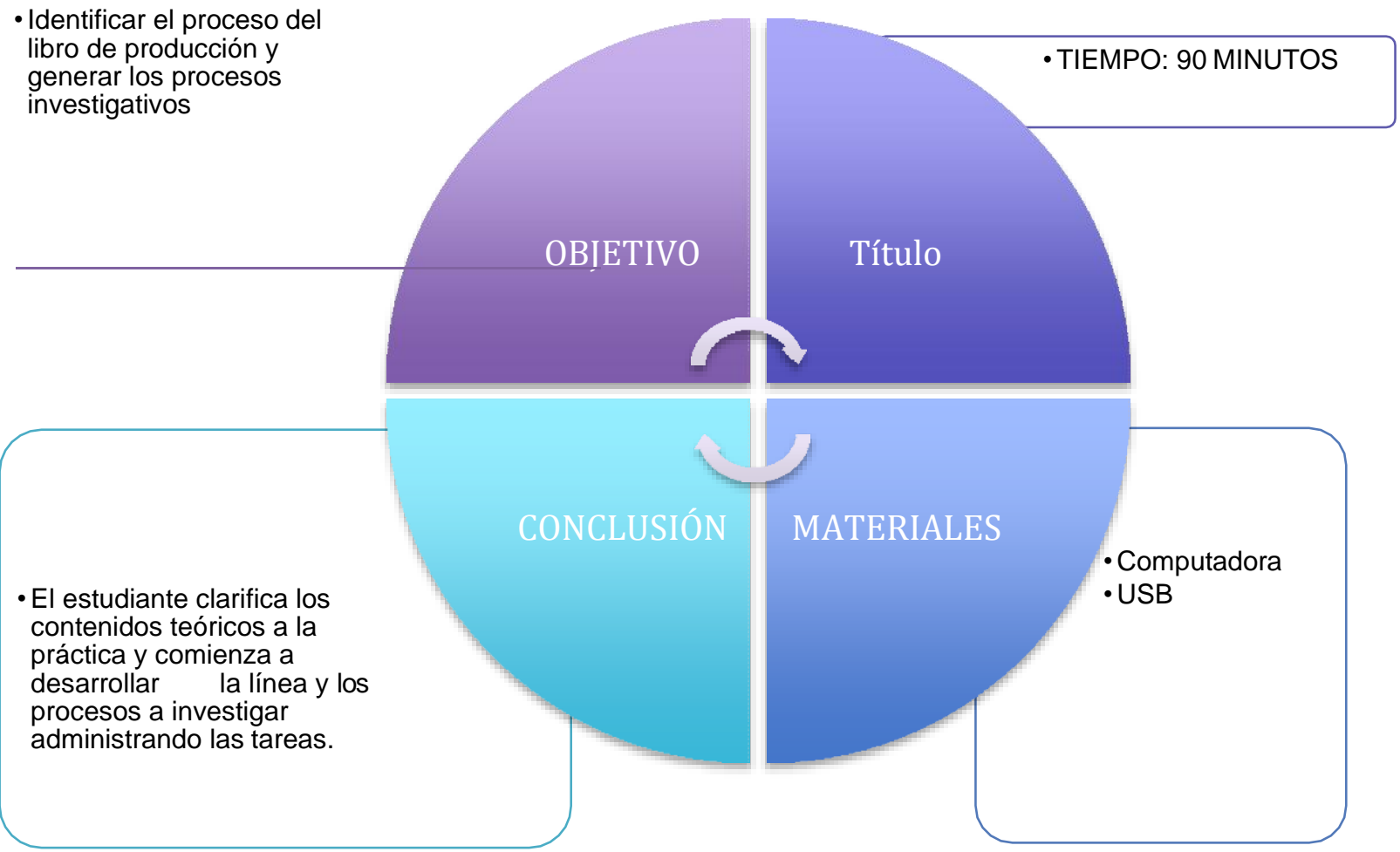


Actividad a desarrollarse en la sesión cinco: Storytelling en formatos digitales

\section{DETRÁS DE CÁMARAS}

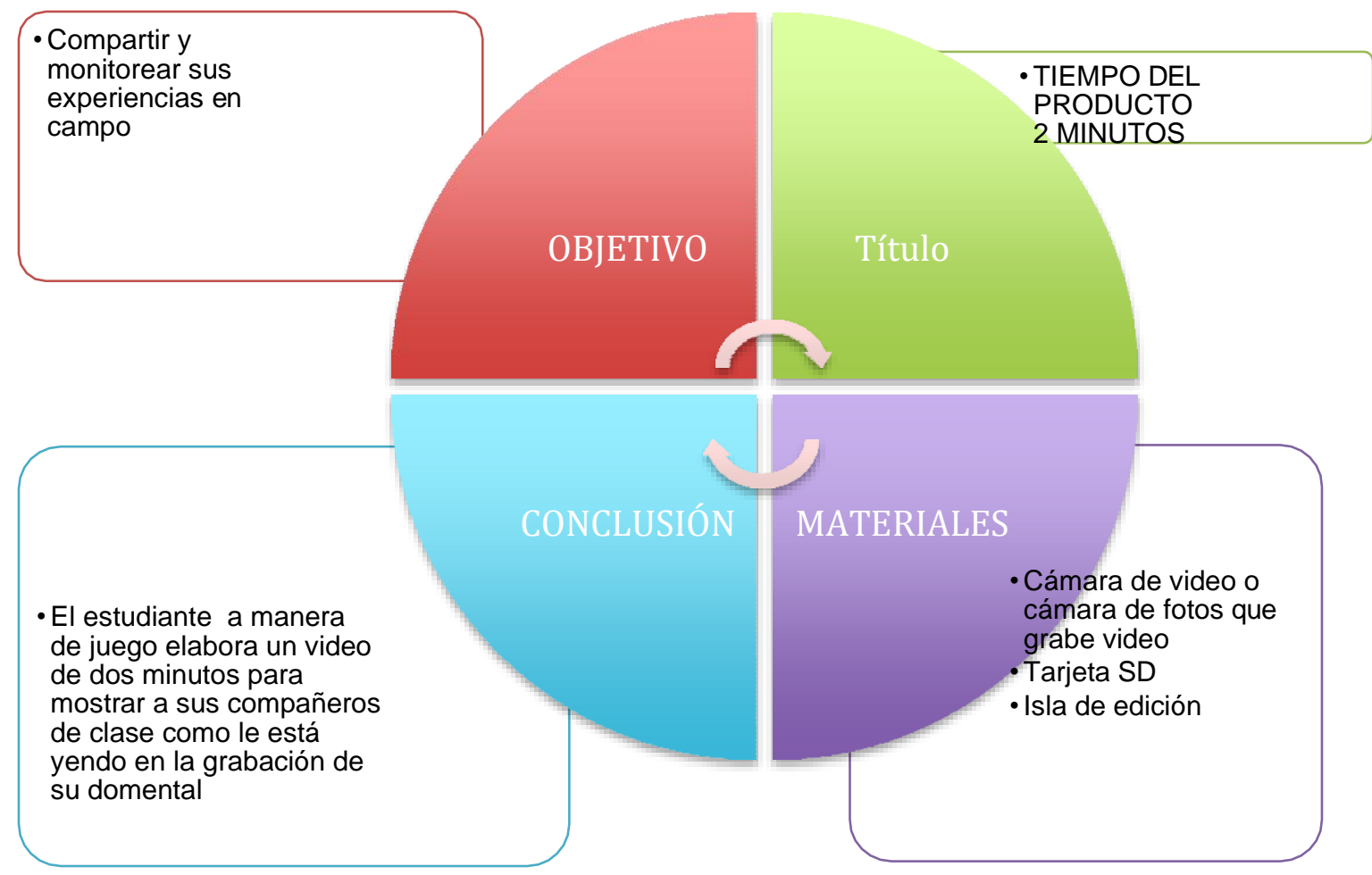




\section{Desarrollo de la actividad:}

-El estudiante el primer día de su realización audiovisual tiene que grabar un detrás de cámaras par mostrarlo en clase.

- Esta actividad se desrrolla fuera del horario de clase.

- La siguiente clase todos los grupos deberán de traer su detrás de cámaras de dos minutos de grabación.

- Se elegirá al ganador del detrás de cámara por votación de los alumnos, del docente y de un docente invitado.

- Los citerios a calificar serán: Edición, originalidad y síntesis.

- El trabajo del grupo ganador será colgado en el face del curso.

Actividad a desarrollarse en la sesión seis: Desglose y plan de trabajo

\section{INFOGRAFÍA}

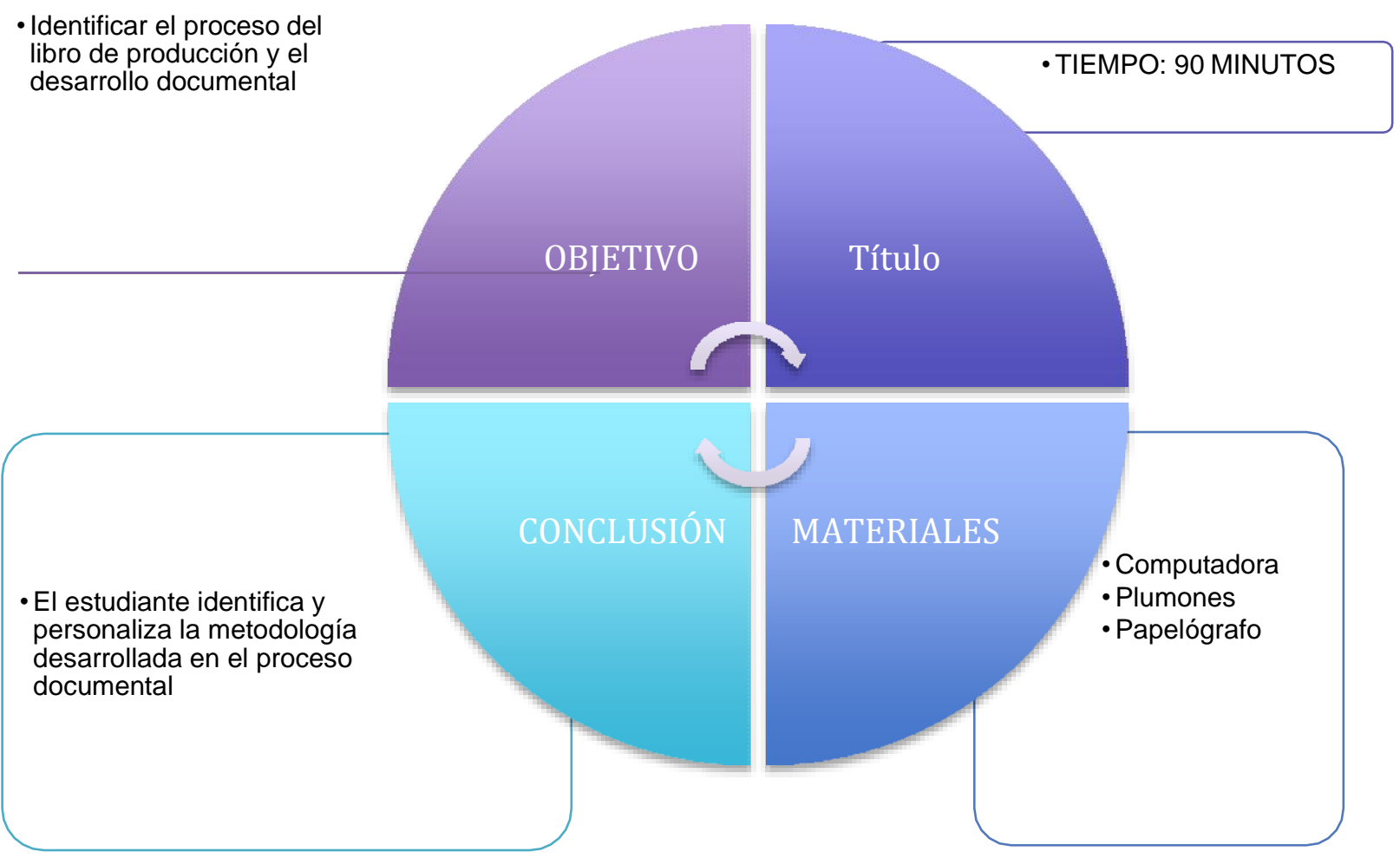


Desarrollo de la actividad:

-Formación de grupos de seis estudiantes (de acuerdo a los grupos fromados para el documental).

-El docente facilita a cada grupo los materiales.

-El docente pide a los grupos que elaboren una infografía de su proceso en la elaboración del documental.

Los estudiantes tienen que evidenciar en la tarea donde se encuentran en su proceso.

-Se les da un tiempo de 30 minutos.

- Se sortea el orden de los grupos.

-Cuando se acabe el tiempo cada grupo saldrá a exponerde acuerdo al sorteo al azar.

\section{Sesión de aprendizaje 1}

Área curricular: Comunicación audiovisual

Ciclo $\mathrm{V}$

Título de la sesión : La preproducción audiovisual

Duración : 6 horas académicas

1. Logro Construye los principios básicos del libro de producción en base a un tema elegido para el desarrollo del documental.

\section{Secuencia didáctica}

\begin{tabular}{|l|c|}
\hline ACTIVIDADES DE APRENDIZAJE & TIEMPO \\
\hline INICIO DE SESIÓN & \multirow{2}{*}{ minutos } \\
\hline $\begin{array}{l}\text { ORIENTACIÓN DEL NUEVO CONTENIDO (TRENDING TOPIC) } \\
\text { SE FORMAN GRUPOS DE } 5 \text { A } 6 \text { PERSONAS Y SE ELIGE EL TEMA QUE SE } \\
\text { TOCARÁ PARA LA REALIZACIÓN DEL DOCUMENTAL }\end{array}$ & \\
\hline $\begin{array}{l}\text { DESARROLLO DE SESIÓN } \\
\text { Luego de encontrar el tema documental a desarrollar por cada grupo, el docente } \\
\text { pondrá en la pizarra } 5 \text { cuadros con las características de los cargos de producción a } \\
\text { emplearse en el documental, cada estudiante se acercará a leer las actividades como } \\
\text { dinámica de museo y se colocará debajo del cargo con el que se sienta cómodo. Esta } \\
\begin{array}{l}\text { actividad nos ayudará a saber que alumnos se sienten más cómodos con tal o cual } \\
\text { trabajo de campo para la investigación del documental y para la elección de dicho } \\
\text { cargo en el grupo }\end{array}\end{array}$ \\
\hline $\begin{array}{l}\text { DOMINIO DE LA HABILIDAD(STORIES) } \\
\text { Se agruparán de acuerdo a las habilidades escogidas y buscarán en relación a }\end{array}$
\end{tabular}




\begin{tabular}{|l|l|}
\hline $\begin{array}{l}\text { realizarán una exposición en PPT, además de ello tendrán que buscar un dato adicional } \\
\text { y poner como ejemplo a un representante de ese cargo con su respectiva descripción, } \\
\text { entonces comenzamos el proceso de contar historias. }\end{array}$ & $\begin{array}{l}20 \text { MINUTOS } \\
\text { EXPICIÓN }\end{array}$ \\
\hline $\begin{array}{l}\text { Se creará un fan page del curso y este tendrá contenido proporcionado por los } \\
\text { alumnos. Lo que ha comprendido en la sesión de clase debe evidenciarse en una } \\
\text { publicación o foto en la red social, con un propósito claro. }\end{array}$ & 30 minutos \\
\hline $\begin{array}{l}\text { SALIDA DE SESIÓN } \\
\text { EVALUACIÓN (SELFIE) } \\
\text { EL docente colocará una diapositiva donde preguntará a los estudiantes sobre } \\
\text { su desempeño en clase de manera individual y cual de sus compañeros merece una } \\
\text { calificación sobresaliente. Esta evaluación se realizará de manera personal enviándola } \\
\text { al correo institucional del docente. }\end{array}$ & 10 minutos \\
\hline
\end{tabular}

\section{Evaluación}

\begin{tabular}{|l|l|l|}
\hline CAPACIDAD & INDICADOR & $\begin{array}{l}\text { TÉCNICA / } \\
\text { INSTRUMENTO }\end{array}$ \\
\hline $\begin{array}{l}\text { AUTOEVALUA } \\
\text { Y CRITICA }\end{array}$ & $\begin{array}{l}\text { GESTIONA Y EVALUA SU PROPIO } \\
\text { APRENDIZAJE Y EL DE SUS PARES }\end{array}$ & $\begin{array}{l}\text { AUTOEVALUACIÓN Y } \\
\text { COEVALUACIÓN }\end{array}$ \\
\hline
\end{tabular}

\section{Sesión de aprendizaje 2}

ÁREA CURRICULAR : COMUNICACIÓN AUDIOVISUAL

CICLO

$\mathrm{V}$

TÍTULO DE LA SESIÓN $\quad$ :TIPOS DE DOCUMENTAL

DURACIÓN :6 horas académicas

\begin{tabular}{|l|ll|}
\hline 1. LOGRO & $\bullet$ & $\begin{array}{l}\text { Investigar la temática a utilizar en el documental. } \\
\text { Identificar que documental realizará, diferenciándolo de los otros tiposy } \\
\text { de la ficción }\end{array}$ \\
\hline
\end{tabular}

\section{SECUENCIA DIDÁCTICA}

\begin{tabular}{|l|c|}
\hline ACTIVIDADES DE APRENDIZAJE & TIEMPO \\
\hline INICIO DE SESIÓN & 20 \\
& Minutos \\
\hline
\end{tabular}




\begin{tabular}{|c|c|}
\hline $\begin{array}{l}\text { ORIENTACIÓN DEL NUEVO CONTENIDO (TRENDING TOPIC) } \\
\text { Se motrará al alumno } 4 \text { videos de un minuto cada uno y se le preguntará los puntos } \\
\text { semejantes y diferentes de cada uno }\end{array}$ & \\
\hline DESAROLLO DE SESIÓN & \\
\hline $\begin{array}{l}\text { ASIMILACIÓN DE LA HABILIDAD(CHECK-IN) } \\
\text { Luego de que el docente explique los tipos de documental y de ficción, cada alumno } \\
\text { escribirá el tema y una breve sinopsis de un documental creado por él con los } \\
\text { siguientes datos del libro de producción: motivación o justificación, investigación } \\
\text { bibliográfica y audiovisual y sinopsis de la historia. }\end{array}$ & 30 minutos \\
\hline $\begin{array}{l}\text { DOMINIO DE LA HABILIDAD(STORIES) } \\
\text { Una vez terminada la creación del documental escrito, se recogerá los paples de la } \\
\text { tarea. Luego se mezclarán los papeles y se le entregará a los alumnos de vuelta los } \\
\text { guiones pero a ninguno le correspondrá el suyo, ahora es momento de crear, el } \\
\text { alumno con la historia documental que le han proporcionado tendrá que crear una } \\
\text { ficción. }\end{array}$ & $\begin{array}{l}40 \text { minutos } \\
+ \\
40 \text { MINUTOS } \\
\text { EXPOSICIÓN }\end{array}$ \\
\hline $\begin{array}{l}\text { SISTEMATIZACIÓN DE LA HABILIDAD(TRANSMEDIAR) } \\
\text { Se hará una votación en clase para elegir a la historia más original y está será } \\
\text { colocada en el fan page de la clase }\end{array}$ & 20 minutos \\
\hline SALIDA DE SESIÓN & \\
\hline $\begin{array}{l}\text { EVALUACIÓN (SELFIE) } \\
\qquad \text { El alumno tundra que evaluar a sus compañeros y al mismo con estos tres } \\
\text { indicadores sobre las historias creadas: creatividad, investigación y respeto a la idea } \\
\text { del otro. }\end{array}$ & 20 minutos \\
\hline
\end{tabular}

\section{EVALUACIÓN}

\begin{tabular}{|l|l|l|}
\hline CAPACIDAD & INDICADOR & $\begin{array}{l}\text { TECNICA / } \\
\text { INSTRUMENTO }\end{array}$ \\
\hline $\begin{array}{l}\text { AUTOEVALUA } \\
\text { Y CRITICA }\end{array}$ & $\begin{array}{l}\text { GESTIONA Y EVALUA SU PROPIO } \\
\text { APRENDIZAJE Y EL DE SUS PARES }\end{array}$ & $\begin{array}{l}\text { AUTOEVALUACIÓN Y } \\
\text { COEVALUACIÓN }\end{array}$ \\
\hline
\end{tabular}




\section{Tabla 7}

\section{Indicadores de las sesiones de clase}

\begin{tabular}{|c|c|c|c|}
\hline Sesión & Contenido & Indicador & Etapa \\
\hline 1 & $\begin{array}{l}\text { La preproducción } \\
\text { audiovisual }\end{array}$ & $\begin{array}{l}\text { Construye los principios básicos del libro de producción en } \\
\text { base a un tema elegido para el desarrollo del documental. }\end{array}$ & Planificación \\
\hline 2 & $\begin{array}{l}\text { Tipos de } \\
\text { documental }\end{array}$ & $\begin{array}{l}\text { Investiga la temática a utilizar en el documental. } \\
\text { Identifica que documental realizará, diferenciándolo de los } \\
\text { otros tipos. }\end{array}$ & $\begin{array}{l}\text { Planificación } \\
\text { Realización }\end{array}$ \\
\hline 3 & $\begin{array}{l}\text { Formatos: plan de } \\
\text { rodaje, storyboard }\end{array}$ & $\begin{array}{l}\text { Construye a partir de lo aprendido sus propios formatos de } \\
\text { acuerdo al tema escogido en su documental. }\end{array}$ & Planificación \\
\hline 4 & Flujo de trabajo & $\begin{array}{l}\text { Organiza de acuerdo a lo investigado el trabajo en las } \\
\text { diferentes áreas de producción }\end{array}$ & Planificación \\
\hline 5 & $\begin{array}{l}\text { Storytelling en } \\
\text { fomatos digitales }\end{array}$ & $\begin{array}{l}\text { Identifica la línea narrativa que seguirá su documental, } \\
\text { incluyendo las características del sotytelling. }\end{array}$ & Realización \\
\hline 6 & $\begin{array}{l}\text { Desglose, plan de } \\
\text { trabajo }\end{array}$ & $\begin{array}{l}\text { Construir un plan de trabajo y un desglose de producción } \\
\text { adecuado al tema y al tiempo del documental }\end{array}$ & Planificación \\
\hline 7 & Postproducción & $\begin{array}{l}\text { Construye a partir de lo visto en clase la línea de tiempo de } \\
\text { su documental.Construye el esquema de distribución de su } \\
\text { producto audiovisual. }\end{array}$ & Sistematización \\
\hline 8 & $\begin{array}{l}\text { Storyworld y } \\
\text { transmedia }\end{array}$ & Construye un universo audiovisual en torno a su documental & Sistematización \\
\hline 9 & $\begin{array}{l}\text { Avance del libro } \\
\text { de producción }\end{array}$ & $\begin{array}{l}\text { Corrige elementos que puedan impedir el buen desempeño } \\
\text { de su libro de producción }\end{array}$ & Sistematización \\
\hline 10 & $\begin{array}{l}\text { Derechos de } \\
\text { autor }\end{array}$ & $\begin{array}{l}\text { Identifica y aplica los procesos de copyright, copyleft y } \\
\text { creative commons en su documental Identifica y }\end{array}$ & Realización \\
\hline 11 & $\begin{array}{l}\text { Perfil de } \\
\text { personaje }\end{array}$ & $\begin{array}{l}\text { construye el perfil del o de los personajes } \\
\text { Replantea o sustenta los fundamentos de su }\end{array}$ & Realización \\
\hline 12 & $\begin{array}{l}\text { Avance } \\
\text { documental }\end{array}$ & propuesta audiovisual & Sistematizaci ón \\
\hline 13 & Visionado & $\begin{array}{l}\text { Rectifica contenidos del documental y del libro de } \\
\text { producción }\end{array}$ & $\begin{array}{l}\text { Sistematizaci ón } \\
\text { Realización }\end{array}$ \\
\hline 14 & Transmedia & $\begin{array}{l}\text { Construye y reconfirma los formatos transmedia } \\
\text { planteados }\end{array}$ & \\
\hline
\end{tabular}


FINAL

Fuente: Elaboracion propia (2019) 


\section{Conclusiones aproximativas de la propuesta}

La propuesta sugerida redirecciona el tratamiento de un curso al aspecto de metodología científica en relación con un producto audiovisual claramente definido, el documental, que ayudará sosteniblemente al desarrollo de las habilidades investigativas del alumno de quinto ciclo de la Carrera de Comunicaciones.

En base a 3 etapas claras el docente podrá ver la evolución de estas habilidades acompañando al estudiante en su formación investigativa de la mano con referentes que le son familiares como las redes sociales y el entorno audiovisual. Todo esto en base a la trasmediación del contenido temático del formato documental.

Un formato documental es el claro pretexto de realizar una investigación sin etiquetarla como tal, de llevar un manejo de grupo sin mencionar el trabajo colaborativo y un claro aprendizaje en base a proyectos sin definirlo como tal, es así que el alumno de un manera más natural y orgánica desarrollará habilidades para poder llegar a cumplir los objetivos en base a tareas y didácticas realizadas en clase.

El ser, el saber hacer, el saber ser y el convivir van de la mano con la metodología ayudando a formar estudiantes integrales y holísticos en el campo profesional y vivencial. Cada sesión de aprendizaje tiene 5 momentos o fases que ayudarán al alumno a reforzar las habilidades requeridas, pero si un alumno no logra los objetivos en una sesión existirá dentro de las 16 sesiones de aprendizaje otra oportunidad para generar o transformar esa habilidad dormida. Es decir, la sesión no es conclusiva al contrario es inclusiva con el resto de sesiones de aprendizaje.

Un docente investigador es pieza clave para desarrollar una habilidad investigativa, si el docente no conoce el proceso o la metodología científica para realizar una investigación es muy difícil que el alumno logre llegar al objetivo investigativo.

\section{Validación de la propuesta}

\section{Validación de la estrategia por juicio de especialistas.}

Para validar la propuesta que pretende modificar el estado actual de las habilidades investigativas en estudiantes de $\mathrm{V}$ ciclo de la facultad de comunicaciones de la UPN, se utilizó la técnica de consulta a juicio de expertos con 10 indicadores y validacion interna y extrerna. Los expertos fueron seleccionados por la idoneidad de su trabajo en la investigación educacional de tipo aplicada. 


\section{Características de los especialistas.}

Los especialistas seleccionados para avalar la propuesta fueron tres docentes con el grado académico y científicos requeridos, con más de 25 años de experiencia profesional y la autoridad académica para valorar la propuesta de tesis.

\section{Tabla 8}

Especialistas de la Validación.

\begin{tabular}{lllll}
\hline Apellidos y nombres & $\begin{array}{l}\text { Grado } \\
\text { académico }\end{array}$ & Especialidad/Profesión & Ocupación & $\begin{array}{l}\text { Año de } \\
\text { experiencia }\end{array}$ \\
\hline $\begin{array}{l}\text { Flores Valdiviezo, } \\
\text { Hernán }\end{array}$ & Magister & Sociólogo & $\begin{array}{l}\text { Docente de } \\
\text { escuela de }\end{array}$ & \\
Muños Salazar, José & Doctor & Ciencias de la Educación & $\begin{array}{l}\text { Dostgrado } \\
\text { Docente de }\end{array}$ & 25 años \\
Manuel & & & $\begin{array}{l}\text { escuela de } \\
\text { postgrado }\end{array}$ & \\
& & Psicología de la & Docente & 20 años \\
Medina Zuta, Patricia & Doctor & Educación & investigador & \\
\hline
\end{tabular}

Fuente: Adaptado del modelo USIL (2019) 
El Maestro Flores Valdiviezo Hernán, es un profesional dedicado a la investigación con mas de 25 años de experiencia, trabajó y trabaja en diferentes universidades como docente de investigacion cientifica, es asesor de tesis, revisor de estilos de redacción.

José Manuel Muños Salazar, es doctor en Ciaencias de le educación con más de 25 años de experiencia, trabaja en diferentes universidades asesorando tesis y siendo docente en la escuela de postgrado de la USIL.

Por último la doctora Patricia Medina Zuta, es docente de varias escuelas de Postgrado y doctora en Psicología de la educación.

\section{Valoración interna.}

La validación interna (contenido) cuyo informe de opinión generado por el especialista ha considerado 10 criteriores de evaluación, para reflejar una visión global de la apreciación del especialista, como: en este caso constituyen: factibilidad de aplicación del resultado que se presenta, claridad de la propuesta para ser aplicado por otros; posibilidad de la propuesta de extensión a otros contextos semejantes; correspondencia con las necesidades sociales e individuales actuales; congruencia entre el resultado propuesto y el objetivo fijado, novedad en el uso de conceptos y procedimientos de la propuesta; la modelación contiene propósitos basados en los fundamentos educativos, curriculares y pedagógicos, detallado; preciso y efectivo; la propuesta está contextualizada a la realidad en estudio; presenta objetivos claros, coherentes y posibles de alcanzar y contiene un plan de acción de lo general a lo particular con una escala de calificación de deficiente (puntaje 1), bajo (puntaje 2), regular (puntaje 3), buena (puntaje 4) y muy buena (puntaje 5). Además contiene aspectos que el especialista debe registrar, con la idea de señalar los aspectos positivos relevantes o negativos, así como las sugerencias que se necesitan ser superadas.

\section{Tabla 9}

\section{Validez interna por juicio de expertos}

\begin{tabular}{|c|c|c|c|c|c|c|}
\hline \multirow[t]{2}{*}{ Indicadores } & \multicolumn{2}{|c|}{ Juez 1} & \multicolumn{2}{|c|}{ Juez 2} & \multicolumn{2}{|c|}{ Juez 3} \\
\hline & $\mathbf{n}$ & $\%$ & $\mathbf{N}$ & $\%$ & $\mathbf{n}$ & $\%$ \\
\hline Factibilidad de aplicación del resultado & 5 & 10 & 5 & 10 & 4 & 8 \\
\hline Claridad de la propuesta para ser aplicado por otros & 4 & 8 & 4 & 8 & 3 & 6 \\
\hline Posibilidad de la propuesta de extensión a otros & & & & & & \\
\hline contextos semejantes & 5 & 10 & 4 & 8 & 5 & 10 \\
\hline
\end{tabular}


Correspondencia con las necesidades sociales e individuales actuales

$\begin{array}{llllll}4 & 8 & 4 & 10 & 5 & 10 \\ 5 & 10 & 5 & 10 & 4 & 8 \\ 5 & 10 & 5 & 10 & 5 & 10 \\ & & & & & \\ 4 & 8 & 5 & 10 & 3 & 6 \\ 5 & 10 & 5 & 10 & 5 & 10 \\ & & & & & \\ 5 & 10 & 4 & 8 & 4 & 8 \\ 4 & 8 & 4 & 8 & 5 & 10 \\ 46 & 92 & 45 & 90 & 43 & 86 \\ 90.6 \% & & & & \end{array}$

Congruencia entre el resultado propuesto y el objetivo fijado.

Novedad en el uso de conceptos y procedimientos de la propuesta.

La modelación contiene propósitos basados en los fundamentos educativos, curriculares y pedagógicos, detallado, preciso y efectivo

La propuesta está contextualizada a la realidad en estudio.

Presenta objetivos claros, coherentes y posibles de alcanzar.

Contiene un plan de acción de lo general a lo particular.

Total

Promedio $90.6 \%$

Fuente: Adaptado del modelo USIL (2019)

Los resultados de la valoración interna demuestran que, el Juez 1 dio una valoración de 96\%, el Juez 2 unavaloracion de 90\% y el Juez 3 de $86 \%$, finalmente la valoracion total interna resultó de $88.6 \%$, lo cual indica que la propuesta tiene una valoración interna de muy buena. 


\section{Valoración externa.}

Con relación a la segunda ficha de validación externa (forma) informe de opinión del especialista, para esta se han considerado diez criterios e indicadores: claridad, objetividad, actualidad, organización, suficiente, intencionalidad, consistencia, coherencia, metodología y pertenencia, también con una escala de calificación de deficiente (puntaje 1), bajo (puntaje 2), regular (puntaje 3), buena (puntaje 4) y muy buena (puntaje 5). Además contiene aspectos que el especialista debe registrar, con la idea de señalar los aspectos positivos relevantes o negativos, así como las sugerencias que se necesitan ser superadas.

\section{Tabla 10}

Validez interna por juicio de expertos

\begin{tabular}{lllllll}
\hline Indicadores & Juez $\mathbf{1}$ & \multicolumn{3}{l}{ Juez 2 } & Juez 3 \\
\hline Claridad & $\mathbf{n}$ & $\%$ & $\mathbf{n}$ & $\%$ & $\mathbf{N}$ & $\%$ \\
\cline { 2 - 7 } Objetividad & 5 & 10 & 4 & 8 & 3 & 6 \\
Actualidad & 5 & 10 & 4 & 8 & 3 & 6 \\
Organización & 4 & 8 & 4 & 8 & 4 & 8 \\
Suficiencia & 4 & 8 & 5 & 10 & 4 & 8 \\
Intencionalidad & 5 & 10 & 4 & 8 & 4 & 8 \\
Consistencia & 4 & 8 & 5 & 10 & 3 & 6 \\
Coherencia & 5 & 10 & 5 & 10 & 5 & 10 \\
Metodología & 4 & 8 & 5 & 10 & 3 & 6 \\
Pertinencia & 5 & 10 & 5 & 10 & 4 & 8 \\
Total & 5 & 10 & 4 & 8 & 4 & 8 \\
Promedio & 46 & 92 & 45 & 90 & 37 & 74
\end{tabular}

Fuente: Adaptado del modelo USIL (2019)

Los resultados de la valoración externa demuestran que, el Juez 1 dio una valoración de $92 \%$, el Juez 2 unavaloracion de 90\% y el Juez 3 de 74\%, finalmente la valoracion total externa resultó de $85.3 \%$, lo cual indica que la propuesta tiene una valoración externa de muy buena. Estas se sintetizan en un apartado denominado (resultados) teniendo el puntaje de valoración interna y externa, para la valoración las mismas se consideró frecuencia de rangos y porcentaje de rangos, lo cual permite decidir en qué rango se ubica la validez de la propuesta, lo cual se presenta en la tabla siguiente. 


\section{Tabla 11}

\section{Escala de de Valoración}

\begin{tabular}{lll}
\hline Escala & Rango frecuencia & Rango porcentaje \\
\hline Deficiente & {$[10-17]$} & {$[20 \%-35 \%]$} \\
Baja & {$[18-25]$} & {$[36 \%-51 \%]$} \\
Regular & {$[26-33]$} & {$[52 \%-67 \%]$} \\
Buena & {$[34-41]$} & {$[68 \%-83 \%]$} \\
Muy buena & {$[42-50]$} & {$[84 \%-100 \%]$} \\
\hline
\end{tabular}

Fuente: Adaptado del modelo USIL (2019)

\section{Resultado de la valoración de los especialistas y conclusiones.}

En esta etapa se realiza la sistematización de la información proporcionada por los expertos, para lo cual se presenta: Con relación a la validación interna y externa de la propuesta pedagógica realizada por los expertos.

\section{Tabla 12}

Valoración interna y externa por ctriterio de jueces

\begin{tabular}{lllll}
\hline & Especialista 1 & Especialista 2 & Especialista 3 & Promedio \\
\hline Validación interna & $92 \%$ & $90 \%$ & $86 \%$ & $89 \%$ \\
Validación externa & $92 \%$ & $90 \%$ & $74 \%$ & $85 \%$ \\
Promedio por especialista & $92 \%$ & $90 \%$ & $80 \%$ & \\
& & & Promedio final & $87 \%$ \\
\hline
\end{tabular}

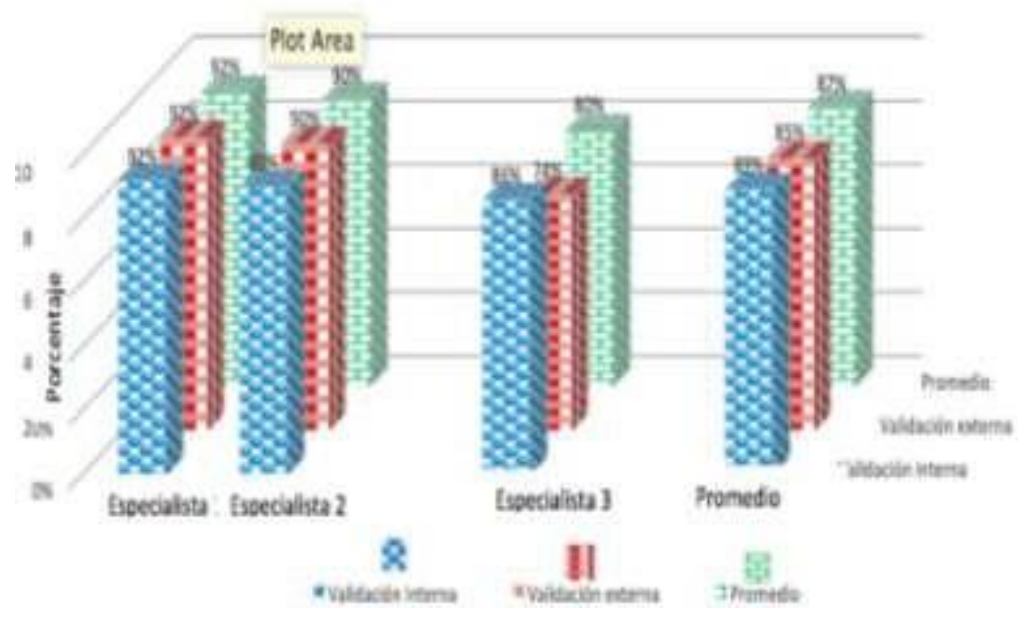

Figura 15. Valoración interna y externa por ctriterio de jueces

Los resultados de la validación de los expertos reflejan según la escala de apreciación como muy buena la propuesta pedagógica, alcanzando un promedio de $87 \%$ de validez, porque responde a los objetivos planteados y a la realidad. Además, las 
recomendaciones realizadas, están orientadas a profundizar y desarrollar la creatividad por la edad propicia en la que se encuentran para mejorar las capacidades de crear, inventar, etc. Además, la importancia que le da uno de los evaluadores a la generalización, como un proceso de lograr las sucesiones. Estas recomendaciones se han considerado para hacer las mejoras en la propuesta. 


\section{Conclusiones}

Al dar por término el proceso de investigación mediante los referentes científicos, el diagnóstico del trabajo de campo, la modelación de la estrategia metodológica propuesta para desarrollar las habilidades investigativas de los estudiantes terciarrios y el objetivo general se formulan las siguientes conclusiones.

\section{Primera}

Se modeló la estrategia metodológica siguiendo el objetivo general para desarrollar las habilidades investigativas en estudiantes de $\mathrm{V}$ ciclo de Comunicaciones de una Universidad Privada de Lima a partir de la ejecución de los procesos de observación, clasificación, hipótesis, experimentación y comprobación.

\section{Segunda}

La Primera pregunta ceintífica, se logró al realizar el recojo de infromación y por consiguiente los procesos de transcripción, docidficación, categorización y trinagulación de los datos, los mismos evidencian estudiantes con dificultades en el manejo de las habilidades investigativas, los estudiantes no relacionan la realidad con la investigación y por ello no tienen metodología para desarrollar investigaciones, a esto se le suma que los docentes no realizan evaluaciones que puedan medir dichas habilidades en los alumos y no adecuan su metodología a la realidad del estudiantes, creando entonces productos audiovisuales sin rigor científico, mediocres e ineficientes.

\section{Tercera}

Con respecto a la segunda tarea científica se logró sistematizar los diferentes teorías, enfoques y modelos relacionadas a las categorías apriorísticas, tal como señala Delors (1994) y Montes de Oca (2009), se requiere del dominio de ciertas acciones y procesos ligados al conocimiento y la resolución de problemas, no solo en el campo laboral sino en su desempeño cotidiano en materia de investigación y estas competencias se logran desarrollando las habilidades investigativas dentro del proceso de enseñanza aprendizaje.

\section{Cuarta}

La tercera tarea científica se cumplió con el diseño una popuesta metodológica la cual surge ante la necesidad de mejorar las capacidades del estudiante universitario de 
comunicaciones en relación a la investigación y como aprovechar su entorno tecnológico y mediático para motivar su acercamiento al campo científico y de desarrollo metodológico de la ciencia.De esta manera de acompaña metodológicamente al alumno en base de plataformas audiovisuales y lenguaje de medios que él ya conoce, para desarrollar las habilidades de un investigador, motivando al estudiante a crear dotes de investigador que más adelante lo ayudarán a ser un profesional más capaz y un ser humano holístico.

\section{Quinta}

Los resultados de la validación alcanzan niveles de alta aceptación por parte de los expertos, llegando a un $87 \%$ de promedio de valoración interna y externa, por consiguiente enfatizan los argumentos teóricos y de diagnóstico que llevan a dicho diseño a cumplir con sus objetivos generales para desarrollar habilidades i nvestigativas en el curso de Diseño y Producción de narrativas audiovisuales del quinto ciclo de Comunicaciones. 


\section{Recomendaciones}

\section{Primera}

Es necesario un docente investigador que monitoree los procesos teóricos y prácticos para poder desempeñar con éxito la labor desde la base de una recopilación de información correcta y una verificación de la calidad de las fuentes, buscando un desarrollo unificado del proceso vivencial con la teoría y el manejo de los contenidos audiovisuales

\section{Segunda}

Es recomendable que los docentes aprovechen como herramienta investigativa los procesos documentales, ayudando a que estos se vuelvan una representación de la realidad. Es importante destacar que el docente encargado de este acompañamiento tiene que problematizar, dialogar, reflexionar y valorar el contenido de la metodología.

\section{Tercera}

En el curso de Narrativas Audiovisuales es importante que el alumno se acerque a generar investigación, pero también la estrategia de venta, los canales de distribución y donde y que otros productos van a colaborar a que la historia sea exitosa y atrape a su público objetivo, entonces debe tomarse el proyecto no como algo ficticio sino como algo real y posiblemente aplicable.

\section{Cuarta}

La implementación del curso necesita de dos tipos de sistematización: visual y escrita. Los productos que sostendrán nuestro modelo básicamente son dos: un documental de 30 minutos de duración y un libro de producción de dicho documental donde se evidenciará los procesos de forma sistematizada, el documental es el producto final y el libro de producción es la evidencia de la investigación realizada para la culminación de ese proyecto. 


\section{Referencias}

De Armas, N., Lorences, J. y Perdomo, J. (2003). Caracterización y diseño de los resultados científicos como aportes de la investigación educativa. Evento Internacional Pedagogía 2003. La Habana, Cuba

Baer, A y Schnettler, B (2009). Hacia una metodología cualitativa audiovisual.

Capítulo para: Aldo Merlino (ed.), Investigación Cualitativa en las Ciencias

Sociales: Temas y problemas, Buenos Aires (en prensa)

Barriga y Hernández (2002). Estrategias docentes para un aprendizaje significativo. Interamericana Editores. México.

Bateson, G, y Mead, M. (1986). Use of the Camera in Anthropology. New York Academy of Sciences, Nueva York.

Blanco, N., Herrera, D., Reyes, Y., Ugarte, M. y Betancurt, Y. (2014). Dificultades en el desarrollo de las habilidades investigativas en los estudiantes de medicina. Edumecentro vol. 6. No. 1. Santa clara.cuba.

Blumen, S. (2017). Propuesta de un curso propedéutico para la formación en posgrado: métodos de investigación. Pontificia Universidad Católica del Perú.

Castillo, V. (2006). Estrategias docentes para un aprendizaje significativo. Universidad Mayor de San Andrés, La Paz- Bolivia.

Cardoza, B. Carmons, S., Ramos, J y Ribón, C(2015). Estrategias metodológicas para fortalecer las habilidades comunicativas de lectura y escritura de los estudiantes del grado primero de la institución educativa Luis Carlos López. Universidad de Cartagena- Colombia.

CONCYTEC (21016). I Censo Nacional de Investigación y Desarrollo a Centros de Investigación.

Consejo Nacional de ciencia, tecnología e innovación tecnológica, Perú.

Cerezal, J. y Fiallo , J.(2016). Métodos científicos de las investigaciones pedagógicas. Instituto Pedagógico Latinoamericano y Caribeño. República de Cuba.

Cerezal, J. y Fiallo, J. (2005). Cómo investigar en pedagogía. La Habana: Pueblo y Educación. Delors, J. (1998). La Educación encierra un tesoro. Informe de la UNESCO de la educación en el siglo XXI

Díaz-Barriga, F. (2012). Reformas curriculares y cambio sistémico: una articulación ausente pero necesaria para la innovación. Revista iberoamericana de educación superior.

Dumont, H; Istance, D y Benavides, F (2012). La Naturaleza del aprendizaje. OCDE. Espinoza, A. (2017). Competencias investigativas y liderazgo creativo en estudiantes de ciencias matemáticas e informática de la UNCP. Universidad Nacional del Centro del Perú, Huancayo-Perú. De La Garza, E. (2017). La metodología configuracionista para la investigación social. Editorial 
Gedisa, S.A. Barcelona, España.

El Peruano(2014). Ley Universitaria. El Peruano. Perú

Foro Económico Mundial (2014)

Recuperado de https://es.weforum.org/reports/global-competitiveness-report-2014-2015

García G., M. E. (2008). La imagen en la investigación social en La investigación

en Ciencias Sociales:Técnicas de recolección de información. Bogotá, Ediciones

Universidad Piloto de Colombia.

Gibbs, G. (2012). El análisis de los datos cualitativos en investigación cualitativa.

Ediciones Morata, S. L. España.

Gil Pérez, D. y Valdés Castro, P. (1996). Tendencias actuales en la enseñanza-aprendizaje de la Física. Editorial Pueblo y Educación, La Habana

Goffman, E. (1983). The interaction order, American Sociological Review.

Recuperado de : http://dx.doi.org/10.2307/2095141.

Gordillo, N. (2007) Metodología, método y propuestas metodólogicas en trabajos social. Revista Tendencia \& Retos, Colombia.

González, F. (2013). Subjetividad, cultura e investigación cualitativa en

psicología: la ciencia como producción culturalmente. Escritos sobre psicología y sociedad.

Universidad Central de Chile.

Guillen, A(2015). Habilidades investigativas en el área de ciencia y ambiente en los estudiantes de 5 años de la i. E. №3091 Los Olivos. Universidad Peruana Cayetano Heredia.Perú.

Hernándéz Moncada, M (2012). Estrategias de investigación. En seminario de Investigación. México.

Hernándéz Gallardo, S (2012). Objetos de aprendizaje para la adquisición de habilidades

investigativas en el postgrado en línea. Sistema de universidad virtual, México

Hernández Sampieri, R, C. Fernández y P. Baptista (2010). Metodología

de la investigación. México

Hernández, R. , Fernández, C. y Baptista, P. (2014) Metodología de la investigación. Mcgraw-Hill, Interamericana Editores, S.A. México.

Huamán, M.(2015). El uso de la webquest en el desarrollo de habilidades investigativas de los estudiantes del área de ciencia tecnología y ambiente del segundo grado de educación secundaria en el centro experimental de aplicación de la Universidad Nacional de educación. Universidad Nacional de Educación Enrique Guzmán y Valle, Chosica-Perú.

Lanchipa, F.(2009). Método investigativo y desarrollo de habilidades para investigar en estudiantes de la escuela de medicina humana de la universidad nacional "Jorge Basadre Grohmann. Tesis para optar el grado académico de magister en educación con mención en docencia en el nivel superior, Tacna-Perú. 
Lanuez, M., Martínez, M. y Pérez, V. (2008). La investigación educativa en el aula. La Habana: Pueblo y Educación.

Llanos, J. (2005). Integración de recursos Humanos. Editorial Trillas, México D.F. Leontiev, A. (1977) Actividad, Conciencia y Personalidad. Digitales Soyuz.

Mayz, C. (2009). ¿Cómo desarrollar, de una manera comprensiva, el análisis cualitativo de los datos?. Universidad de Carabobo. Venezuela. Educere, 13(44), 55 - 66.

Montes de Oca, N. y Machado Ramírez, E. (2009). El desarrollo de habilidades investigativas en la educación superior: un acercamiento para su desarrollo.Recuperado de:

http://scielo.sld.cu/scielo.php?script=sci arttext\&pid=S1727-81202009000200002

Mosteiro, M. y Porto, A. (2017). La investigación en educación. BA: EDITUS.

Murillo, W. (2008). La investigación científica. Recuperado de http//www.monografias.com/ trabajos15/inves

Liuzzi, A. (2015). El Documental Interactivo en la Era Transmedia: De Géneros Híbridos y Nuevos Códigos Narrativos . OBRA DIGITAL - ISSN 2014-5039. Núm 8.

Ocando, J. (2009). La formación académica del profesor universitario y las estrategias que usa para promover el aprendizaje significativo (Tesis doctoral). Maracaibo, Venezuela.

OCDE (2106).Estrategia de competencias de la OCDE. Reporte Diagnóstico:Perú. Ministerio de trabajo y Promoción del empleo del Perú.

Pollo-Cattaneo, F., Rodriguez, D., Britos, P., García-Martínez, R. (2009). Propuesta de Formación de RRHH en Investigación Basada en un Modelo Colaborativo. Hacia un Cambio de Paradigma. Proceedings of VI International Conference on Engineering and Computer Education. Plataforma de investigación científica de la Universidad complutense de madrid.

Http://plataformadivulgacionucm.com/

Puche, R., \& Colinvaux, D. (2001). El niño que piensa: Un modelo de formación de maestros. Cali: Universidad del Valle/Ministerio de Educación Nacional/OEA.

Quispe, I.(2015). El uso de la webquest en el desarrollo de habilidades investigativas de los estudiantes del área de ciencia tecnología y ambiente del segundo grado de educación secundaria en el centro experimental de aplicación de la Universidad Nacional de educación. Universidad Nacional de Educación Enrique Guzmán y Valle, Chosica-Perú.

Reyes, O (2012). Construcción de Investigaciones sociales. España, UNED-IC Rodriguez, A. y Pérez, A. (2017). Métodos científicos de indagación y de construcción del conocimiento. Revista EAN.

Ruiz, J. (2012). Metodología de la investigación cualitativa. Bilbao: Universidad de Deusto. Salmi, J. (2009). El desafío de crear universidades de rango mundial. Banco Mundial Sánches Puentes, R. (1987). El caso de la enseñanza de la investigación 
histórco-social en el CCH. Cuadernos del CESU, UNAM, México.

Tobón, S. (2013). Socioformación. Los retos de la educación en la sociedad del conocimiento. Multiversidad Management.

Tobón, S. (2015). Socioformación: hacia la gestión del talento humano acorde con la sociedad del conocimiento. México: CIFE.

Tuaréz, E. (2016). Formación de las habilidades investigativas en los estudiantes de tercer semestre de la carrera de ciencias psicológicas de la Universidad de Guayaquil Universidad de Guayaquil. Ecuador.

Universidad Miguel Hernández (2017) libro de producción, España.

Valdes, Ana Teresa Badía; Perez, Zenaida Costales y Condel, A. (2017). Comunicación audiovisual, nuevos paradigmas y tendencias.Cuba, ARCIC. Recuperado de:

http://scielo.sld.cu/scielo.php?script=sci abstract\&pid=S2411-99702017000100003

Valderrama, S. (2014). Pasos para elaborar proyectos de investigación científica: cuantitativa, cualitativa y mixta. Lima: San Marcos.

Velázquez, M. (2014). Propuesta didáctica dirigida a la competencia comunicativa en la construcción de textos escritos en los estudiantes de sexto grado en la educación primaria (tesis doctoral). Pontificia Universidad Católica Americana de los Estados Unidos.

Vygotsky, L.S. (1978). Psicología del arte. Moscú. Editora del Arte. 
Anexo 1: Matriz metodológica y de categorización

\begin{tabular}{|c|c|c|c|c|c|c|c|c|c|}
\hline $\begin{array}{l}\text { PROBLEMA } \\
\text { GENERAL }\end{array}$ & $\begin{array}{l}\text { PROBLEMAS } \\
\text { ESPECIFIICOS }\end{array}$ & Objetivo general & $\begin{array}{l}\text { Objetivos } \\
\text { específicos }\end{array}$ & Categorías & Sub-categorías & Unidad de análisis & Método & Técnicas & Instrumentos \\
\hline \multirow{7}{*}{$\begin{array}{l}\text { ¿Cómo } \\
\text { contribuir al } \\
\text { desarrollo de } \\
\text { las habilidades } \\
\text { investigativas } \\
\text { en estudiantes } \\
\text { del quinto ciclo } \\
\text { de } \\
\text { Comunicacion } \\
\text { es de una } \\
\text { universidad } \\
\text { privada de } \\
\text { Lima? }\end{array}$} & \multirow{7}{*}{$\begin{array}{l}\text { ¿Cuál es el } \\
\text { estado actual } \\
\text { del desarrollo de } \\
\text { las habilidades } \\
\text { investigativas en } \\
\text { estudiantes del } \\
\text { quinto ciclo de } \\
\text { Comunicaciones } \\
\text { de una } \\
\text { universidad } \\
\text { privada de } \\
\text { Lima? }\end{array}$} & \multirow{7}{*}{$\begin{array}{l}\text { Proponer una } \\
\text { estrategia } \\
\text { metodológica para } \\
\text { desarrollar las } \\
\text { habilidades } \\
\text { investigativas en } \\
\text { estudiantes del quinto } \\
\text { ciclo de } \\
\text { Comunicaciones de } \\
\text { una universidad } \\
\text { privada de Lima }\end{array}$} & \multirow{7}{*}{$\begin{array}{l}\text { Diagnosticar el } \\
\text { estado actual del } \\
\text { desarrollo de las } \\
\text { habilidades } \\
\text { investigativas en } \\
\text { estudiantes del quinto } \\
\text { ciclo de } \\
\text { Comunicaciones de } \\
\text { una universidad } \\
\text { privada de Lima }\end{array}$} & \multirow{5}{*}{$\begin{array}{l}\text { Habilidades } \\
\text { investigativas }\end{array}$} & \multirow[t]{3}{*}{$\begin{array}{l}\text { Habilidades } \\
\text { instrumentales } \\
\text { Habilidades sociales }\end{array}$} & \multirow{3}{*}{30 estudiantes } & \multirow{7}{*}{$\begin{array}{l}E \\
M \\
P \\
I \\
R \\
1 \\
C \\
O\end{array}$} & Encuesta & Cuestionario \\
\hline & & & & & & & & Entrevista & Guía de entrevista \\
\hline & & & & & & & & \multirow{2}{*}{ Encuesta } & \multirow{2}{*}{ Cuestionario } \\
\hline & & & & & \multirow{2}{*}{$\begin{array}{l}\text { Esquema ruta-meta } \\
\text { Pilares del } \\
\text { conocimiento }\end{array}$} & \multirow[t]{2}{*}{30 estudiantes } & & & \\
\hline & & & & & & & & Entrevista & Guía de entrevista \\
\hline & & & & \multirow[t]{2}{*}{ metodológica } & \multirow[t]{2}{*}{$\begin{array}{l}\text { Experimentación } \\
\text { Etapas y } \\
\text { procedimiento } \\
\text { Evaluación }\end{array}$} & \multirow[t]{2}{*}{30 estudiantes } & & Encuesta & Cuestionario \\
\hline & & & & & & & & Entrevista & Guía de entrevista \\
\hline \multirow{7}{*}{$\begin{array}{l}\text { ¿Cómo } \\
\text { contribuir al } \\
\text { desarrollo de } \\
\text { las habilidades } \\
\text { investigativas } \\
\text { en estudiantes } \\
\text { del quinto ciclo } \\
\text { de } \\
\text { Comunicacion } \\
\text { es de una } \\
\text { universidad } \\
\text { privada de } \\
\text { Lima? }\end{array}$} & \multirow{7}{*}{$\begin{array}{l}\text { ¿Cuáles son los } \\
\text { fundamentos } \\
\text { teóricos de la } \\
\text { estrategia } \\
\text { metodológica } \\
\text { para desarrollar } \\
\text { habilidades } \\
\text { investigativas en } \\
\text { estudiantes del } \\
\text { quinto ciclo de } \\
\text { Comunicaciones } \\
\text { de una } \\
\text { universidad } \\
\text { privada de } \\
\text { Lima? }\end{array}$} & \multirow{7}{*}{$\begin{array}{l}\text { Proponer una } \\
\text { estrategia } \\
\text { metodológica para } \\
\text { desarrollar las } \\
\text { habilidades } \\
\text { investigativas en } \\
\text { estudiantes del quinto } \\
\text { ciclo de } \\
\text { Comunicaciones de } \\
\text { una universidad } \\
\text { privada de Lima }\end{array}$} & \multirow{7}{*}{$\begin{array}{l}\text { Sistematizar los } \\
\text { fundamentos teóricos } \\
\text { de la estrategia } \\
\text { metodológica para } \\
\text { desarrollar las } \\
\text { habilidades } \\
\text { investigativas en } \\
\text { estudiantes del quinto } \\
\text { ciclo de } \\
\text { Comunicaciones de } \\
\text { una universidad } \\
\text { privada de Lima }\end{array}$} & \multirow{7}{*}{$\begin{array}{l}\text { Habilidades } \\
\text { investigativas }\end{array}$} & \multirow{3}{*}{$\begin{array}{l}\text { Habilidades } \\
\text { instrumentales } \\
\text { Habilidades sociales }\end{array}$} & \multirow{3}{*}{30 estudiantes } & \multirow{7}{*}{$\begin{array}{l}\text { Métodos } \\
\text { teóricos }\end{array}$} & & \\
\hline & & & & & & & & & \\
\hline & & & & & & & & & \\
\hline & & & & & $\begin{array}{l}\text { Esquema ruta-meta } \\
\text { Pilares del } \\
\text { conocimiento }\end{array}$ & \multirow{2}{*}{30 estudiantes } & & & \\
\hline & & & & & & & & & \\
\hline & & & & & \multirow{2}{*}{\begin{tabular}{|l|} 
Experimentación \\
Etapas y \\
procedimiento \\
Evaluación
\end{tabular}} & \multirow[b]{2}{*}{2 Profesores y 10 estudiantes } & & & \\
\hline & & & & & & & & & \\
\hline \multirow{7}{*}{$\begin{array}{l}\text { ¿Cómo } \\
\text { contribuir al } \\
\text { desarrollo de } \\
\text { las habilidades } \\
\text { investigativas } \\
\text { en estudiantes } \\
\text { del quinto ciclo } \\
\text { de } \\
\text { Comunicacion } \\
\text { es de una } \\
\text { universidad } \\
\text { privada de } \\
\text { Lima? }\end{array}$} & \multirow{7}{*}{$\begin{array}{l}\text { ¿Cómo diseñar } \\
\text { la estrategia } \\
\text { metodológica } \\
\text { para desarrollar } \\
\text { las habilidades } \\
\text { investigativas en } \\
\text { estudiantes del } \\
\text { quinto ciclo de } \\
\text { Comunicaciones } \\
\text { de una } \\
\text { universidad } \\
\text { privada de } \\
\text { Lima? }\end{array}$} & \multirow{7}{*}{$\begin{array}{l}\text { Proponer una } \\
\text { estrategia } \\
\text { metodológica para } \\
\text { desarrollar } \\
\text { habilidades } \\
\text { investigativas en } \\
\text { estudiantes del quinto } \\
\text { ciclo de } \\
\text { Comunicaciones de } \\
\text { una universidad } \\
\text { privada de Lima }\end{array}$} & \multirow{7}{*}{$\begin{array}{l}\text { Diseñar la estrategia } \\
\text { metodológica para } \\
\text { desarrollar } \\
\text { habilidades } \\
\text { investigativas en } \\
\text { estudiantes del quinto } \\
\text { ciclo de } \\
\text { Comunicaciones de } \\
\text { una universidad } \\
\text { privada de Lima }\end{array}$} & \multirow{7}{*}{$\begin{array}{l}\text { Habilidades } \\
\text { investigativas }\end{array}$} & & \multirow{3}{*}{2 Profesores y 20 estudiantes } & \multirow{7}{*}{ Modelacíon } & & \\
\hline & & & & & instrumentales & & & & \\
\hline & & & & & Habilidades sociales & & & & \\
\hline & & & & & $\begin{array}{l}\text { Esquema ruta-meta } \\
\text { Pilares del }\end{array}$ & 2 Profesores y 20 estudiantes & & & \\
\hline & & & & & & & & & \\
\hline & & & & & Experimentación & & & & \\
\hline & & & & & \begin{tabular}{|l} 
Etapas y \\
procedimiento \\
Evaluación
\end{tabular} & 2 Profesores y 20 estudiantes & & & \\
\hline
\end{tabular}




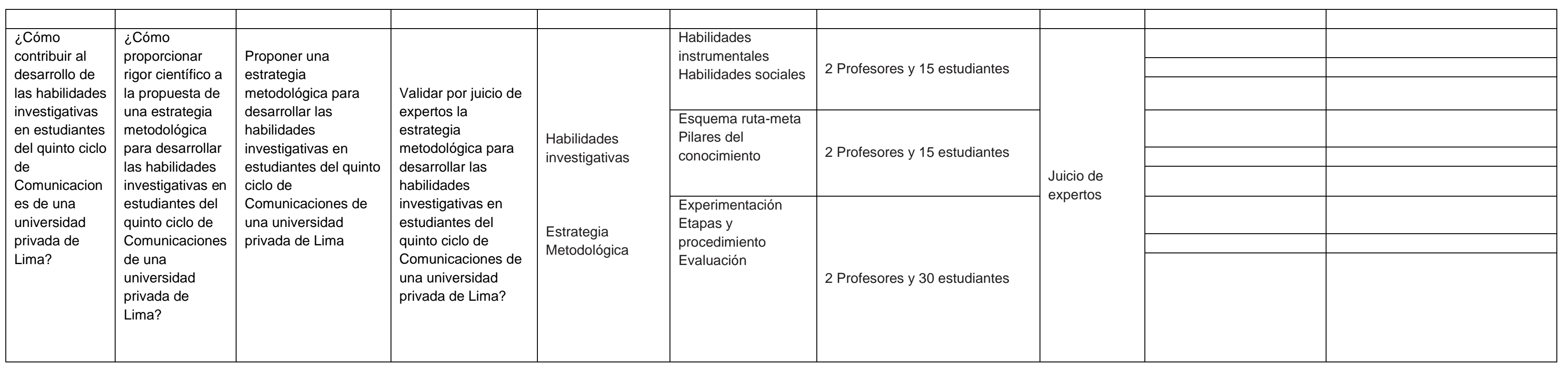

Matriz de Categorización

\begin{tabular}{|c|c|c|c|c|c|c|c|c|}
\hline PROBLEMA & Objetivo principal & Categorías & Subcategorías & Indicadores & $\begin{array}{l}\text { Items } \\
\text { Entevista a } \\
\text { docentes }\end{array}$ & $\begin{array}{l}\text { Items } \\
\text { Cuestionari } \\
\text { o }\end{array}$ & $\begin{array}{l}\text { Items } \\
\text { Prueba }\end{array}$ & $\begin{array}{l}\text { Items } \\
\text { Guía } \\
\text { de } \\
\text { obsern } \\
\text { ación }\end{array}$ \\
\hline \multirow{8}{*}{$\begin{array}{l}\text { ¿Cómo } \\
\text { desarrollar } \\
\text { habilidades } \\
\text { investigativas } \\
\text { en los } \\
\text { estudiantes } \\
\text { del V ciclo de } \\
\text { la carrera de } \\
\text { Comunicacion } \\
\text { es de una } \\
\text { universidad } \\
\text { privada de } \\
\text { Lima? }\end{array}$} & \multirow{8}{*}{$\begin{array}{l}\text { Diseñar una } \\
\text { estrategia } \\
\text { metodológica para } \\
\text { desarrollar } \\
\text { habilidades } \\
\text { investigativas en los } \\
\text { estudiantes del V } \\
\text { ciclo de la carera de } \\
\text { Comunicaciones de } \\
\text { una universidad } \\
\text { privada de Lima }\end{array}$} & \multirow{8}{*}{$\begin{array}{l}\text { Habilidades } \\
\text { Investigativas: } \\
\text { Habilidades } \\
\text { profesionales que } \\
\text { son comunes en } \\
\text { cualquier carrera } \\
\text { universitaria y } \\
\text { contienen las } \\
\text { etapas de } \\
\text { observación, } \\
\text { clasificación, } \\
\text { hipótesis, } \\
\text { experimentación }\end{array}$} & \multirow{5}{*}{$\begin{array}{l}\text { Observación: } \\
\text { la observación es un medio que el alumno posee para } \\
\text { resolver el mundo de manera eficiente y exitosa. } \\
\text { Convirtiéndose en productor. (Puche 2001) }\end{array}$} & Capacidad de argumentar lo observado & $1,2,13$ & 2,15 & 6 & 2 \\
\hline & & & & Capacidad de interpretar lo observado & $2,8,12$ & 1,6 & 2 & 1 \\
\hline & & & & $\begin{array}{l}\text { Manejo de instrumentos para obtener } \\
\text { información }\end{array}$ & 2,12 & 3 & 2 & 1 \\
\hline & & & & $\begin{array}{l}\text { Manejo de la atención para poder identificar } \\
\text { elementos específicos de interés }\end{array}$ & $3,8,10$ & 3 & & 2 \\
\hline & & & & $\begin{array}{l}\text { Habilidad para identificar el estímulo de la } \\
\text { sensación de lo observado }\end{array}$ & $3,4,8,12$ & 3 & 1 & 2 \\
\hline & & & \multirow{3}{*}{$\begin{array}{l}\text { Clasificación: } \\
\text { Identificación de semejanzas y diferencias de los } \\
\text { objetos para poder agruparlos identificando sus } \\
\text { criterios (Puche, 2001) }\end{array}$} & Identifica las categorías o familias & 8 & 3 & 6 & 3 \\
\hline & & & & Crear criterios de agrupación & 8 & 3,10 & 6 & 6 \\
\hline & & & & $\begin{array}{l}\text { Formula ideas y las sustenta sobre los } \\
\text { procesos de clasificación }\end{array}$ & 4,8 & 4,14 & 7 & 8 \\
\hline
\end{tabular}




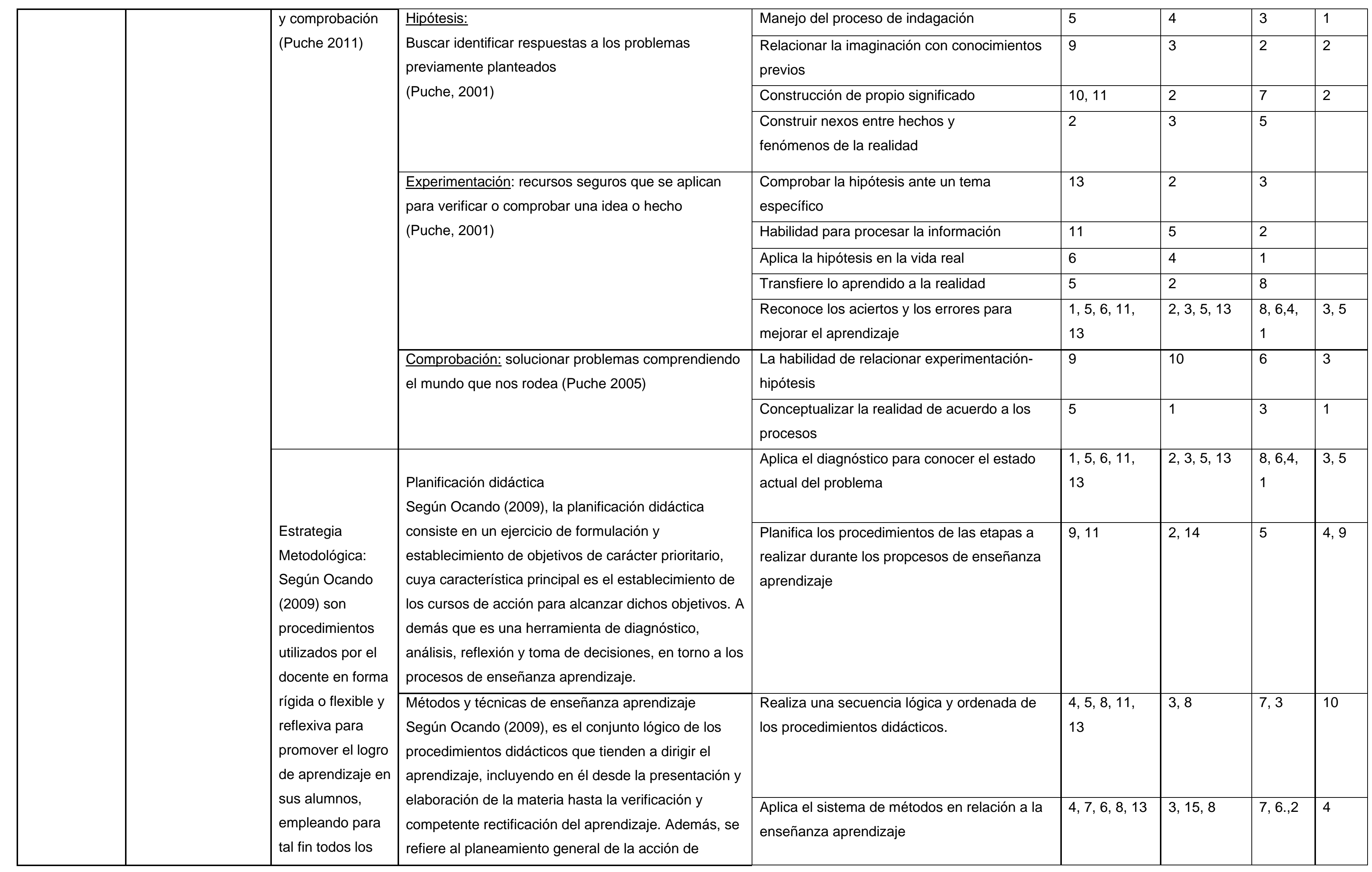




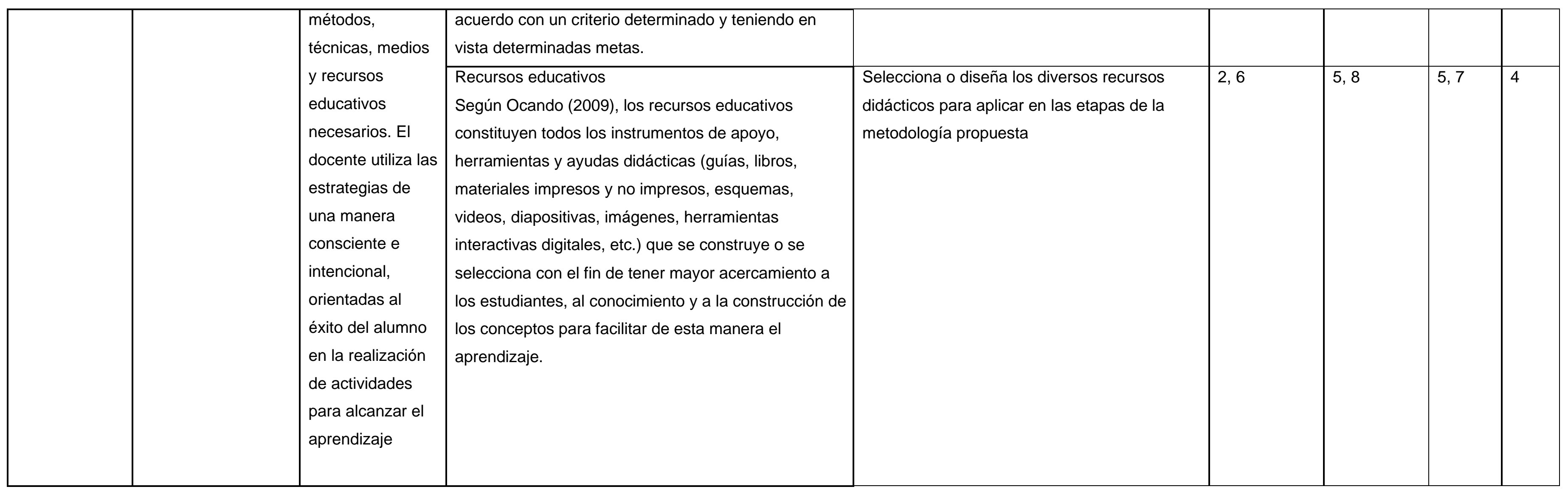




\section{Anexo 2: Instrumentos de recolección de datos}

Entrevista semi estructurada a docentes

\section{DATOS INFORMATIVOS:}

OBJETIVO: Constatar el conocimiento teórico y metodológico de los docentes del curso de Narrativas Audiovisuales en la carrera de comunicación audiovisual de ua universidad privada de Lima.

\section{Entrevistador:}

\section{Lugar y Fecha:}

\section{Duración:}

1. ¿Cuál es la importancia que le da usted a la investigación científica en el curso de Narrativas audiovisuales?

2. ¿Cuál es el concepto que tiene de habilidades investigativas?

3. ¿Qué potencialidades considera usted que posee la investigación en la carrera de Comunicaciones para contribuir al desarrollo de las habilidades investigativas?

4. ¿Qué características en investigación utilizo en el curso de Narrativas Audiovisuales para facilitar el desarrollo de las habilidades investigativas?

5. ¿Qué metodología utiliza en su clase para contribuir al desarrollo de las habilidades investigativas de sus estudiantes?

6. ¿Qué actividades y tareas realizan sus estudiantes de Comunicaciones que evidencie el desarrollo de sus habilidades investigativas?

7. ¿Cuáles son los mayores obstáculos para el desarrollo de las habilidades investigativas en los estudiantes?

8. ¿Los alumnos se expresan correctamente en el desarrollo de sus ideas investigativas?

9. ¿Usted orienta a sus estudiantes cómo aplicar la teoría en la práctica y qué importancia tienen en su desarrollo profesional?

10. ¿Sus estudiantes se orientan sobre los objetivos que deben alcanzar a nivel investigativo en las clases y el curso?

11. ¿Qué hace usted para conocer las fortalezas y debilidades investigativas de sus estudiantes y qué tratamiento le da en la clase?

12. ¿Qué aspectos o momentos considera para la planificación de una investigación audiovisual?

13. ¿Qué evaluación ejecuta a nivel investigativo y cómo la aplica en su clase? 


\section{Cuestionario a Estudiantes}

\section{DATOS GENERALES:}

Carrera:

Ciclo:

Edad: Sexo: Femenino ( ) Masculino ( ) Fecha:

OBJETIVO: Constatar el nivel de satisfacción que experimentan los estudiantes del V ciclo del curso Narrativas Audiovisuales con la manera en que el docente del $\mathrm{V}$ ciclo dirige el proceso de enseñanza - aprendizaje para contribuir al desarrollo de sus habilidades investigativas en la carrera de comunicación audiovisual de ua universidad privada de Lima.

\section{Instrucciones:}

Estimado estudiante, como parte de una investigación necesitamos que colabores con tu opinión respecto a los contenidos de la carrera y la forma como el docente dirige los conocimientos de investigación. Para ello te pedimos que leas atentamente el siguiente cuestionario para responder con sinceridad las siguientes preguntas.

\section{PREGUNTAS}

1. ¿Consideras que la investigación científica es importante para tu desarrollo profesional y personal?

Muy importante ( ) Importante ( ) Poco importante ( ) Nada importante ( )

2. ¿Sientes que en la carrera de comunicación audiovisual y sus diferentes cursos han ayudado al desarrollo de tus habilidades para trazar un objetivo, desarollar correctamente las etapas de la investigación y llegar a una evaluación correcta de las conclusiones?

Siempre ( ) Casisiempre ( ) Pocas veces ( ) Nunca ( )

3. ¿El profesor realiza actividades en clases que te permiten desarrollar tus habilidades como la observación, la clasificación, la formulación de hipótesis, la experimentación y la comprobación? 
Siempre ( ) Casi siempre ( ) Pocas veces ( ) Nunca (

4. ¿En el desarrollo de la clases los docentes explican cómo el contenido teórico es aplicado en la práctica de la profesión y cuál es su importancia?

Siempre ( ) Casi siempre ( ) Pocas veces ( ) Nunca (

5. ¿Qué métodos emplean los docentes en el desarrollo de la clases?. Puedes marcar más de una alternativa?

\begin{tabular}{|c|c|c|c|}
\hline Expositivos ( ) & $\cos (）$ & Investigativos ( ) & Creativos ( ) \\
\hline Trabajo colaborativo ( ) & Talleres ( ) & Seminarios ( ) & Debates ( ) \\
\hline
\end{tabular}

6. ¿Los métodos que utilizan los docentes en las clases, motivan tu interés para realizar actividades científicas orientadas hacia la profesión?

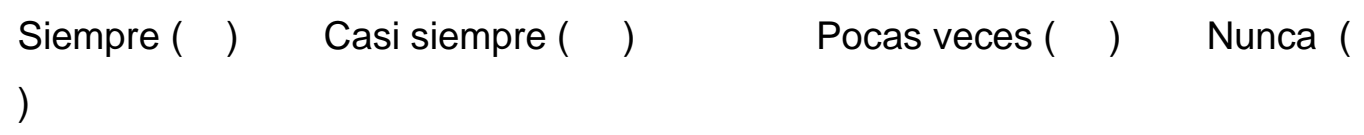

7. ¿Los profesores orienta y precisa los objetivos investigativos que deben ser alcanzados en la carera?

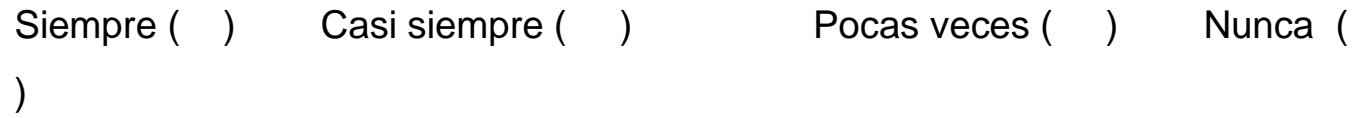

8. ¿Antes de desarrollar la estrategia, el docente explica claramente en qué consisten las actividades que se van a utilizar para lograr los objetivos científicos?

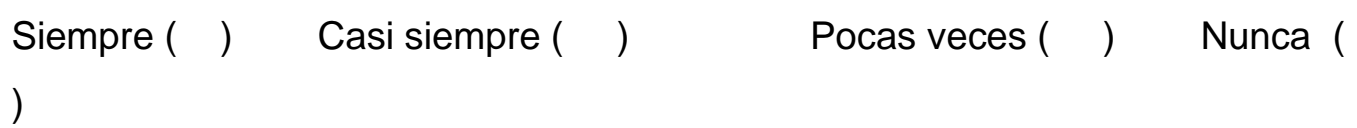

9. ¿El docente emplea métodos para conocer al grupo de estudiantes, así como los problemas que podrían suscitarse en el aula para planificar la clase?

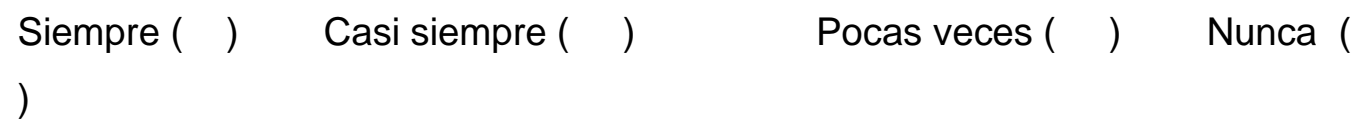


10. ¿El profesor contribuye a tu desarrollo de comprender la observación de la problemática?

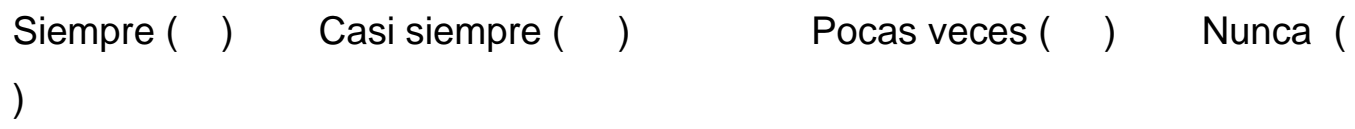

11. ¿Consideras que la forma de evaluación del profesor contribuye para que logres las habilidades investigativas?

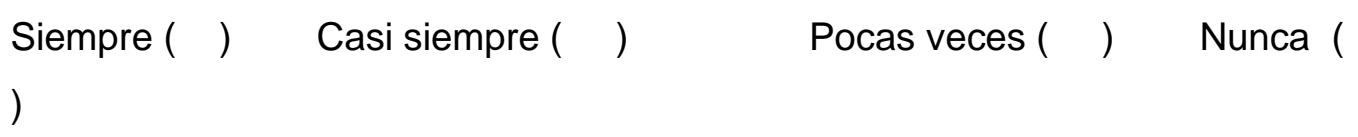

12. ¿Qué tipo(s) de evaluación emplea el docente? Puedes marcar más de una opción.

Autoevaluación（） Coevaluación（ ） Heteroevaluación（）Evaluación sumativa ( ) Evaluación participativa ( ) Evaluación de desempeños ( ) Evaluación parcial y final ( ) Evaluación metacognitiva ( )

13. ¿El profesor se preocupa por constatar el logro de los objetivos de aprendizaje? Siempre ( ) Casi siempre ( ) Pocas veces ( ) Nunca ( )

14. ¿El docente emplea instrumentos científicos que te permiten explorar la realidad?

Siempre ( ) Casi siempre ( ) Pocas veces ( ) Nunca (

\section{Guía de Observación}

\section{DATOS GENERALES:}

Observador:

Carrera: Ciclo: 
Asignatura:

Tema de la sesión de clase:

Fecha:

Horario:

OBJETIVO: Constatar la preparación teórica y metodológica que poseen los docentes sobre el desarrollo de las habilidades investigativas al dirigir el proceso de enseñanza aprendizaje del curso de Narrativas Audiovisuales en los estudiantes del V ciclo de la carrera Comunicaciones de una universidad privada de Lima

\begin{tabular}{|c|c|}
\hline № & ITEMS A EVALUAR \\
\hline & INICIO \\
\hline 1 & $\begin{array}{l}\text { Inicia con una situación PROBLEMÁTICA apoyándose en el uso de videos, } \\
\text { multimedia, una frase, una noticia una anécdota u otros, cuyo contenido se } \\
\text { relaciona con el contenido de la clase, movilizando los saberes previos de los } \\
\text { estudiantes a través de un sistema de preguntas logrando el interés y la } \\
\text { motivación inicial. }\end{array}$ \\
\hline 2 & $\begin{array}{l}\text { El diálogo con los estudiantes permite estimular y encontrar el objetivo de la } \\
\text { investigación }\end{array}$ \\
\hline & DESARROLLO \\
\hline 3 & $\begin{array}{l}\text { El docente presenta el contenido demostrando dominio y el empleo de recursos } \\
\text { metodológicos que facilitan el rol activo y participativo de los estudiantes que a } \\
\text { través del intercambio expresan libremente sus opiniones, preguntas o juicios } \\
\text { respecto al contenido, llevándolos a delimitar su objeto de estudio }\end{array}$ \\
\hline 4 & $\begin{array}{l}\text { Presenta una situación problemática y a través de preguntas va orientando las } \\
\text { acciones que deben realizar los estudiantes para fomentar la verificación de } \\
\text { objetivos, etapas metodológicas y procesos para poder llegar a una conclusión de } \\
\text { la investigación. }\end{array}$ \\
\hline
\end{tabular}




\begin{tabular}{|c|c|}
\hline 5 & $\begin{array}{l}\text { Para orientar a los estudiantes en la solución del problema, el docente explica los } \\
\text { pasos a seguir a través de ejemplos variados contextualizados en la práctica } \\
\text { profesional, solicitando a los estudiantes sus opiniones, los cuales reciben } \\
\text { retroalimentación permanente. }\end{array}$ \\
\hline 6 & $\begin{array}{l}\text { Luego, presenta otros ejemplos con la finalidad de que los estudiantes asimilen y } \\
\text { comprendan el contenido y desarrollen las habilidades necesarias para lograr el } \\
\text { objetivo de aprendizaje para la sesión. }\end{array}$ \\
\hline 7 & $\begin{array}{l}\text { Seguidamente organiza una serie de actividades grupales con la finalidad de que } \\
\text { los estudiantes puedan aplicar el contenido tratado en clase de manera } \\
\text { autónoma orientados hacia la comprensión y a que apliquen acciones } \\
\text { conceptuales, procedimentales y actitudinales que contribuyen a la formación } \\
\text { investigativa de los estudiantes y al logro de los objetivos de aprendizaje. }\end{array}$ \\
\hline 8 & El profesor explica la actividad y cómo serán evaluados integralmente en la clase. \\
\hline 9 & $\begin{array}{l}\text { El profesor utiliza métodos de enseñanza que promueven el rol activo de los } \\
\text { estudiantes para estimular el desarrollo de las habilidades investigativas como el } \\
\text { análisis, síntesis, comparación, diagnóstico y plantear solución de problemas de } \\
\text { la profesión. }\end{array}$ \\
\hline 10 & $\begin{array}{l}\text { Durante la realización de las actividades, el docente fomenta el respeto a las } \\
\text { opiniones de los demás, el profesionalismo, la ética, el compromiso con la } \\
\text { profesión y la actividad científica. }\end{array}$ \\
\hline & CIERRE \\
\hline 11 & $\begin{array}{l}\text { Los estudiantes exponen los resultados de los trabajos en equipos y el resto del } \\
\text { aula emite criterios de la calidad del trabajo presentado a través de la } \\
\text { autoevaluación, coevaluación y heteroevaluación. }\end{array}$ \\
\hline 12 & $\begin{array}{l}\text { El docente reconoce los procesos de las actividades y las tareas de aprendizaje, } \\
\text { utilizando un modelo de evaluación que estimula la metacognición y } \\
\text { autorregulación de los estudiantes. }\end{array}$ \\
\hline 13 & $\begin{array}{l}\text { El profesor destaca los logros de la clase y las actitudes de los estudiantes y } \\
\text { motiva a los demás a seguir mejorando su aprendizaje con acciones concretas } \\
\text { para cada equipo e integrante. }\end{array}$ \\
\hline
\end{tabular}




\section{Prueba Pedagógica}

DATOS GENERALES:

Carrera:

Ciclo:

Edad:___ Sexo: Femenino ( ) Masculino ( ) Fecha:

OBJETIVO: Comprobar el nivel de conocimientos teóricos sobre el curso de Narrativas Audiovisuales y el nivel de desarrollo de las habilidades investigativas de los estudiantes del V ciclo de la carrera de Comunicaciones de una universidad privada de Lima

INSTRUCCIONES: Estimado estudiante, como parte de una investigación que estamos realizando para mejorar el proceso de enseñanza - aprendizaje en el curso Narrativas audiovisuales, requerimos de tu colaboración. A continuación, te presentamos algunas preguntas relacionadas con los conocimientos adquiridos en la asignatura Narrativas audiovisuales, léelas atentamente y responde como corresponda.

1. ¿Cuál es la diferencia entre un documental y una ficción?

2. ¿Qué elementos de investigación son básicos en un documental?

3. ¿Cual es el procedimiento o etapas para realizar un documental? Explica cada etapa

a.

b.

c.

4. ¿Qué elemento es importante en un producción documental además del producto audiovisual? Ponlos en orden si hay de uno, considerando el primero de mayor importancia y explicando porque? Libro de Producción ( ) Escaleta ( ) Plan de rodaje ( )

5. ¿Cuáles son las partes del libro de producción?

6. ¿Qué elementos de la clase ayudan a que usted pueda generar una investigación audiovisual?

7. ¿Qué recursos me ayudan para generar una buena investigación a nivel comunicacional? 


\section{Anexo 4: Validación de recolección de información}

\section{VALIDACIÓN DE LOS INSTRUMENTOS}
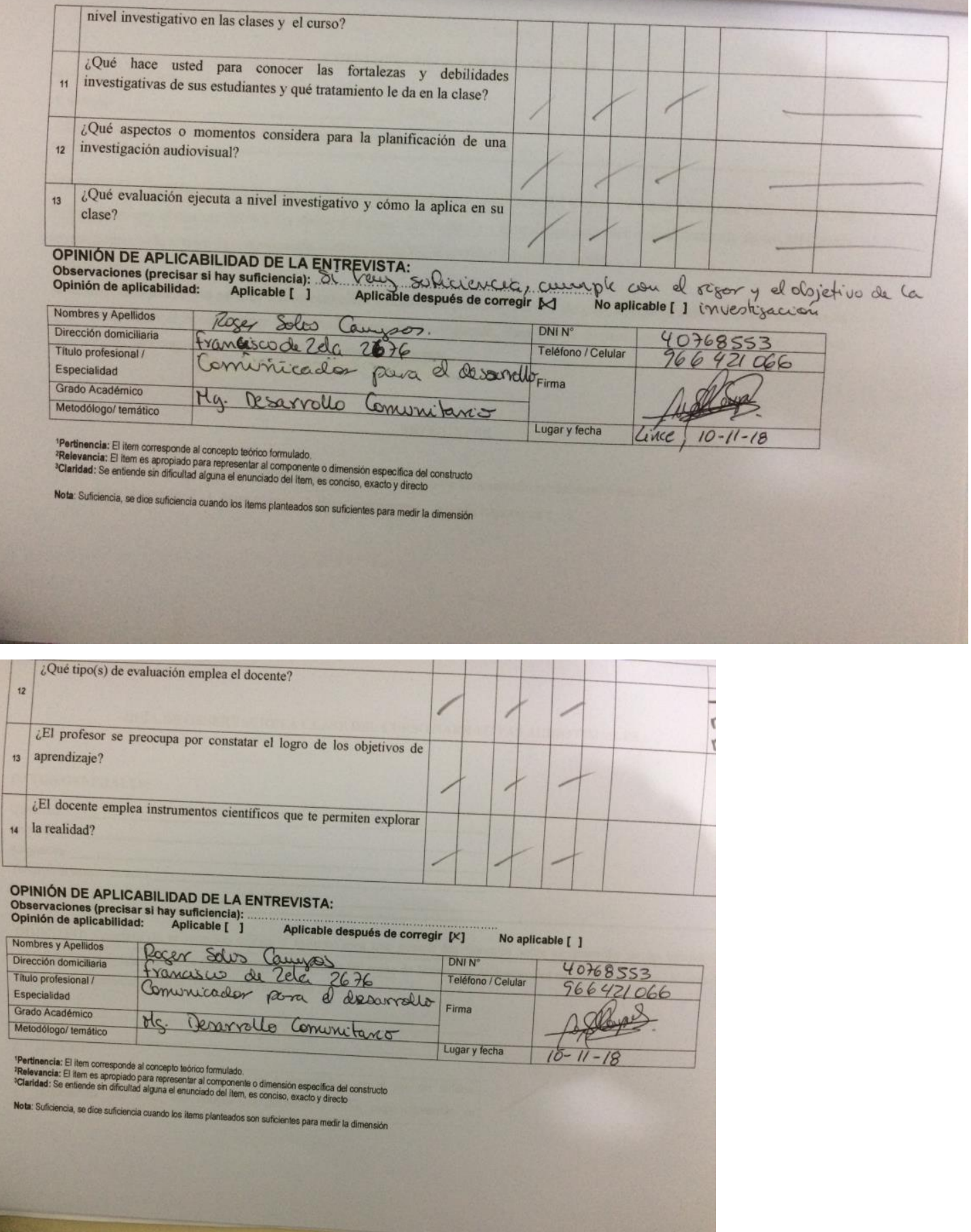


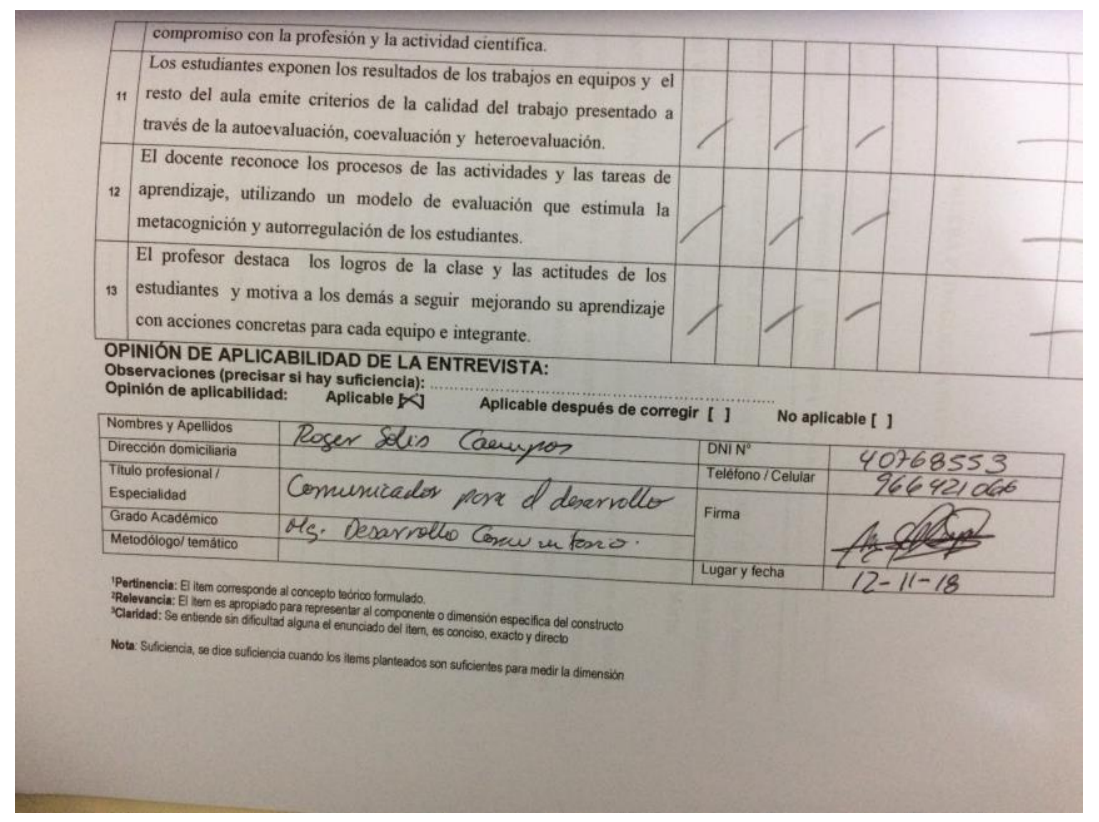

OPINIÓN DE APLICABILIDAD DE LA ENTREVISTA

Opinión de aplicabilidad: Aplicable 1 :

Aplicable después de corregir [ ] No aplicable [ ]

\begin{tabular}{|c|c|c|c|}
\hline Nombres y Apellidos & & & \\
\hline Dirección domiciliaria & loger sees canysos & $\mathrm{DNIN}^{\circ}$ & 40768553 \\
\hline Titulo profesional/ & Francesco de 2ella 2676 & Teléfono/Celular & 966421066 \\
\hline Especialidad & a dexarvollo & Firma & \\
\hline Metodólogo/ temático & Mg. Desarrollo Comwntoxio. & & \\
\hline
\end{tabular}

TPertinencia: El item corresponde al conceppt teónioo tormulado.

Lugary fecha $\quad 13-11-18$

: Se entiende sin dificultad alguna el e enunciado del tian

Notar Suficiencia, se dive suficiencia cuando los hlems planteados son suficientes para medir la dimensión 

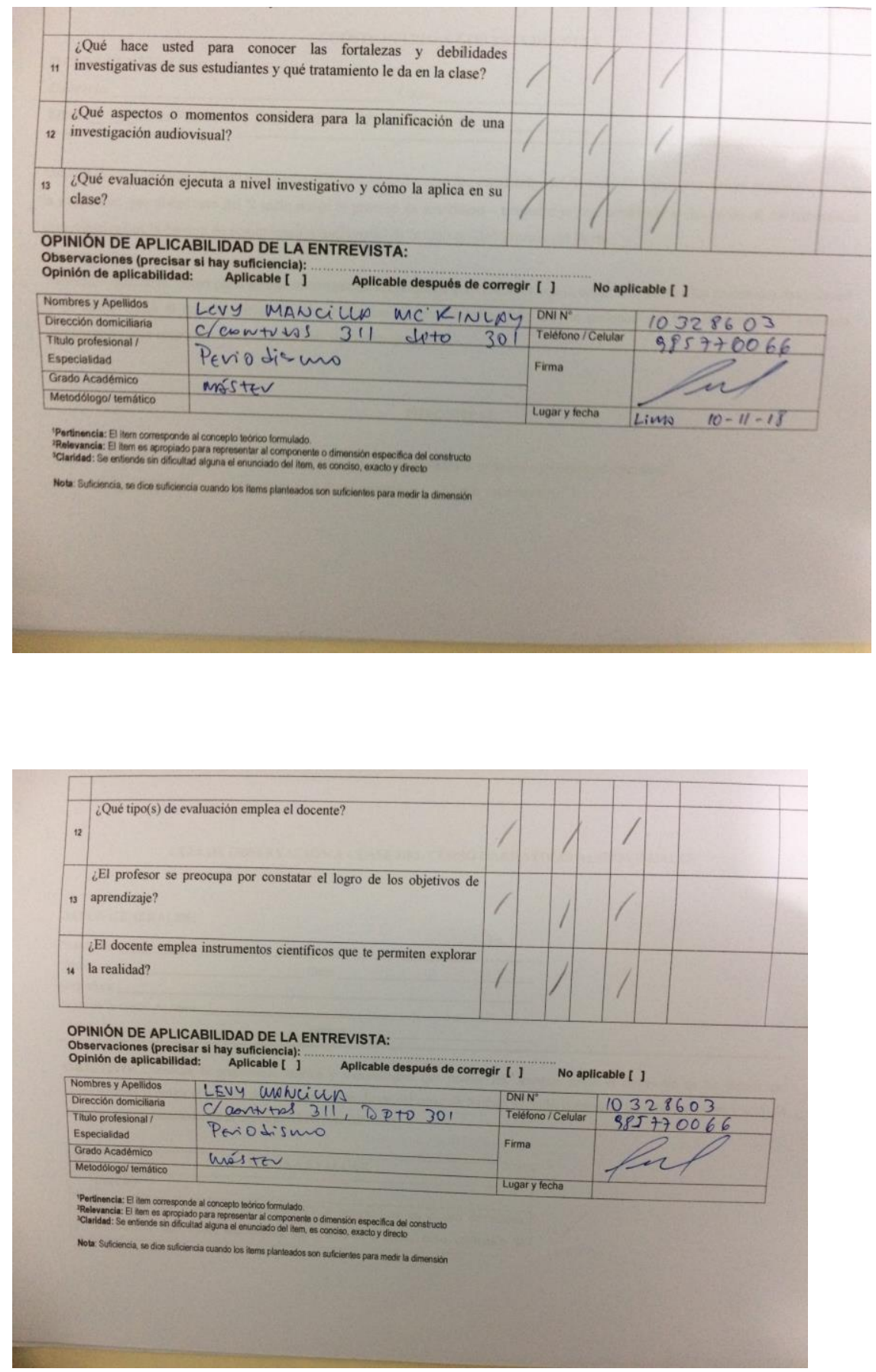

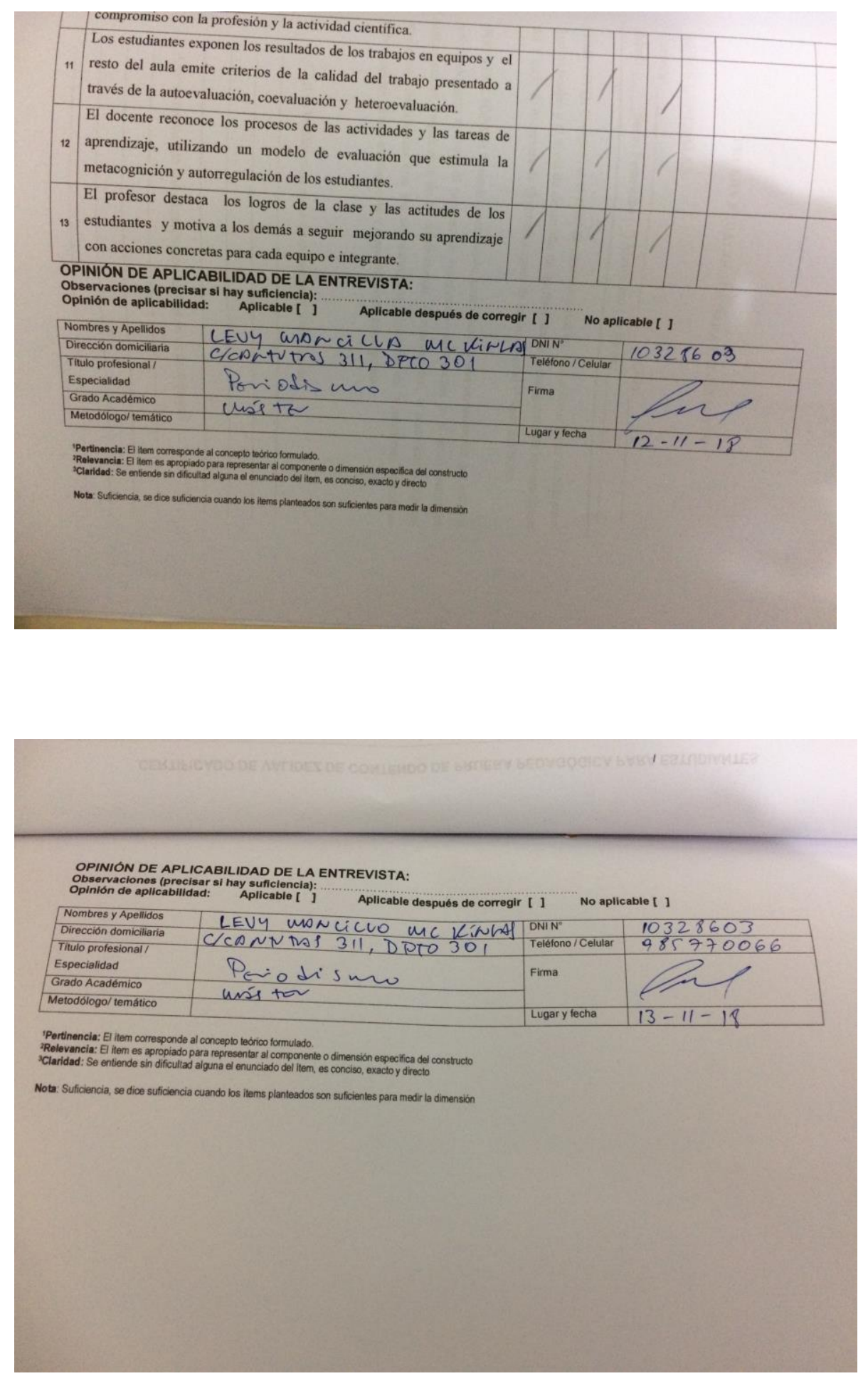

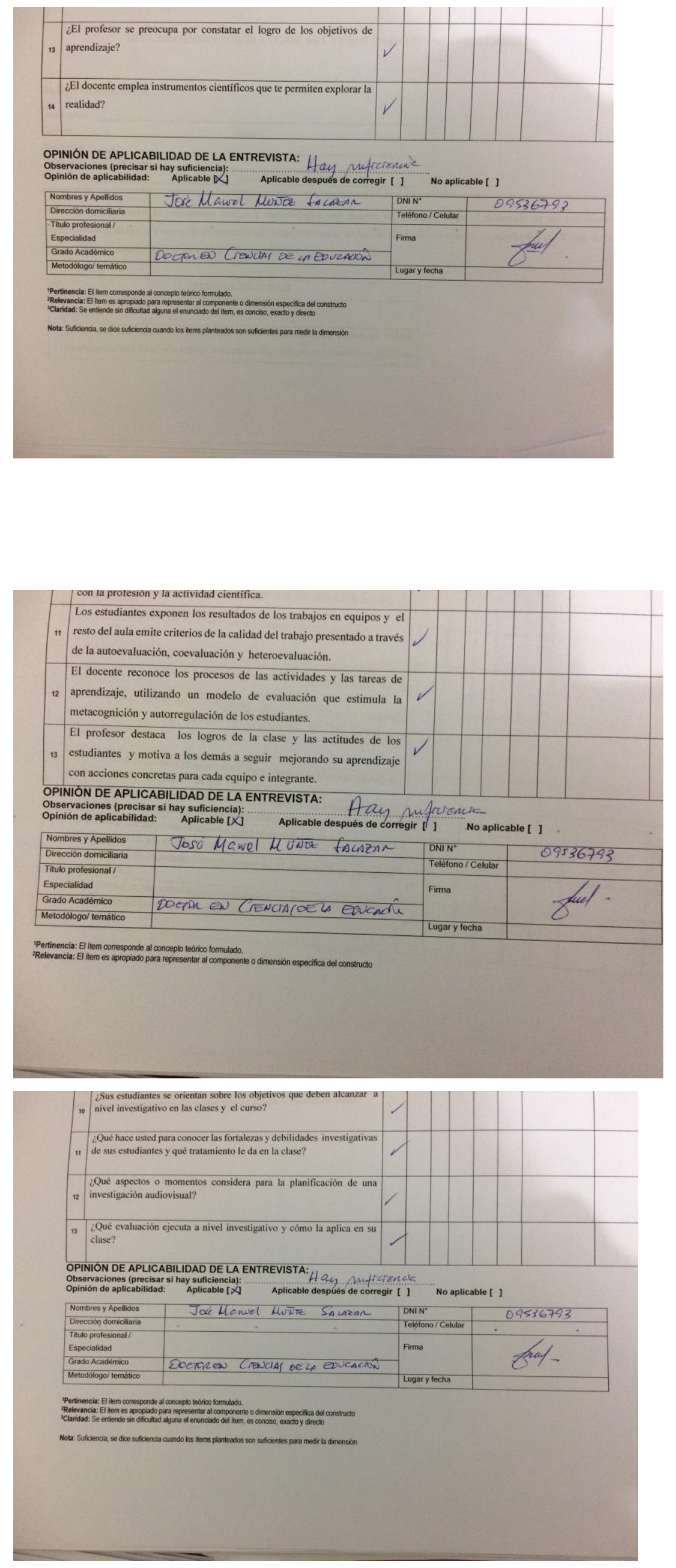
OPINIÓN DE APLICABILIDAD DE LA ENTREVISTA:

- A traner

$\begin{array}{lll}\text { Opinión de aplicabilidad: } & \text { Aplicable }[X] & \text { Aplicable después de corregir [ ] No }\end{array}$ No aplicable [ ]

\begin{tabular}{|c|c|c|c|}
\hline Nombres y Apellidos & MUNDZ SACDZAR & $\mathrm{DNIN}^{\circ}$ & 09536793 \\
\hline Dirección domiciliaria & & Teléfono / Celular & \\
\hline $\begin{array}{l}\text { Titulo profesional/ } \\
\text { Especialidad }\end{array}$ & & Firma & \\
\hline Grado Académico & Cranciarde un educactá & & \\
\hline Metodólogo/ temático & & Lugar y fecha & \\
\hline
\end{tabular}

Pertinencia: El item corresponde al concepto teónico formulado.

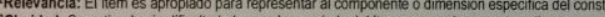

"Claridad: Se entiende sin dificultad alguna el enunciado del item, es conciso, exacto y directo

Nota: Suficiencia, se dice sufficiencia cuando los ittems planteados son suficientes para medir la dimensión

\section{VALIDACION DE LA PROPUESTA}




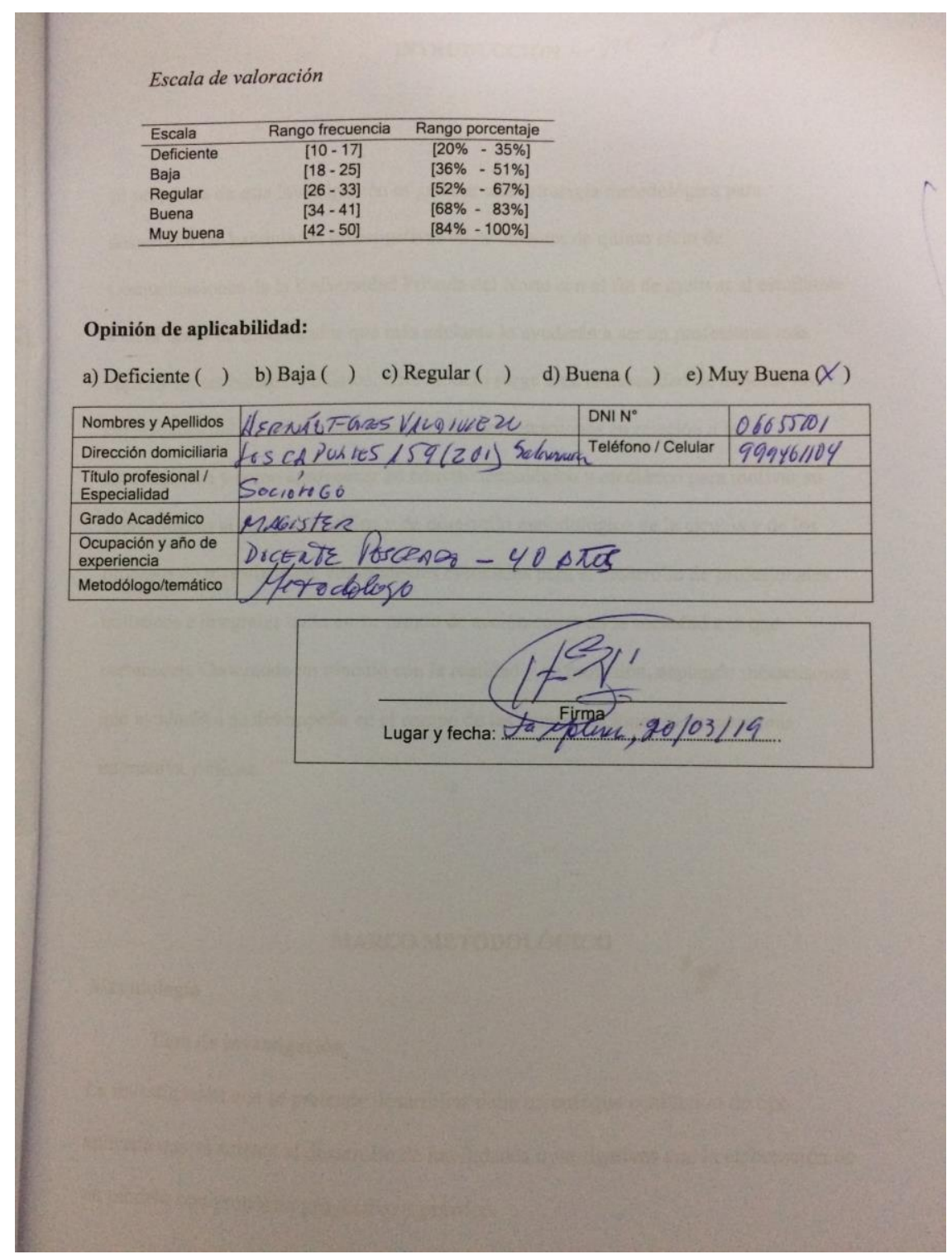




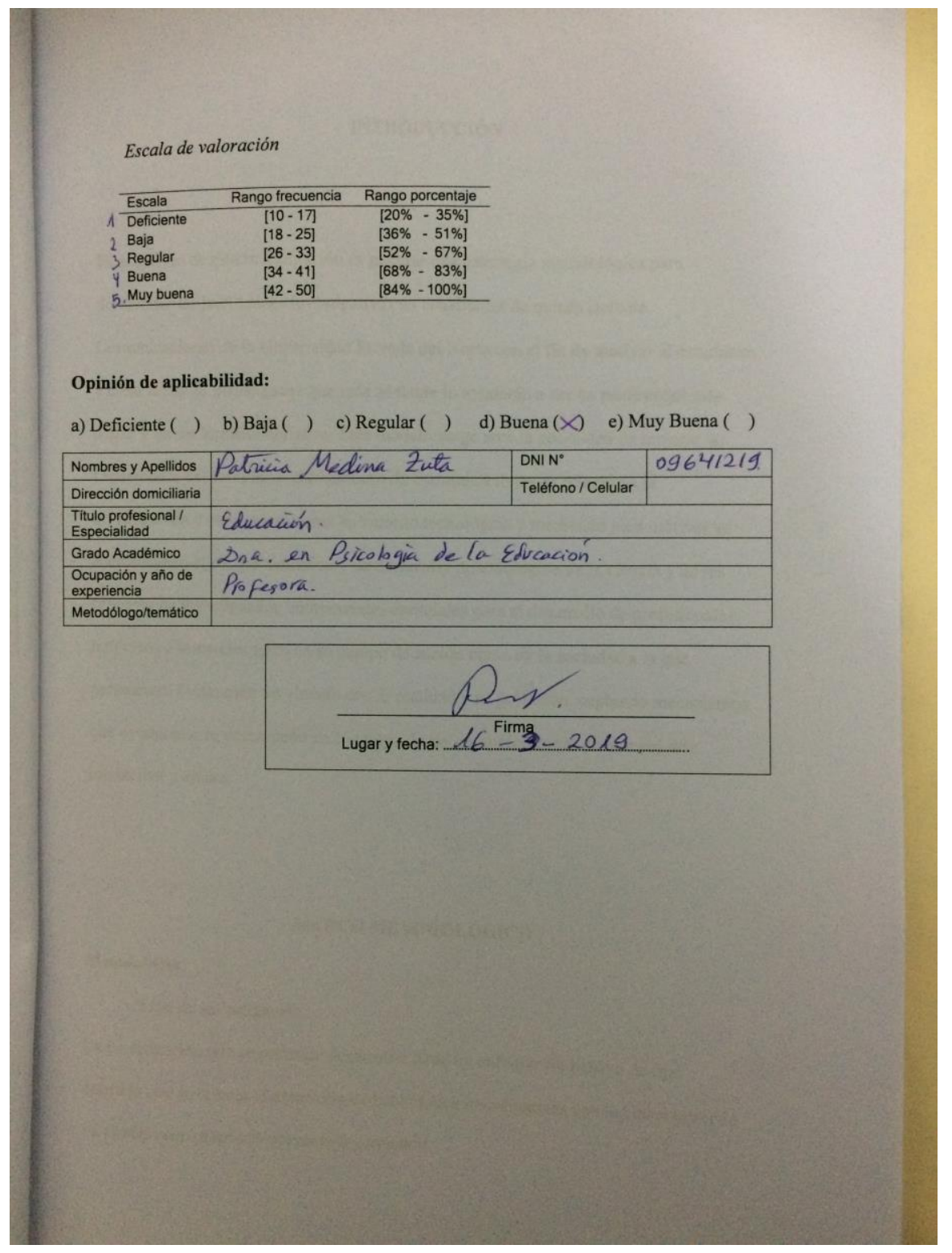


Escala de valoración

\begin{tabular}{lcc}
\hline Escala & Rango frecuencia & Rango porcentaje \\
\hline Deficiente & {$[10-17]$} & {$[20 \%-35 \%]$} \\
Baja & {$[18-25]$} & {$[36 \%-51 \%]$} \\
Regular & {$[26-33]$} & {$[52 \%-67 \%]$} \\
Buena & {$[34-41]$} & {$[68 \%-83 \%]$} \\
Muy buena & {$[42-50]$} & {$[84 \%-100 \%]$} \\
\hline
\end{tabular}

\section{Opinión de aplicabilidad:}
a) Deficiente ( )
b) Baja ( )
c) Regular ( )
d) Buena ( )
e) Muy Buena ( $X$ )

\begin{tabular}{|c|c|c|c|}
\hline Nombres y Apellidos & José Manued Muñoz Salazar & $\mathrm{DNIN}^{\circ}$ & 09536793 \\
\hline Dirección domiciliaria & & Teléfono / Celular & \\
\hline \multicolumn{4}{|l|}{$\begin{array}{l}\text { Titulo profesional / } \\
\text { Especialidad }\end{array}$} \\
\hline Grado Académico & Doctor En CrEnctas oE lD & EDUCACNON & \\
\hline \multicolumn{4}{|l|}{$\begin{array}{l}\text { Ocupación y año de } \\
\text { experiencia }\end{array}$} \\
\hline Metodólogo/temático & & & \\
\hline
\end{tabular}

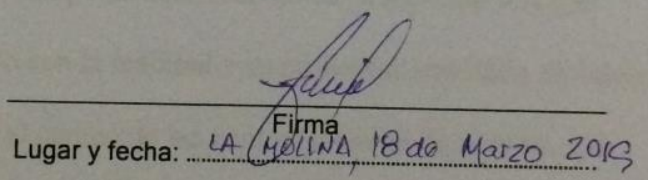

